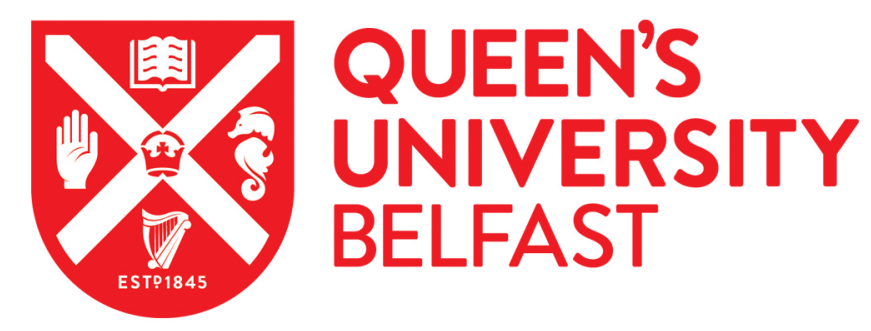

\title{
Essential scientific mapping of the value chain of thermochemical converted second-generation bio-fuels
}

Zhang, X. (2016). Essential scientific mapping of the value chain of thermochemical converted secondgeneration bio-fuels. Green Chemistry, 18, 5086-5117. https://doi.org/10.1039/C6GC02335E

\author{
Published in: \\ Green Chemistry
}

Document Version:

Peer reviewed version

Queen's University Belfast - Research Portal:

Link to publication record in Queen's University Belfast Research Portal

Publisher rights

(C) 2016 The Royal Society of Chemistry

\section{General rights}

Copyright for the publications made accessible via the Queen's University Belfast Research Portal is retained by the author(s) and / or other copyright owners and it is a condition of accessing these publications that users recognise and abide by the legal requirements associated with these rights.

Take down policy

The Research Portal is Queen's institutional repository that provides access to Queen's research output. Every effort has been made to ensure that content in the Research Portal does not infringe any person's rights, or applicable UK laws. If you discover content in the Research Portal that you believe breaches copyright or violates any law, please contact openaccess@qub.ac.uk. 


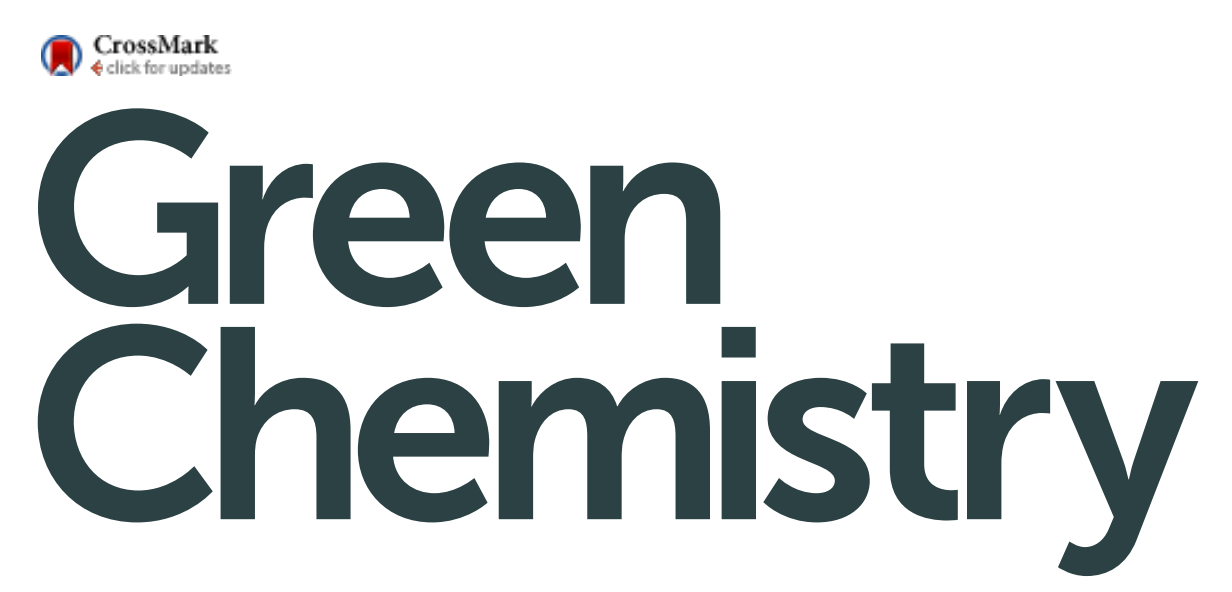

\section{Accepted Manuscript}

This article can be cited before page numbers have been issued, to do this please use: X. Zhang, Green Chem., 2016, DOI: 10.1039/C6GC02335E.

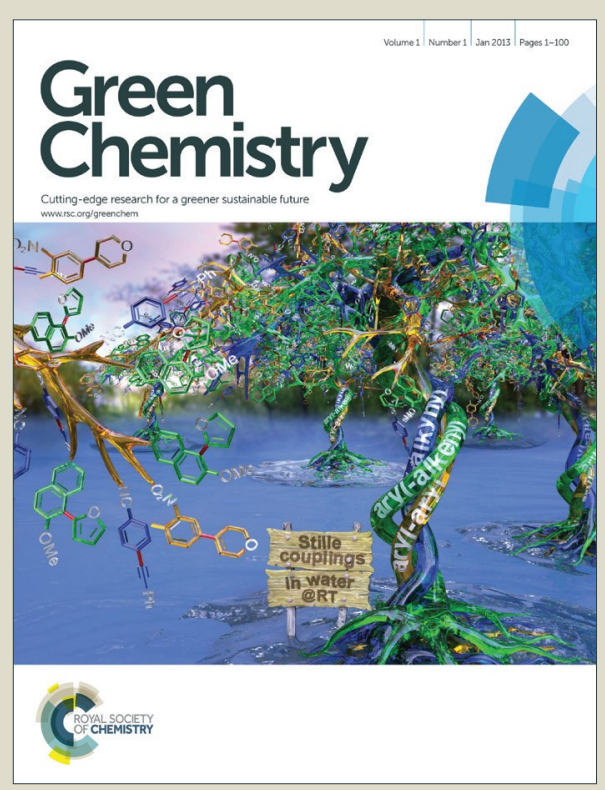

This is an Accepted Manuscript, which has been through the Royal Society of Chemistry peer review process and has been accepted for publication.

Accepted Manuscripts are published online shortly after acceptance, before technical editing, formatting and proof reading. Using this free service, authors can make their results available to the community, in citable form, before we publish the edited article. We will replace this Accepted Manuscript with the edited and formatted Advance Article as soon as it is available.

You can find more information about Accepted Manuscripts in the Information for Authors.

Please note that technical editing may introduce minor changes to the text and/or graphics, which may alter content. The journal's standard Terms \& Conditions and the Ethical guidelines still apply. In no event shall the Royal Society of Chemistry be held responsible for any errors or omissions in this Accepted Manuscript or any consequences arising from the use of any information it contains. 


\section{Green Chemistry}

\section{Essential scientific mapping of the value chain of thermochemical converted second-generation bio-fuels}

Received 00th January 20xx, Accepted 00th January 20xx

DOI: $10.1039 / \times 0 x x 00000 x$

www.rsc.org/

\begin{abstract}
Xiaolei Zhang ${ }^{\mathrm{a}^{*}}$
As the largest contributor to renewable energy, biomass (especially lignocellulosic biomass) has significant potential to address atmospheric emission and energy shortage issues. The bio-fuels derived from lignocellulosic biomass are popularly referred to as second-generation bio-fuels. To date, several thermochemical conversion pathways for the production of second-generation bio-fuels have shown commercial promise; however, most of these remain at various pre-commercial stages. In view of their imminent commercialization, it is important to conduct a profound and comprehensive comparison of these production techniques. Accordingly, the scope of this review is to fill this essential knowledge gap by mapping the entire value chain of second-generation bio-fuels, from technical, economic, and environmental perspectives. This value chain covers i) the thermochemical technologies used to convert solid biomass feedstock into easier-to-handle intermediates, such as bio-oil, syngas, methanol, and Fischer-Tropsch fuel; and ii) the upgrading technologies used to convert intermediates into end products, including diesel, gasoline, renewable jet fuels, hydrogen, char, olefins, and oxygenated compounds. This review also provides an economic and commercial assessment of these technologies, with the aim of identifying the most adaptable technology for the production of bio-fuels, fuel additives, and bio-chemicals. A detailed mapping of the carbon footprints of the various thermochemical routes to second-generation bio-fuels is also carried out. The review concludes by identifying key challenges and future trends for second-generation petroleum substitute bio-fuels.
\end{abstract}

\section{Broader context}

Lignocellulosic biomass is currently utilized predominantly for the generation of heat and electricity. However, a more efficient way to exploit its full value is the production of combustible bio-fuels and allied fuel additives and bio-chemicals. The novelty of this review lies in mapping the techno-commercial and environmental aspects of all existing thermochemical pathways to produce second-generation bio-fuels and allied products. Although previously published reviews have focused on detailing either specific technologies or specific feedstocks, or providing economic analyses of specific routes, these alone cannot address the significant challenge of comparing all technologies. Such knowledge is pivotal to bridging the gap between academic research and practical development.

\section{Introduction}

The worldwide concerns of global warming have brought both industries and academic researchers in attempts to develop technologies aiming to address the unprecedented challenge of reducing carbon emissions. Given the fact that global $\mathrm{CO}_{2}$ emissions in 1973 were $15,633 \mathrm{Mt}$, increasing to $31,734 \mathrm{Mt}$ by 2012 , a $200 \%$ increase has been seen in merely 40 years. ${ }^{1}$ Fossil fuels (oil, gas, and coal) remain the predominant sources of both energy supply and $\mathrm{CO}_{2}$ emissions globally-in 2012, approximately $81.7 \%$ of the total primary energy supply, $67.9 \%$ of electricity generation, and $99.5 \%$ of $\mathrm{CO}_{2}$ emissions resulted from the consumption of fossil fuels. ${ }^{1}$ In addition to the considerable $\mathrm{CO}_{2}$ emissions, the depletion of fossil fuel resources is yet another major concern, as reserves of petroleum, natural gas, and coal are expected to be exhausted within the next 45, 60, and 120 years respectively. ${ }^{2}$ At the same time, global energy demand is increasing dramatically, from 13,214 Mtoe (Million tonnes of oil equivalent) in 2010 to an estimated 15,888 Mtoe by 2020 , and further to 20,680 Mtoe by $2040 .^{3}$

The use of alternative energy resources is necessary to address this inevitable and foreseeable demand-supply gap in the energy sector. In 2014, it was reported that, by 2040 , oil, gas, coal, and lowcarbon sources would supply roughly equal proportions of energy, which is around $25 \%$ each; this means that approximately $75 \%$ of total energy will still be derived from fossil fuels. ${ }^{4}$ This consumption level is expected to lead to an increase in global temperature of $3.6^{\circ} \mathrm{C}$, much higher than the allowable safe limit $\left(2^{\circ} \mathrm{C}\right)$ determined by the Intergovernmental Panel on Climate Change (IPCC) to avoid severe and widespread 
climate change implications. ${ }^{4}$ For this reason, efforts are being made to obtain a higher proportion (> 25\%) of energy from low-carbon sources.

Biomass is considered an attractive low-carbon resource. According to the climate agreement made at COP21 $\left(21^{\text {st }}\right.$ annual Conference of the Parties) in Paris in 2015 , it was agreed that biomass and bioenergy play a crucial role in meeting the $2^{\circ} \mathrm{C}$ target for climate change. In 2012, biomass contributed to around $10 \%$ of world energy consumption and $80 \%$ of global renewable energy production, and it will continue to play a dominant role among renewable resources throughout the first half of this century. ${ }^{5}$ Legislation to mandatorily increase the share of bioenergy has been enacted in several nations. For example, there are targets to obtain $20 \%$ of transportation fuel from biomass by 2030 in the US, and targets for biomass to provide $20 \%$ of the renewable energy share and $10 \%$ of transportation renewable energy in the EU by $2020 .^{6}$ By $2050,30 \%$ of the world's energy demand is expected to be met by bioenergy. ${ }^{7}$ However, these ambitious targets raise a question: is the existing biomass sufficient? The answer is in the affirmative. The quantity of biomass is enormous and the total energy stored in biomass plant materials is three to four times greater than the global energy demand. ${ }^{7}$ Efficient utilization of bioenergy would therefore provide an ideal alternative energy resource.

Theoretically, biomass is a resource that can be used to produce all types of energy: heat, electricity, and fuels. Currently, heat is the major product of biomass utilization, with roughly $60 \%$ of worldwide bioenergy comprising traditional applications for cooking and heating in developing countries. ${ }^{5}$ With regard to electricity production from biomass, dedicated biomass power plants or biomass co-firing plants are feasible means of reducing $\mathrm{CO}_{2}$ emissions and producing green energy. In fact, as of 2011, there were 230 biomass co-firing plants in operation worldwide, generating electricity and heat. ${ }^{8}$ However, combustion of biomass does not represent its optimal use; it can be more efficiently utilized if converted into bio-fuel or related products, since biomass is the only renewable energy resource that contains all elements needed for the generation of fuels and allied products. The various types of fuels derived from biomass, whether gaseous (syngas, biogas), liquid (biomassderived diesel, ethanol, gasoline), or solid (pellets, briquettes, charcoal), have the potential to replace conventional gaseous, liquid, and solid fuels, respectively. It is thus increasingly important to develop technologies for the efficient production of high-quality fuels, rather than exploiting the direct conversion of biomass into heat and electricity.

Over the past decades, considerable efforts have been made to convert lignocellulosic biomass into biofuels, fuel additives, and bio-chemicals, especially after the oil crisis of the mid-1970s. Various conversion pathways, including thermochemical and biochemical routes, have been explored. Thermochemical routes convert biomass into fuels by controlling heating and oxidation, while biochemical routes are normally controlled by enzyme-catalysis. The commercial potential of both pathways has been proven. ${ }^{9}$ The main advantages for the scale-up of thermochemical conversion technologies are related to the high temperatures and short residence times involved. High temperatures enable the actuation of all the components of the plant material, especially lignin, which is the most difficult to break down, whereas the feedstocks for biochemical conversions are limited to sugars. The short residence times of most thermochemical conversion technologies, comprising minutes or even seconds, compared to hours or days for biochemical conversion processes, allows the construction of reactors on smaller scales, enabling more economically viable pathways. ${ }^{10}$

Extensive scientific research has been carried out into the production of second-generation bio-fuels via thermochemical conversion pathways. However, in practice, all proposed conversion technologies remain at laboratory, pilot, or pre-commercialization stages. Additionally, there is a related need to synthesize research and practice-based knowledge to guide future development. This review provides such a synthesis through a rigorous comparison of technical, economic, and environmental aspects of different thermochemical technologies, with a view to facilitating the emerging industry of second-generation bio-fuels. Combustion is not considered here, since this is a mature technology aimed only at generating heat and electricity rather than bio-fuels and bio-chemicals. The review first explains the thermochemical processing of biomass from mass, energy, economic and environmental perspectives, which are then then described in detail in subsequent sections. The review concludes with a discussion of challenges and future trends in the conversion of biomass into fuel and related products.

\section{Essentials of biomass thermochemical conversion}

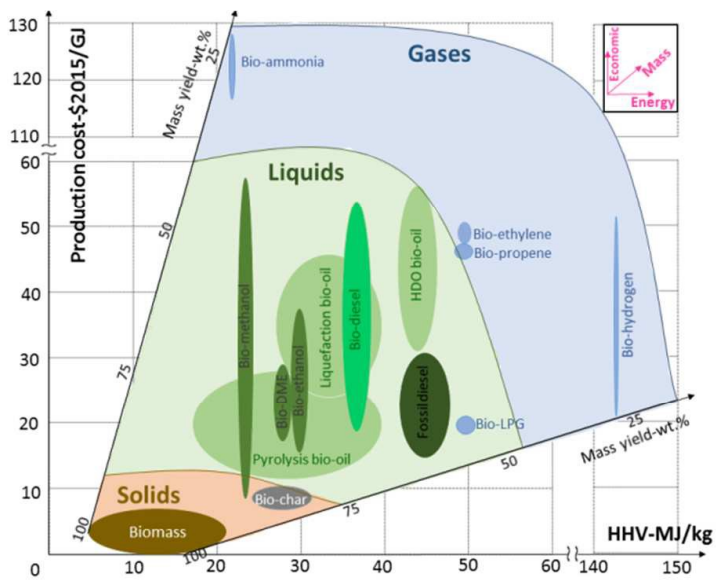

Figure 1. Mass-energy-economic comparison of secondgeneration bio-fuels generated via thermochemical conversion processes.

Biomass thermochemical conversion comprises a set of chemical reactions that simultaneously generate 
or absorb heat to convert raw biomass feedstock into energy (electricity and heat), energy carriers (bio-fuels, fuel additives), or chemical products (bio-chemicals). Essentially, the thermochemical conversion of biomass to produce bio-fuels and allied products is a process that separates useful from non-useful biomass components. The solid, liquid, and gas fuels generated represent energy carriers that can be further utilized, but the process also generates undesirable products, mainly in the form of $\mathrm{CO}_{2}, \mathrm{H}_{2} \mathrm{O}$, and environmentally unfriendly emissions. For example, one of the main problems of using biomass feedstock is its high water content when compared with fossil fuels. Water is useless as an energy carrier and needs to be removed, requiring the consumption of external energy. Similarly, the high oxygen content of biomass is not useful for second-generation bio-fuels, and it is typically removed using either $\mathrm{H}$ or $\mathrm{C}$ to produce $\mathrm{H}_{2} \mathrm{O}$, $\mathrm{CO}_{2}$, or $\mathrm{CO}$.

Considering all conversion pathways and products, Fig. 1 provides an overall evaluation of the thermochemical conversion of lignocellulosic biomass from mass, energy and economic perspectives. Among the three main forms of second-generation bio-fuels, solid products such as firewood, woodchips, wood pellets, and charcoal are more widely available as source materials and have higher conversion efficiency, with effective conversion technologies and lower production costs. However, solid products are bulky and difficult to handle, and can only be used in solid fuel burners. Second-generation liquid bio-fuels are energy dense, easier to transport, and have the potential to substitute for conventional transport fuel. It is important to note that liquid fuel is still expected to dominate the transportation fuel sector, at least until 2050, due to the existing liquid fuel supply system, which restricts automobile utilization of natural gas, hydrogen, and electric power sources. ${ }^{7}$ However, the energy efficiency of converting biomass into liquid fuel is low and production costs are high. Moreover, the technologies for converting lignocellulosic biomass into liquid bio-fuel that can be directly used have not yet been fully commercialized. With regard to gaseous products, there are a number of quite widely used techniques available, with the main challenges involved being those of upgrading intermediate gases and disposing of unwanted byproducts. $^{7}$

The production of solid fuels from raw biomass is considered low-level decomposition, while the decomposition level for liquid products is higher than that of solid fuel, and the production of gaseous fuel represents the greatest decomposition of raw biomass. As such, the mass yields of solid, liquid, and gaseous products derived from biomass are around $75-90 \%$, $40-80 \%$, and $20-50 \%$, respectively. It is evident that higher-level decomposition leads to a lower mass yield. From energy and economic perspectives, a higher level of biomass decomposition will provide purer products with higher heating values, because the low quality and low energy density portions have been removed. However, high-level decomposition involves higher production costs, as shown in Fig. 1. Thus, the appropriate and maximal utility of bio-fuels needs to be evaluated, considering all three aspects of technical feasibility, energy efficiency, and economic costs.

\section{Technical forefront}

\subsection{All pathways}

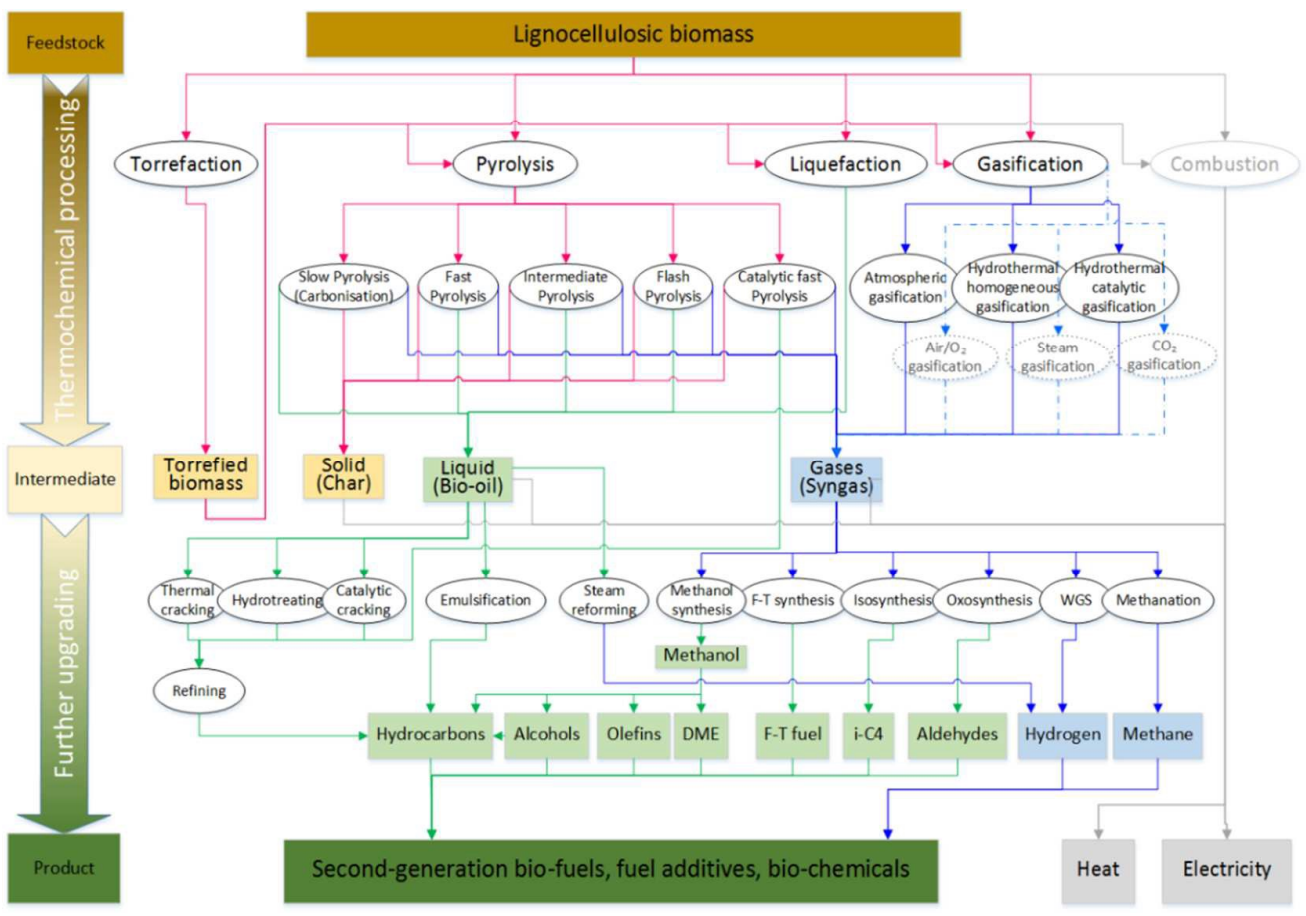


Figure 2. Thermochemical and further upgrading pathways for converting lignocellulosic biomass into second-generation biofuels, fuel additives, and bio-chemicals. F-T: Fischer-Tropsch; WGS: Water-gas-shift; i-C4: isobutene and isobutane; DME: dimethyl ether. Pink lines represent solid streams, green lines represent liquid streams, and blue lines represent gaseous streams. Grey lines represent pathways for heat and electricity generation, which are outside the scope of this research, while the dashed blue lines show alternative gasification

Fig. 2 provides a general classification of all and a heating rate that varies greatly from less than biomass thermochemical conversion technologies. Overall, the process of bio-fuel formation can be described as feedstock (lignocellulosic biomass) being converted into solid, liquid, or gaseous intermediates via thermochemical processing technologies, followed by these intermediates being further upgraded into final products (bio-fuels, bio-chemicals, fuel additives) via further conversions. The main thermochemical processing technologies include pyrolysis, gasification, liquefaction, and torrefaction, while the upgrading technologies include bio-oil upgrading and syngas upgrading techniques. The selection of technologies requires a general understanding of the biomass feedstock, the desired product, and the relevant economic and environmental impacts.

\subsubsection{Thermochemical conversion}

\section{Operating conditions}

Three key operating parameters governing the technologies and their end products are temperature, heating rate, and residence time. Fig. 3 summarizes these operating conditions for various thermal conversion technologies.

Torrefaction is a deep pre-treatment technology with operating conditions of a temperature range of $200-300^{\circ} \mathrm{C}$, isolating oxidation, and at atmospheric pressure. The operating temperature is lower than for other thermal conversion technologies and thus requiring lower energy inputs. ${ }^{11}$

Pyrolysis is a thermal conversion technology that can either be considered an initial step for other thermal conversion processes, such as gasification, or as a conversion method to produce bio-fuels in its own right. Pyrolysis decomposes biomass in the absence of oxygen, within a temperature range of $300-900^{\circ} \mathrm{C}^{7}$ and a heating rate that varies greatly from less than
$0.005^{\circ} \mathrm{C} / \mathrm{s}$ to more than $10,000^{\circ} \mathrm{C} / \mathrm{s} .{ }^{12}$ Depending on operating conditions, pyrolysis can be classified as slow, intermediate, fast, or flash pyrolysis. As shown in Fig. 3, preferential conditions for slow pyrolysis are a relatively low heating rate (around $0.005^{\circ} \mathrm{C} / \mathrm{s}$ ), low temperature $\left(300-600^{\circ} \mathrm{C}\right)$, and long residence times (minutes to days). Fast pyrolysis is a process with a heating rate ranging between 5 and $100^{\circ} \mathrm{C} / \mathrm{s},{ }^{13},{ }^{14}$ a temperature range of $375-650^{\circ} \mathrm{C}$, and a short residence time of $1-5 \mathrm{~s}^{15,16}$ Intermediate pyrolysis is a technology with moderate operating temperature and heating rate. Flash pyrolysis has the highest heating rate (up to $10^{4} \mathrm{C} / \mathrm{s}^{17}$ ) and the shortest residence time (< $1 \mathrm{sec})$, and thus special reactors, such as appropriately designed entrained flow reactors or fluidized bed reactors, and fine particles (105-250 $\mu \mathrm{m})^{18}$ are normally required. Depending on operating conditions or energy sources, flash pyrolysis can be subdivided into flash hydro-pyrolysis, rapid thermal process, solar flash pyrolysis, and vacuum pyrolysis, as detailed described by Goyal et al. ${ }^{18}$

Liquefaction normally operates at high pressures (5-40 MPa) and mild temperatures $\left(200-400^{\circ} \mathrm{C}\right)$, in the presence of a solvent. ${ }^{19}$ Water is the most common solvent used for liquefaction due to its lower cost when compared to other options, including creosote oil, ethylene glycol, simple alcohols, and phenol. ${ }^{20}$ The use of high pressure offers the potential to use a mixture of feedstock varieties, including lignocellulosic biomass, after consideration of the difficulties that this poses for processing. ${ }^{19}$ An additional benefit of this hydrothermal process is that neither catalysts nor active organisms are required for pre- or posttreatment, because of the high pressures and temperatures involved. ${ }^{19}$ 

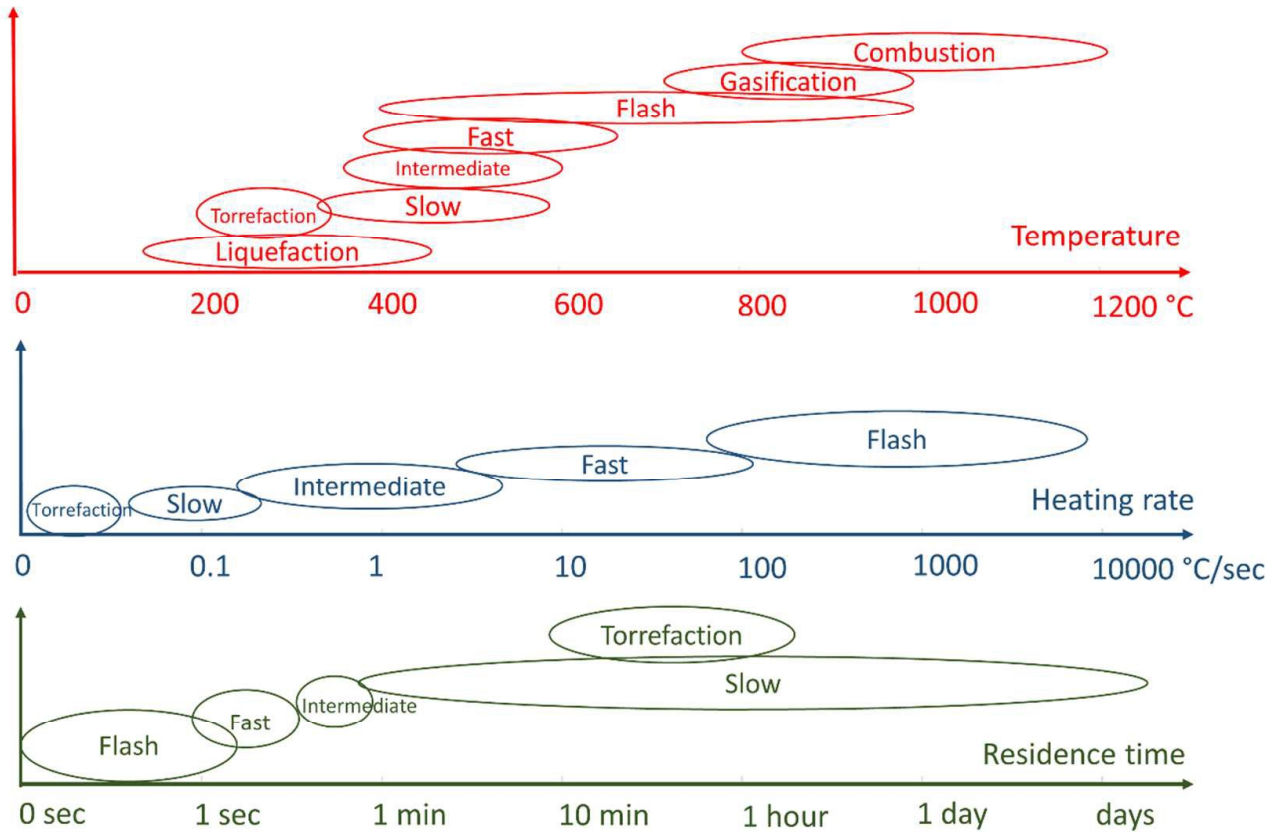

Figure 3. Various operating conditions of the main thermochemical processing technologies for lignocellulosic biomass. Slow: slow pyrolysis; Fast: fast pyrolysis; Intermediate: intermediate pyrolysis; Flash: flash pyrolysis;

Gasification is a partial biomass oxidation process typically conducted at temperatures higher than $800^{\circ} \mathrm{C}$. It is aimed at the production of syngas rich in $\mathrm{CO}$ and $\mathrm{H}_{2} \cdot{ }^{21}$ Under different operating conditions, gasification can be classified into atmospheric gasification, hydrothermal homogeneous gasification, and hydrothermal catalytic gasification. The normal operating conditions for hydrothermal gasification are high pressures (5-40 $\mathrm{MPa}$ ) in a liquid environment and within a temperature range of $400-700^{\circ} \mathrm{C}^{19}$

\section{Product distribution}

Different thermochemical technologies provide different distributions of the three product forms: solid, liquid, or gaseous. This distribution is shown in Fig.

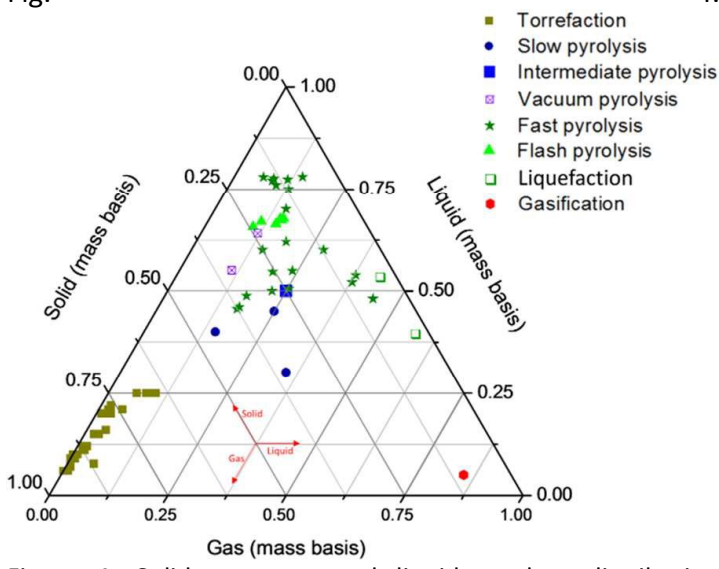

Figure 4. Solid, gaseous, and liquid product distribution diagram for different thermochemical processing pathways for lignocellulosic biomass. ${ }^{11,15,17,22,23,24,25,26,27,28}$

An energy-dense solid product, termed torrefied biomass, is the main product of torrefaction. The solid yield is normally in a range of 65-95 wt\% (see Fig. 4).
The remaining products comprise torrefaction gases that are non-condensable, including $\mathrm{CO}$ and $\mathrm{CO}_{2}$, and condensable, including water, acetic acid, furfural, formic acid, methanol, lactic acid, and phenol. ${ }^{24,}{ }^{29}$ Gaseous yields increase with elevated temperature and extended residence times. Solid char is also the major product of slow pyrolysis and carbonization, with the latter focusing more on the production of charcoal, and less on gas and liquid products, therefore requiring a longer residence time (days) than slow pyrolysis. ${ }^{22}$ An asymptotic relationship for char yield with decreasing heating rate has been noted, and a heating rate of less than $15^{\circ} \mathrm{C} / \mathrm{h}$ stops the wood particles shrinking and cracking, leading to maximal formation of solid char. ${ }^{30}$ The distribution of liquid, gaseous, and solid products from pyrolysis varies with temperature and heating rate and with the complexity of the biomass feedstock. It has been found that the pyrolysis conversion rate increases significantly from $50 \%$ to $80 \%$ with a temperature increase from $673 \mathrm{~K}$ to $973 \mathrm{~K}^{18,26,31}$ Higher heating rates also lead to higher liquid yields; for example, the oil yield from raw biomass at a heating rate of $0.5^{\circ} \mathrm{C} / \mathrm{s}$ (slow pyrolysis) is $51.7 \%,{ }^{14}$ which increases to $68 \%$ at a heating rate of $5^{\circ} \mathrm{C} / \mathrm{s},{ }^{14}$ and increases further to $73 \%$ at heating rates higher than $100^{\circ} \mathrm{C} / \mathrm{s}^{13},{ }^{14,}{ }^{32}$ During fast pyrolysis, lignocellulosic feedstock is first cracked into short chain vapors, which can be rapidly cooled into liquid bio-oil. Secondary reactions, involving the depolymerization of the vapor, are prevented by rapid heating and cooling, ${ }^{33}$ leading to higher liquid yields (up to $70-80 \%)^{5}$ However, it is worth noting that the reason for higher liquid yields from fast pyrolysis, as compared with flash pyrolysis, is the significant secondary cracking of long chain liquid products into gases during flash pyrolysis. 
Gasification produces the highest yield of gaseous products, normally around $85 \%$, with $5 \%$ liquid and $10 \%$ solid products. Four sub-processes are involved in biomass gasification: dehydration, pyrolysis, oxidation, and reduction. Moisture evaporation occurs during dehydration at temperature ranges of around 100$200^{\circ} \mathrm{C}$. As temperature increases, volatile vapors (light hydrocarbons, $\mathrm{CO}, \mathrm{CO}_{2}$ ) and tar (liquid long-chain hydrocarbons) are released, while char is produced as a solid residue. The distribution of gases, tar, and solids varies depending on the feedstock type, operating conditions, and gasifying agents. ${ }^{34}$ During the oxidation stage, non-decomposed materials (biomass, char, volatile vapors, and partial tar) are oxidized by the injected gasifying agent, forming $\mathrm{CO}, \mathrm{CO}_{2}, \mathrm{H}_{2} \mathrm{O}$, and various other species. Finally, $\mathrm{CO}_{2}$ is reduced by char to $\mathrm{CO}$ in the reduction zone of the entire gasification process.

\subsubsection{Bio-oil upgrading}

Direct utilization of crude bio-oil as a transportation fuel is challenging, due to its low quality and immiscibility with conventional liquid fuels. Reported technologies for upgrading bio-oils include chemical (hydro-deoxygenation, catalytic treatment, visbreaking, and steam reforming) and physical methods (emulsification and filtration). ${ }^{35,36}$, Fig. 5 provides a detailed description of the various upgrading technologies.

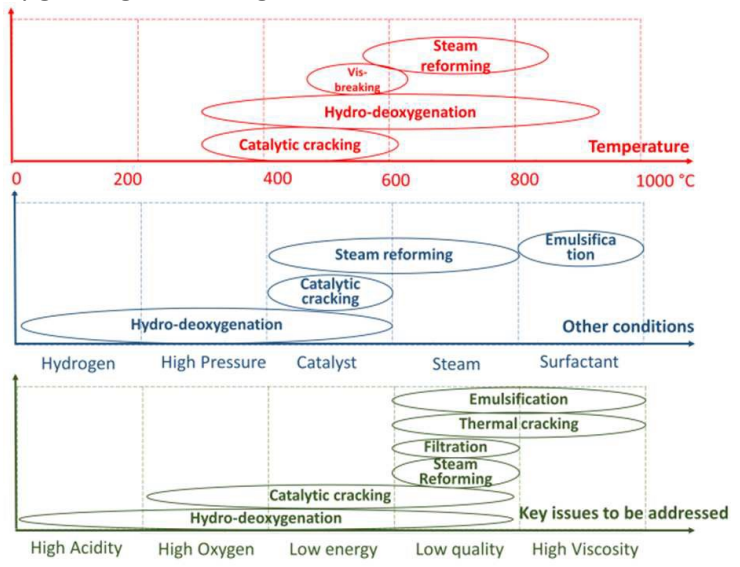

Figure 5. Mapping of operating conditions and key issues facing bio-oil upgrading technologies.

Bio-oil hydro-deoxygenation (HDO) is an extensively studied technology for upgrading lowgrade bio-oil into high-quality liquid fuels that can be further refined in existing oil refineries. The process can be summarized as the reaction of crude bio-oil with $\mathrm{H}_{2}$, during which $\mathrm{C}-\mathrm{O}$ bonds are broken, new $\mathrm{C}-\mathrm{C}$ bonds are formed, and water is produced simultaneously. HDO originates from the hydrodesulfurization (HDS) process in conventional industrial petroleum refineries. ${ }^{6}$ Thus, HDS and HDO have similar reaction pathways and mechanisms, with the difference being that $\mathrm{HDO}$ mainly produces $\mathrm{H}_{2} \mathrm{O}$, while HDS mainly produces $\mathrm{H}_{2} \mathrm{~S}$. The processing temperature is normally $300-900^{\circ} \mathrm{C}$, in the presence of hydrogen at pressures of $3.5-20 \mathrm{MPa}^{25}$ over a heterogeneous catalyst. ${ }^{20}$
Catalytic cracking is another common bio-oil upgrading method, ${ }^{37}$, 38 which takes place at atmospheric pressure. Both HDO and catalytic cracking are used to reduce the high oxygen content of bio-oil; the former requires high-pressure hydrogen in the presence of a catalyst and eliminates oxygen in the form of $\mathrm{H}_{2} \mathrm{O}$, while the latter operates under conditions similar to those in the petroleum refining process, eliminating oxygen in the form of $\mathrm{CO}_{2}$ and $\mathrm{CO}$. The catalytic cracking process can be easily controlled because its operating temperatures $\left(300-600^{\circ} \mathrm{C}\right)$ are similar to those required for bio-oil production processes.

Catalytic fast pyrolysis (CFP) provides another means of converting lignocellulosic biomass into gasoline-compatible aromatics, using a technology that was first proposed at the beginning of the 1980 s. ${ }^{39}$ CFP is normally carried out at a high heating rate (around $\left.500^{\circ} \mathrm{C} / \mathrm{s}\right)$, with a short residence time $(2-10 \mathrm{~s})$ and at temperatures between 400 and $600^{\circ} \mathrm{C}$ (see Fig. 3.) in an inert atmosphere with zeolite catalysts. This catalytic deoxygenation method is carried out during fast pyrolysis and so takes place in a single reactor. Compared with a two-reactor system of pyrolysis followed by catalytic cracking, CFP produces more aromatic products and less coke. A detailed description of CFP was well presented by Carlson et al. ${ }^{40}$

Catalysts play a significant role in the upgrading of bio-oil. The HDO process employs sulfided CoMo and NiMo-based catalysts, which have a high resistance to sulfur poisoning compared to noble metal catalysts. However, a certain amount of sulfur needs to be fed into the system to avoid catalyst deactivation. ${ }^{6}$ Other types of catalysts, such as $\mathrm{Pt} / \mathrm{SiO}_{2}-\mathrm{Al}_{2} \mathrm{O}_{3}$, vanadium nitride, and ruthenium/C, do not necessarily require co-feeding of sulfur and have a much higher hydrogenating capability than conventional HDO catalysts. However, these are generally not preferred due to their higher costs and the occurrence of side decarboxylation reactions. ${ }^{6}$ Various catalysts have been developed for catalytic cracking or for the CFP process, including HZSM-5, H-Y zeolite, mordenite, silicalite, and silica-alumina. Silica-alumina catalysts work to minimize char formation, and $\mathrm{H}-\mathrm{Y}$, silicalite, and silica-alumina catalysts minimize tar formation, resulting in a higher production of aliphatic hydrocarbons. ${ }^{41,42} \mathrm{Al}-\mathrm{MCM}-41, \mathrm{Cu} / \mathrm{Al}-\mathrm{MCM}-41$, and AlMCM-41 can eliminate the formation of levoglucosan and large molecular phenols, increasing the yield of acetic acid, furfural, and furans, and reducing large molecular phenols. ${ }^{43}, 44,45$ The widely used zeolite catalysts $^{46,47,48}$ are inexpensive and produce the highest yield of organic liquid products (34 wt\%), with minimal coke formation. Transition metal catalysts $(\mathrm{Fe} / \mathrm{Cr})$ lead to the selective production of phenol and light phenolics, but their activity is lower than that of zeolites. A robust catalyst is needed for the CFP process, and catalyst regeneration is therefore a key consideration in reactor design. ${ }^{25}$, 49 It has been reported that the use of fluid catalytic cracking (FCC) catalysts with ZSM- 5 additives can improve the quality of bio-oil, however, this also increases the yield of water, non-condensable gases, and char. ${ }^{50}$ More 
selective bi-functional catalysts, formed, for example, by the addition of Ga to ZSM-5, have also been suggested. Pore size narrowing in zeolite can significantly increase $p$-xylene selectivity during biomass CFP, from $32 \%$ to $96 \%{ }^{9}$

Thermal cracking, or visbreaking, is an oil refinery technique for upgrading crude oil, reducing oil viscosity and producing light hydrocarbons, liquefied petroleum gas (LPG), or gasoline. Visbreaking has also been used to upgrade bio-oil, mainly to reduce its viscosity. In some EU countries, visbreaking is preferred over catalytic cracking, especially for oil feedstocks with poisonous catalyst compounds (e.g. metals and aromatic compounds such as asphaltene and resins). ${ }^{51}$, 52 Visbreaking normally takes place at mild temperatures of $470-500^{\circ} \mathrm{C}$ with a short residence time of 1-3 $\mathrm{min}$, in order to maximize liquid yields and minimize coke formation. The latter can also be avoided through low residence times and through blending with $\mathrm{H}$-donor additives such as tetralin. ${ }^{53,54} \mathrm{~A}$ combination of hydro-treatment and visbreaking provides a higher liquid yield than the sole application of visbreaking. 55

Steam reforming provides a feasible means of converting liquid energy carriers into gaseous products, especially hydrogen. The feedstock can be fossil fuel, bio-oil, or black liquor from chemical pulp and paper production. ${ }^{56}$ The technology for steam reforming of fossil fuels is well developed. The technique is usually carried out at temperatures of $600-800^{\circ} \mathrm{C}$, with high space velocities, and usually with $\mathrm{Ni}$ catalysts. ${ }^{20}$ Steam reforming of bio-oil is more complicated than that of petroleum oil, due to the presence of some active bio-oil compounds. Therefore, during steam reforming, bio-oil is first separated into high-value and low-value products, with the latter being subjected to the steam reforming treatment, ${ }^{57}$ using aqueous bio-oil compounds to produce hydrogen. The non-aqueous organic fraction is used to produce chemicals such as phenol-formaldehyde resins or gasoline additives like aromatic hydrocarbons and ethers. $^{58}$

The physical emulsification of bio-oil with gasoline/diesel is considered a simple method for transforming bio-oil into useful liquid fuel by reducing viscosity. However, since bio-oil is not miscible with conventional fuel, a surfactant is required. A higher fraction of bio-oil in an emulsification leads to higher viscosity. ${ }^{59}$ Emulsification can also reduce the corrosiveness of bio-oil; for example, 10-20 wt\% emulsions can reduce the corrosiveness of bio-oil by half. ${ }^{60}$ CANMET in Canada ${ }^{60,61}$ have developed microemulsions with 5-30\% bio-oil in diesel, while researchers at the University of Florence $^{62}$ have developed emulsifications of $10-90 \%$.
Filtration is used to remove the solid contents in bio-oil, reducing the ash content to less than $0.01 \%$, and the alkali content to less than $10 \mathrm{ppm}$; these proportions are much lower than those produced by systems that only use cyclones. ${ }^{25}$ The char in crude biooil can also be reduced by filtration, which can increase liquid yield by up to $20 \%$, since the presence of char will catalytically crack vapors. ${ }^{25}$ Active char will also reduce the average molecular weight of the produced liquid, in turn leading to an increase in burning rate and delayed ignition. ${ }^{25}$ Due to the liquid nature of biooil, filtration of small-sized solid particles $(<5 \mu \mathrm{m})$ is difficult, owing to the greater demands on the pressure drop and the self-cleaning ability of filters. ${ }^{25}$

\subsubsection{Syngas cleaning and upgrading}

The syngas produced directly from biomass gasification is not sufficiently clean to be used either in gas engines or to be further upgraded into high-value products. Its main contaminants include tar, $^{63}$ solid particulates, alkali compounds, sulfur, and a number of catalyst-retarding gases. The currently available syngas cleaning technologies are listed in Table 1, which also summarizes the associated advantages and disadvantages for each cleaning technology for downstream applications and for targeted endproducts.

Gas cleaning and purification technologies can be classified as hot, warm, or cold, corresponding to temperature ranges of more than $300^{\circ} \mathrm{C}$, within 25$300^{\circ} \mathrm{C}$, or lower than $25^{\circ} \mathrm{C}$, respectively. ${ }^{64}$ Cold syngas cleaning can be further subdivided into wet cold cleaning and dry cold cleaning, depending on whether wet scrubbing is involved. Wet cold cleaning has been commercially used in the petrochemical process, however, significant wastewater generation remains a problem and limits its application. Warm cleaning can be used for hydrogen generation. Hot cleaning systems have the advantage of higher efficiency, due to the lower energy loss when a high temperature downstream process, such as combustion in a turbine, is applied, because the raw syngas produced from gasifiers is normally a gaseous mixture at high temperatures. However, for other downstream processes with low operating temperatures, such as F$T$ synthesis, hot cleaning is not preferred from an energy conversion perspective. ${ }^{21}$ The process of syngas cleaning includes various endothermic and exothermic reactions, which can be controlled through different types of heating or cooling mechanisms, depending on the process design.

Cleaned syngas can either be used for direct combustion aimed at power generation, ${ }^{65}$ or can be further synthesized into liquid fuel or bio-chemicals. As shown in Fig. 6, there are various upgrading technologies, including the F-T process, methanol synthesis, isosynthesis, and oxosynthesis.

Table 1. Summary of key syngas cleaning technologies.

\begin{tabular}{|c|c|c|c|c|}
\hline Technologies & $\begin{array}{l}\text { Contaminants } \\
\text { removed }\end{array}$ & $\begin{array}{l}\text { Operating } \\
\text { conditions }\end{array}$ & Contamination problem, advantages, and disadvantages & Ref. \\
\hline Filter & $\begin{array}{l}\text { Solid } \\
\text { Particulate }\end{array}$ & $\begin{array}{l}\text { Cold, warm, } \\
\text { hot }\end{array}$ & $\begin{array}{l}\text { Filter particulates, which damage equipment; filter is inexpensive and } \\
\text { highly efficient, but the short operating period leads to a low chance } \\
\text { for wide plant availability. }\end{array}$ & 64 \\
\hline
\end{tabular}




\begin{tabular}{|c|c|c|c|c|}
\hline Scrubbing & Tar & Cold & $\begin{array}{l}\text { Tar causes equipment fouling and clogging, reducing gasification } \\
\text { efficiency; scrubbing is efficient but economically impractical when } \\
\text { working at elevated temperatures. }\end{array}$ & 21,66 \\
\hline $\begin{array}{l}\text { Thermal } \\
\text { cracking }\end{array}$ & Tar & Hot & $\begin{array}{l}\text { Thermal cracking reduces tar and increases gas yield by breaking } \\
\text { down long chain tar hydrocarbons into smaller molecules such as CO } \\
\text { and } \mathrm{H}_{2} \text {. It improves thermal integration and biomass utilization } \\
\text { efficiency, but suffers from problems of coke formation. Dolomite and } \\
\text { olivine catalysts can be used to enhance tar cracking; these are cheap } \\
\text { but still cannot remove tar completely. Nickel-based catalysts can } \\
\text { remove tar efficiently but their easy deactivation by coke must be } \\
\text { considered. }\end{array}$ & $\begin{array}{l}66-68, \\
69\end{array}$ \\
\hline $\begin{array}{l}\text { Steam } \\
\text { reforming }\end{array}$ & Tar & Warm, hot & $\begin{array}{l}\text { Steam reforming reduces tar and increases gas yield, as hydrocarbons } \\
\text { in tar react with steam to produce } \mathrm{CO} \text { and } \mathrm{H}_{2} \text {; the temperature } \\
\text { normally ranges from } 650^{\circ} \mathrm{C} \text { to } 700^{\circ} \mathrm{C} \text {. A further water-gas-shift } \\
\text { reaction can be added to adjust the targeted } \mathrm{H}_{2} / \mathrm{CO} \text { ratio. Coke } \\
\text { formation remains a problem, but can be reduced by providing } \\
\text { sufficient steam, or using appropriate catalysts to reduce tar and char } \\
\text { formation concurrently. }\end{array}$ & $\begin{array}{l}21,70, \\
71,72\end{array}$ \\
\hline Sorbents & Sulfur & Cold & $\begin{array}{l}\text { Sulfur creates catalyst poisoning, especially during subsequent F-T } \\
\text { synthesis. Sorption capacity is a key factor for evaluating the } \\
\text { efficiency of sulfur removal, and sorption capacity is highly dependent } \\
\text { on material porosity. High porosity facilitates sorption; however, this } \\
\text { also decreases the material's tensile strength. As a result, } \\
\text { optimization of porosity is needed. }\end{array}$ & 21,73 \\
\hline Sorbents & Alkali & Cold & $\begin{array}{l}\text { Alkalis cause irreversible damage to equipment. Similar to sulfur } \\
\text { sorption, the sorption capacity is a key factor and is highly dependent } \\
\text { on material porosity. }\end{array}$ & 21 \\
\hline $\begin{array}{l}\text { Water } \\
\text { scrubber }\end{array}$ & $\mathrm{NH}_{3}$ & Cold & $\begin{array}{l}\mathrm{NH}_{3} \text { poisons the zeolite catalyst. Water scrubbers can help to remove } \\
\mathrm{NH}_{3} \text {, and a water scrubber can be easily operated. }\end{array}$ & 74 \\
\hline
\end{tabular}

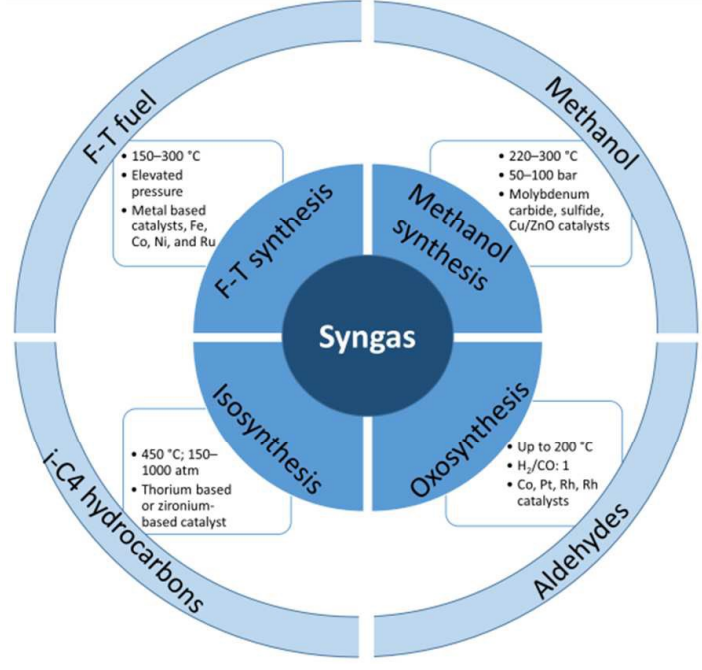

Figure 6. Syngas upgrading technologies.

F-T synthesis is one of the leading technologies for the conversion of gaseous into liquid fuel. During the syngas F-T process, cleaned syngas can be polymerized into long-chain liquid hydrocarbons $\left(\mathrm{C}_{n} \mathrm{H}_{2 n-2}\right)$. The operating requirements for this process are temperatures of $150-300^{\circ} \mathrm{C}$ and elevated pressures of tens of atmospheres, to avoid the formation of short chain hydrocarbons $\left(\mathrm{CH}_{4}\right){ }^{21}$ The need for high pressure is a disadvantage because it increases costs. F-T synthesis uses transition metal-based catalysts, including $\mathrm{Fe}, \mathrm{Co}, \mathrm{Ni}$, and $\mathrm{Ru}$. In the case of Co-based catalysts, it is better for syngas to have a $\mathrm{H}_{2} / \mathrm{CO}$ ratio close to 2, while Fe-based catalysts have lower hydrogen requirements because they promote the formation of $\mathrm{H}_{2}$ through water-gas-shift reactions. The $\mathrm{F}-\mathrm{T}$ process involves $\mathrm{CO}$ adsorption onto the metal surface to form metal carbonyls, with further hydrogenation and hydrogenolysis, and the formation of many intermediates with bonded $\mathrm{C}, \mathrm{H}$, and $\mathrm{O}$, before a final C-C bond-formation step. ${ }^{75}$ To ensure efficient functioning of the catalyst, and given that sulfur can poison the F-T catalyst, a proper desulfurization stage for raw syngas is required. ${ }^{21}$ The liquid products and their quality are highly dependent on the catalyst and on operating conditions, especially synthesis temperature. ${ }^{21,76}$ The hydrocarbon products from F-T synthesis have carbon numbers from 1 to more than 12; hydrocarbons with chains that are too long and are solid at room temperature are not needed, and are referred to as F-T wax. F-T wax, which has a boiling point of more than $370^{\circ} \mathrm{C}$, can be further converted into the desired liquid hydrocarbons through hydrocracking, thus enhancing F-T product quality. ${ }^{21,74}$ Catalysts and hydrogen injection are also needed for F-T wax hydrocracking, and the proper selection of catalysts helps to control the degree of hydrocracking to ensure that the wax decomposes into hydrocarbons of a preferred chain length. ${ }^{21}$ Potential sources of hydrogen are gasification, tar thermal cracking, and tar steam reforming.

Methanol synthesis has been widely used as another means for converting syngas into liquid. The process can be summarized as follows: gases are initially chemisorbed onto the transition metal surface to form a highly reactive intermediate metal carbonyl, which can be further formed into methanol. The key step is the chemisorption of gaseous $\mathrm{CO}$ onto the metal surface. ${ }^{74}$ The process is exothermic, which poses challenges for reactor design, as heat removal is required. ${ }^{20}$ Methanol synthesis normally occurs at low temperatures of $220-300^{\circ} \mathrm{C}$ and high pressures of 50 100 bar over $\mathrm{Cu} / \mathrm{ZnO}$-based catalysts. ${ }^{20}$ The copper catalyst has a lifetime of 2-5 years, but it can be poisoned by sulfur; therefore, sulfur should be reduced 
to less than $0.1 \%{ }^{20} \mathrm{Cu}$ catalysts will also sinter in the presence of $\mathrm{Cl}^{20}$ Methanol synthesis produces a number of side products, including methane, dimethyl ether, methyl formate, higher alcohols, and acetone, which together decrease methanol yield. ${ }^{20}$

Isosynthesis reactions can be described as the conversion of syngas into i-C4 hydrocarbons (isobutane and isobutene), using a thorium or zirconium catalyst. The selective formation of $\mathrm{i}-\mathrm{C} 4$ is affected by $\mathrm{CO}_{2}$ content in the reactant mixture, ${ }^{77}$ and a potential means of improving carbon efficiency is to recycle $\mathrm{CO}_{2}$ back into the synthesis process. This also simultaneously reduces $\mathrm{CO}_{2}$ emissions. Extreme optimum reaction conditions $\left(450^{\circ} \mathrm{C}\right.$ and $150-1000$ atm $)^{78}$ are needed to obtain optimum i-C4 production from the isosynthesis reaction. Undesired alcohols will form at low temperatures, while methane and aromatics form at high temperatures. The choice of optimum reaction conditions varies with the use of different catalysts. For example, for thorium-based catalysts, 150 atm and $450^{\circ} \mathrm{C}$ are the preferred conditions for the isosynthesis reaction, with $46 \%$ CO conversion, the product is $10 \%$ isobutene, with isobutane comprising much of the remainder. For zirconium-based catalysts, the overall CO conversion is comparatively lower. For example, under the same operating conditions (150 atm and $450^{\circ} \mathrm{C}$ ), only $32 \%$ of $\mathrm{CO}$ can be converted. Another difference between the two catalysts is that the latter has higher selectivity for isobutene than thorium-based catalysts, and has also received more attention in the literature. ${ }^{77,79}$ Pure isosynthesis catalysts (either thorium- or zirconiumbased) can be improved by using promoters such as $\mathrm{Al}_{2} \mathrm{O}_{3}, \mathrm{Zn}$, or $\mathrm{Cr}$.

Another pathway that directly converts syngas is oxosynthesis, also referred to as hydroformylation, to produce aldehydes through hydroformylate olefin intermediates. The operating conditions for oxosynthesis are temperatures of up to $200^{\circ} \mathrm{C}$, with a 1:1 ratio of $\mathrm{H}_{2} / \mathrm{CO}$. Oxosynthesis is an exothermic reaction $^{74}$, and during the initial stage of the process, a metal-carbonyl complex is formed by the combination of an olefin and a metal. This is followed by the formation of an alkyl-metal carbonyl complex through combination of the olefin and a metal-hydrogen bond. Finally, aldehyde can be formed through the insertion of $\mathrm{CO}$, followed by $\mathrm{H}_{2}$, into the carbon-metal bond in the alkyl-metal carbonyl complex. ${ }^{74}$ The catalysts used in oxosynthesis processes are $\mathrm{Co}, \mathrm{Pt}, \mathrm{Rh}$, and $\mathrm{Rh}$, among which, Co and Rh are predominantly used in commercial plants. ${ }^{78}$

\subsection{Feedstock classification and characterization}

Based on various biomass feedstock types, biofuels can be classified into four generations (see Table 2). ${ }^{9}$ First-, second-, and third-generation bio-fuels are produced from edible feedstocks, non-food competitive feedstocks, and aqueous biomass, respectively, while fourth-generation bio-fuels apply similar technologies but also consider carbon capture and storage (CCS), which is outside the scope of this review.

First-generation biomass feedstocks are not considered sustainable, due to the inherent fuel versus food competition, and significant social and environmental problems related to water and land..$^{21}$ It is expected that, in the near future, second- and thirdgeneration biomass sources will dominate. ${ }^{80}$ Secondgeneration bio-fuels provide a compelling alternative fuel option, and their exploration has begun through a growing number of demonstration or pilot-scale plants. In addition to the advantage of not competing with food, there is also wider availability of secondgeneration biomass than of first-generation feedstock. It is believed that second-generation feedstocks will be able to meet fuel provision requirements once commercialized. ${ }^{81}$ Moreover, they are more environmental-friendly than conventional energy crops, due to their tolerance to a wide range of soil and environmental stressors, fast growth rates, lower land use requirements, and reduced $\mathrm{CO}_{2}$ emissions. ${ }^{81}$ The latter is a key environmental advantage over firstgeneration feedstocks and fossil fuels. ${ }^{9}$ Microalgae constitute the main feedstock of third-generation biofuels, due to their rapid growth rate, high feedstock production efficiency, environmental benefits, and high liquid fuel production capacity. It should be noted that the mass production of oil from microalgae is 30 times that from oil seed crops when using the same area of land. ${ }^{82}$ However, the technologies involved are expensive and cannot compete in the short-term with other energy sources. ${ }^{9,83}$ Therefore, the near-term strategy is to increase bio-fuel production through a transition from first-generation to second-generation bio-fuels, reaping the associated social and environmental benefits. The transition process will be slow and must be steady. ${ }^{84}$

Table 2. Various biomass feedstocks and their corresponding generations of bio-fuels.

\begin{tabular}{|c|c|c|c|}
\hline \multicolumn{2}{|c|}{ Biomass feedstocks } & \multicolumn{2}{|l|}{ Bio-fuels } \\
\hline \multirow{3}{*}{$\begin{array}{l}\text { Edible } \\
\text { feedstock }\end{array}$} & Starch (wheat, barley, corn, potato) & \multirow{3}{*}{ Bioethanol, biodiesel } & \multirow{3}{*}{ First-generation bio-fuel } \\
\hline & Sugars (sugarcane, sugar beet) & & \\
\hline & $\begin{array}{l}\text { Oil crops (rapeseed, soybeans, sunflower, } \\
\text { palm, coconut, used cooking oil, animal fats) }\end{array}$ & & \\
\hline \multirow{4}{*}{$\begin{array}{l}\text { Non-food- } \\
\text { based }\end{array}$} & Forest and forest residue & \multirow{4}{*}{$\begin{array}{l}\text { Hydrocarbon fuels, hydrogen, } \\
\text { methanol, alcohols, F-T fuel, } \\
\text { aviation fuel, olefins }\end{array}$} & \multirow{4}{*}{ Second-generation bio-fue } \\
\hline & Agricultural biomass (straw, grass) & & \\
\hline & Energy crops (jatropha, cassava, miscanthus) & & \\
\hline & Municipal solid waste & & \\
\hline \multirow{3}{*}{$\begin{array}{l}\text { Aquatic } \\
\text { biomass }\end{array}$} & Microalgae & \multirow{3}{*}{$\begin{array}{l}\text { Naphtha, diesel, hydrogen, } \\
\text { methanol, ethanol }\end{array}$} & \multirow{3}{*}{ Third-generation bio-fuel } \\
\hline & Seaweed & & \\
\hline & Microbes & & \\
\hline \multicolumn{3}{|c|}{ Based on the same technologies of first-, second-, third-generation bio-fuels, but including carbon } & Fourth-generation bio-fuel \\
\hline
\end{tabular}


capture and storage (CCS) for each conversion technology

Typical feedstock for second-generation bio-fuels include: i) woody biomass and related waste; ii) agricultural biomass and related waste; iii) energy crops; iv) Municipal Solid Waste (MSW); and v) animal manure. The first three of these are generally referred to as lignocellulosic biomass. This is the most abundant biomass type, comprising more than $95 \%$ of all global biomass sources. ${ }^{6}$ Its utilization has a long history, primarily for cooking and heating, predating the use of fossil fuels in the $19^{\text {th }}$ century. ${ }^{7,20}$ Of the different lignocellulosic biomass types, woody biomass is generally preferred, owing to lower concentrations of fertilizers and pesticides, and the fact that less land is required for the same level of production. $^{11}$ Considerable focus has been placed on energy crops, due to their fast growth rates, the environmental benefits for increasing carbon storage in soil, and the improvement of surface water quality. ${ }^{85,86,87,88}$ Energy crops can also grow on land that is unsuitable for growing food crops, reducing land erosion, and restoring soil. ${ }^{9}$ However, the environmental benefits of energy crops vary with land use. For example, normal utilization of temperate energy crops releases fewer

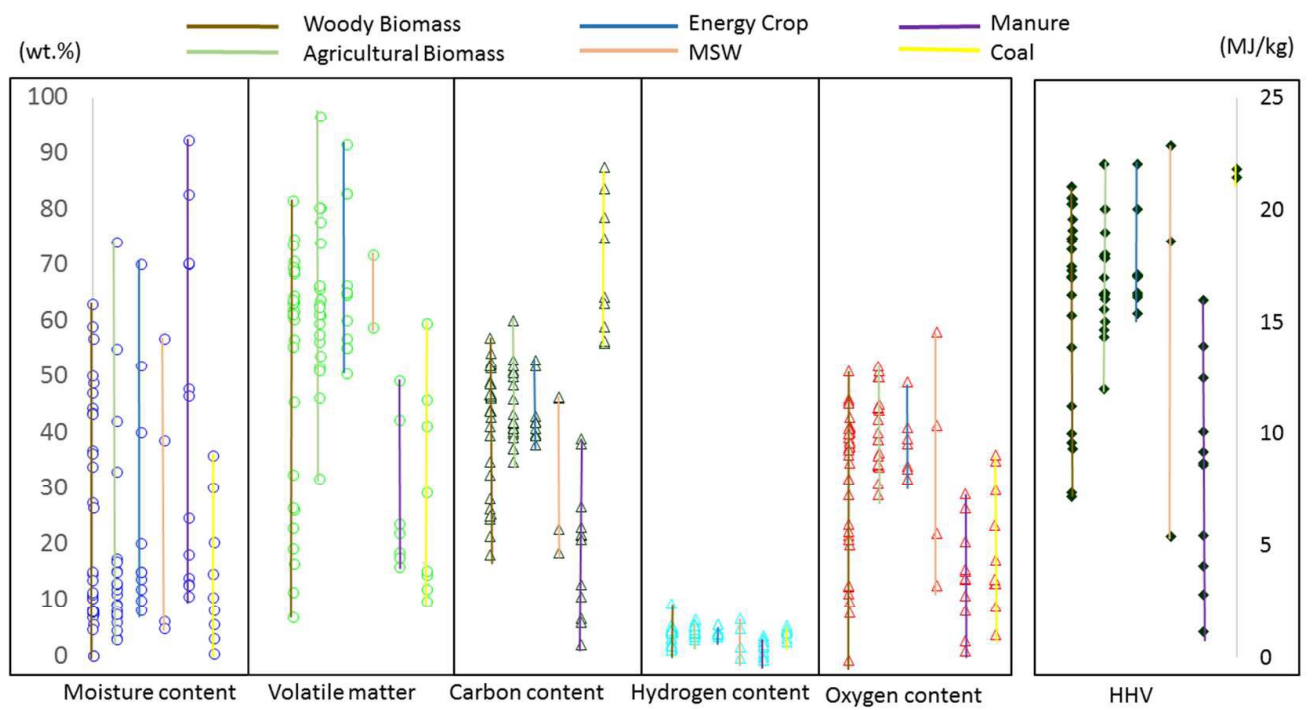
$\underset{93,94}{\text { Figure 7. Key properties of typical biomass feedstocks and coal. MSW: municipal solid waste; HHV: high heating value., }}$

Moisture content significantly influences the heating value, especially the low heating value (LHV), since moisture evaporation requires large quantities of energy, ${ }^{95}$ and the presence of moisture reduces the efficiency of most thermochemical conversion processes. Table 3 shows moisture content requirements for the main thermochemical conversion technologies. Moisture content varies significantly with different feedstocks and with other factors, such as climate. Normally, green unseasoned wood has a moisture content of $40-100 \%$ on a dry basis, even if the content of intrinsic water that is chemically bonded to biomass is low. ${ }^{80}$ In contrast, seasoned, air-dried wood has a much lower moisture content of $10-25 \%$ on a dry basis, and this can be reduced to $5-10 \%$ after pelletization. greenhouse gases (GHG) than using diesel or gasoline, but emissions are up to $20 \%$ higher than those of diesel or gasoline if the crops are grown on arable land converted from pasture. ${ }^{89}$ Additionally, the GHG emissions of tropical energy crops are higher than those of fossil fuels if grown on tropical rainforest soils, but are lower when grown on degraded land. ${ }^{89}$

Feedstock characterization can be performed on the basis of biochemical, proximate, and ultimate analysis. $^{80}$ Biochemical analysis determines the main biomass components, including cellulose, oils, fats, proteins, terpenes, alkaloids, terpenoids, and waxes ${ }^{6}$. Proximate analyses determine the thermal properties of the feedstock thermal properties, including moisture content, fixed carbon, volatile matter, and ash, the latter comprising mainly of inorganic remains following combustion. Ultimate analysis determines individual element contents, including $\mathrm{C}, \mathrm{H}, \mathrm{O}, \mathrm{N}$, and $\mathrm{S}$. Fig. 7 provides a general description of some most important factors in key biomass

feedstocks. hemicellulose, and lignin, with minor amounts of other thermochemical conversion technologies.

\begin{tabular}{|l|l|l|l|}
\hline & Normally & $\begin{array}{l}\text { MC (maximum } \\
\text { value) }\end{array}$ & Ref \\
\hline Combustion & $5 \%$ & $35 \%$ & 95 \\
\hline Gasification & $15 \%$ & $10-20 \%$ & 96 \\
\hline Liquefaction & $\begin{array}{l}\text { No drying } \\
\text { needed }\end{array}$ & $\begin{array}{l}\text { No drying } \\
\text { needed }\end{array}$ & \\
\hline Fast pyrolysis & $<10 \%$ & Up to $15 \%$ & $\mathbf{2 2}$ \\
\hline
\end{tabular}

Biomass normally has a higher content of volatiles (64-98\%) compared to coal $(<40 \%),{ }^{94}$ and a lower fixed carbon content than fossil fuels. Levels of volatiles and fixed carbon significantly influence the distribution of gaseous, liquid, and solid products. Greater quantities of gaseous products can be obtained from the cracking of volatiles contained in the feedstock, while a high liquid yield normally 
requires external hydrogen. Some degree of hydroprocessing, hydrogen addition, or steam reforming is therefore needed to increase liquid quality. ${ }^{80}$ A larger content of fixed carbon will lead to more solid char formation. ${ }^{97}$ Compared with fossil fuels, biomass has a lower carbon content, ${ }^{11,12}$ leading to low energy density. Biomass generally contains less sulfur (0.05$0.1 \%$ ) than fossil fuels, and $\mathrm{SO}_{\mathrm{x}}$ emissions from subsequent biomass combustion are not significant. However, the presence of sulfur in syngas poses problems for further syngas upgrading. ${ }^{98}$ The nitrogen content of biomass is similar to or greater than that of fossil fuels, and must be dealt with during the upgrading process. ${ }^{99}$

It is worth noting that inorganic elements in biomass, mainly in the form of inert and thermally stable ashes, do not contribute to the heating value of feedstock. However, inorganic elements have considerable influence on the yield and quality of produced bio-fuels, ${ }^{100,}{ }^{101}$ not only accelerating the primary decomposition of biomass into cellulose, hemicellulose, and lignin, but also promoting further volatile cracking to form light compounds and char. ${ }^{93,}$ 102 However, the presence of inorganic elements also creates problems such as slagging and fouling, due to the high alkali content of biomass ash, especially in agricultural biomass. ${ }^{7,80}$ When compared with woody biomass, herbaceous biomass has a higher ash content, and is especially high in silica and potassium, leading to greater gasifier slagging. ${ }^{7}$ For example, the ash content of switchgrass is $4.5-6.4 \%,{ }^{103}$ which is undesirably high for conversion into bio-fuel, and therefore must be addressed. ${ }^{102}$

\subsection{Second-generation bio-fuels and allied products}

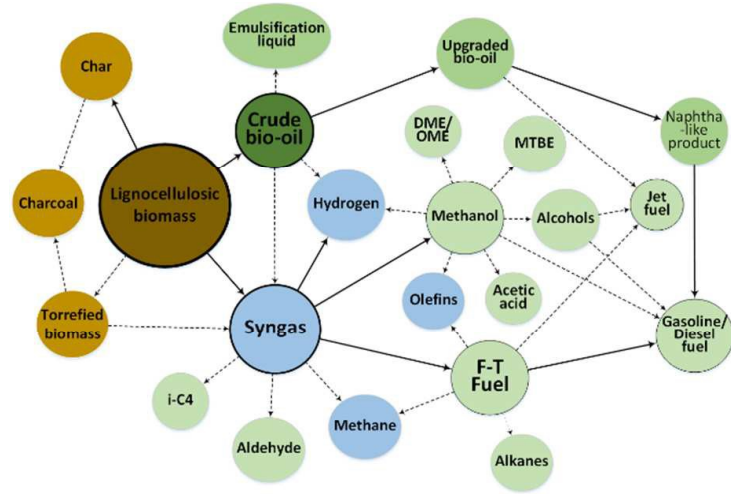

Figure 8. Network of second-generation bio-fuels and allied fuel additives and bio-chemicals. Brown backgrounds represent solid feedstocks or products, green backgrounds represent liquid products, and blue backgrounds represent gaseous products. F-T: Fischer-Tropsch; i-C4: isobutene and isobutane; DME: dimethyl ether; OME: oxymethylene ethers; MTBE: Methyl tert-butyl ether; HRJs: hydro-processed renewable jet fuels.

Fig. 8 shows the network of second-generation biofuels and allied fuel additives and bio-chemicals. Key intermediates include torrefied biomass, bio-oil, syngas, methanol, and F-T fuel. End products mainly include charcoal, gasoline/diesel-range hydrocarbons, jet fuels, aldehydes, and hydrogen.

\subsubsection{Torrefied biomass}

Compared with untreated biomass, torrefied biomass is a more attractive fuel, with enhanced physical properties providing both energetic and economic advantages for downstream conversions including gasification and combustion. ${ }^{11}{ }^{104}$ Torrefaction can significantly reduce the high moisture content of raw biomass, directly improving energy efficiency, and enhancing ignition behavior. Another important advantage of torrefied biomass over raw biomass is its higher calorific value, due to its lower moisture and oxygen contents. Energy densification, defined as the dimensionless energy density ratio of torrefied to raw biomass, can range from 1.0 to 1.45 , depending on feedstocks and operating conditions. ${ }^{11,24}$ The improvement in energy density provides additional cost-saving advantages during handling and transportation. Moreover, the grindability of torrefied biomass is improved by breaking down feedstock fibers; ${ }^{105}$ as a result, the energy consumption of a biomass mill can be significantly reduced. ${ }^{24,106}$ Biomass fuel uniformity can also be increased through torrefaction, enabling the production of torrefied biomass with similar physical and chemical properties from a variety of raw materials. ${ }^{104}$

\subsubsection{Syngas}

Syngas is the general name for gaseous products derived from gasification. The composition of syngas varies with different gasification technologies, operating conditions, and gasifying agents. ${ }^{19}, 107$ Chemically, syngas consists of $30-60 \% \mathrm{CO}, 25-30 \% \mathrm{H}_{2}$, 5-15\% $\mathrm{CO}_{2}, 0-5 \% \mathrm{CH}_{4}$, and small proportions of tar, particulates, water vapor, $\mathrm{H}_{2} \mathrm{~S}, \mathrm{COS}, \mathrm{NH}_{3}$, and other compounds. ${ }^{7}$ High-value products derived from syngas upgrading include methanol, F-T fuel, i-C4, and aldehydes, as shown in Fig. 6 and described in section 3.1.3. Other products that can be obtained directly or indirectly from syngas are higher alcohols, dimethyl ether (DME), and hydrogen. Higher alcohols include ethanol, propanols, and butanols. ${ }^{74}{ }^{108}$ Based on standard enthalpy and Gibbs free energy of formation, the order of alcohol formation, with increasing difficulty, can be summarized as follows: isobutanol < butanol < propanol < ethanol. ${ }^{74}$ It has been shown that ethanol yields from syngas are similar to those from corn fermentation. ${ }^{20,109,110,111}$

\subsubsection{Methanol}

For the syngas-to-methanol process, it has been shown that a lower temperatures leads to higher methanol yield, ${ }^{112}$ and a certain quantity of water promotes the methanol process via a water-gas-shift reaction. However, extra water blocks the active sites and reduces methanol yield. ${ }^{78} \mathrm{H}_{2}, \mathrm{CO}$, and $\mathrm{CO}_{2}$ are all present during the methanol synthesis process, and the preferred ratio of $\left(\mathrm{H}_{2}-\mathrm{CO}_{2}\right) /\left(\mathrm{CO}+\mathrm{CO}_{2}\right)$ is around 2.1. ${ }^{113}$ However, the rate of methanol production from a $\mathrm{H}_{2}-\mathrm{CO}-\mathrm{CO}_{2}$ mixture is thought to be significantly higher ( 7 times) than that from a $\mathrm{H}_{2}-\mathrm{CO}_{2}$ or $\mathrm{H}_{2}-\mathrm{CO}$ mixture. ${ }^{20} \mathrm{CO}_{2}$ in the product gas may originate either from gasification reactions or from the water-gas-shift reaction. ${ }^{112}$ The presence of $\mathrm{CO}_{2}$ promotes the formation of methanol, as this helps to maintain the 
to reduce moisture, acid, and oxygen, with each deoxygenation technology aiming to achieve one or more of these targets.

HDO treatment can significantly reduce oxygen content, from $40-50$ wt\% to $1-28 w t \%{ }^{129,130,131,132,133}$ The conversion rate from crude bio-oil to upgraded HDO bio-oil is up to $85 \% .{ }^{28}$ When co-processing HDO in standard refinery units, it was found that up to $70 \mathrm{wt} \%$ of carbon in pyrolysis oil was recovered during the HDO process. Even so, the oxygen content of the upgraded bio-oil is still high compared to conventional oil. However, $20 \mathrm{wt} \%$ of the product is miscible with FCC feed with a long residue. Additionally, HDO also minimizes the yields of light gases, char, and coke. ${ }^{129}$ The liquid viscosity will be increased during the HDO process, thus a lower limiting value of $5 \mathrm{wt} \%$ for the oxygen content is needed to ensure low viscosity. ${ }^{20}$ Considering the different bio-oil compounds involved in HDO, mainly aromatics and aliphatic compounds, the energy required to break down $\mathrm{C}-\mathrm{O}$ bonds is higher for the former than the latter, ${ }^{20}$ and the reaction of aromatics with hydrogen should be avoided because it decreases the octane number and consumes more hydrogen.

Catalytic cracking leads to the removal of oxygen, with the main products being $\mathrm{CO}$ and $\mathrm{CO}_{2}$. The yield of gasoline-compatible aromatics from this process is $20 \%$ of the raw biomass material on a mass basis and $45 \%$ on an energy basis. ${ }^{25,134}$

When comparing upgraded bio-oil from different upgrading technologies, hydro-treating typically produces high quality oil, with high energy content and low corrosivity. However, the technology requires high-pressure $\mathrm{H}_{2}$, and the product water reduces the caloric value of the produced bio-oil to some extent. ${ }^{28}$ Catalytic cracking does not need $\mathrm{H}_{2}$, but the formation of coke influences catalyst reactivity. The naphtha equivalents for both HDO and catalytic cracking are $25 \%$ of the mass of the biomass, and $55 \%$ of the energy, without considering hydrogen provision. ${ }^{134}$ Compared to catalytic cracking, thermal bio-oil from visbreaking has a lower hydrocarbon content and a higher proportion of heavy oxygenated compounds. ${ }^{9}$ Physical emulsion with diesel fuel requires expensive emulsifying agents and produces highly corrosive oil. Steam reforming is a technically feasible route, however, the rate of conversion to fuel is low. ${ }^{20}$ 
Please do not adjust margins

Table 5. Main physical properties of crude bio-oil, with sources, advantages, and disadvantages.

\begin{tabular}{|c|c|c|c|c|c|}
\hline & Normally & $\begin{array}{l}\text { Petroleum } \\
\text { fuel }\end{array}$ & Source & Advantages and disadvantages & Ref \\
\hline Moisture content & $15-35 \%$ & $0.1 \%$ & Biomass feedstock. & $\begin{array}{l}\text { Moisture content in bio-oil reduces its viscosity and produces enhanced fluidity, which is good for its } \\
\text { combustion in engines; however, its energy density and flame temperature are reduced. }\end{array}$ & 23,134 \\
\hline Oxygen content & $35-50 \%$ & $0.5-2 \%$ & Biomass composition. & $\begin{array}{l}\text { High oxygen content leads to poor chemical stability, low energy density, high reactivity, and } \\
\text { immiscibility with hydrocarbon fuels. Additionally, the lower energy released when burning leads to } \\
\text { higher } \mathrm{CO}_{2} \text { emissions per unit energy. } \\
\text { The highest oxygen content that the FCC unit can tolerate is } 10 \mathrm{wt} \% \text {. } \\
\text { However, oxygen content cannot be reduced too much as the oxygen content of gasoline is so low } \\
\text { (near to zero) that anti-knock agents (gasoline additives) are needed to ensure auto-ignition. }\end{array}$ & $\begin{array}{l}126, \\
128, \\
134- \\
136,\end{array}$ \\
\hline $\mathrm{pH}$ & $2-3$ & $3.5-4$ & $\begin{array}{l}\text { Organic acids from } \\
\text { biopolymer degradation. }\end{array}$ & $\begin{array}{l}\text { Acidity leads to corrosion of vessels and pipework. Given that the industry standard is }<1.5 \mathrm{mg} \mathrm{KOH} / \mathrm{g} \\
\text { before FCC, the acid number of bio-oil needs to be reduced by using } 317 \text { stainless steel cladding, which } \\
\text { is able to tolerate the acid number of bio-oil, but this has not yet been applied in standard refinery } \\
\text { units. The acidity of bio-oil is mainly caused by carboxylic acid in the liquid; this leads to the } \\
\text { composition of bio-oil changing over time due to the reactions of aldehydes under acid conditions, } \\
\text { leading to further storage difficulties. }\end{array}$ & $\begin{array}{l}25, \\
33,134, \\
137\end{array}$ \\
\hline Ash & $0-0.2$ wt\% & $\begin{array}{l}0.001-0.180 \\
w t \%\end{array}$ & $\begin{array}{l}\text { The ash content of pyrolysis } \\
\text { oil has been shown to be } \\
\text { directly related to the char } \\
\text { content of oil. }\end{array}$ & $\begin{array}{l}\text { Existence of ash reduces the oil quality. The ash content can be reduced to }<0.01 \% \text { by hot-gas } \\
\text { filtration, meeting the requirement for even the best quality diesel fuel. } \\
\text { Alkalis leads to problems such as catalyst poisoning, deposition of solids in combustion, erosion, and } \\
\text { corrosion, slag formation, and creates damage to turbines. A guard bed with ion exchanger can be } \\
\text { used to remove metals contained in bio-oil. Alkali content can be lowered to about } 2 \mathrm{ppm} \text {, very close } \\
\text { to the level recommended for gas-turbine fuels. }\end{array}$ & $\begin{array}{l}6,25, \\
134\end{array}$ \\
\hline Char & NA & NA & $\begin{array}{l}\text { Incomplete char separation } \\
\text { during the process. }\end{array}$ & $\begin{array}{l}\text { Char causes problems like oil aging, sedimentation, filter blockage, catalyst blockage, engine injector } \\
\text { blockage, and alkali metal poisoning. }\end{array}$ & 25 \\
\hline Distillability & Poor & NA & $\begin{array}{l}\text { Reactive mixture of } \\
\text { degradation products. }\end{array}$ & $\begin{array}{l}\text { Bio-oil cannot be distilled - typical maximum is } 50 \% \text {. Liquid begins to react at }<100^{\circ} \mathrm{C} \text { and substantially } \\
\text { decomposes at }>100^{\circ} \mathrm{C} \text {. }\end{array}$ & 25 \\
\hline LHV & $15-20 \mathrm{MJ} / \mathrm{kg}$ & $\begin{array}{l}35-40 \\
\mathrm{MJ} / \mathrm{kg}\end{array}$ & $\begin{array}{l}\text { High moisture content, high } \\
\text { oxygen content }\end{array}$ & Low energy density creates utilization difficulties & 25 \\
\hline Viscosity & $\begin{array}{l}25-1000 \\
\text { centistokes }\end{array}$ & $\begin{array}{l}3-400 \\
\text { centistokes }\end{array}$ & $\begin{array}{l}\text { Chemical composition of bio- } \\
\text { oil. }\end{array}$ & $\begin{array}{l}\text { High viscosity leads to high pressure drop, increasing equipment costs, high pumping cost, poor } \\
\text { atomization, fairly high and variable with time, greater temperature influence than hydrocarbons. }\end{array}$ & 22,25 \\
\hline $\mathrm{H}: \mathrm{C}$ ratio & Low & NA & $\begin{array}{l}\text { Low } \mathrm{H}: \mathrm{C} \text { ratio in biomass } \\
\text { feedstock. }\end{array}$ & Upgrading to hydrocarbons is more difficult. & 25 \\
\hline $\begin{array}{l}\text { Miscibility with } \\
\text { hydrocarbons }\end{array}$ & Very low & NA & $\begin{array}{l}\text { Highly oxygenated nature of } \\
\text { bio-oil. }\end{array}$ & Will not mix with any hydrocarbons and integration into a refinery is thus more difficult. & 25 \\
\hline Nitrogen & $0-0.2 \mathrm{wt} \%$ & $0-0.02$ wt\% & $\begin{array}{l}\text { Contaminants in biomass } \\
\text { feed. } \\
\text { High nitrogen feed such as } \\
\text { proteins in wastes. }\end{array}$ & $\begin{array}{l}\text { Existence of nitrogen leads to unpleasant smell, catalyst poisoning during upgrading, and release of } \\
\mathrm{NO}_{x} \text { in combustion. }\end{array}$ & $\begin{array}{l}25,134, \\
138\end{array}$ \\
\hline $\begin{array}{l}\text { Phase separation } \\
\text { or inhomogeneity }\end{array}$ & NA & NA & $\begin{array}{l}\text { High feed water. } \\
\text { High ash in feed. } \\
\text { Poor char separation. }\end{array}$ & $\begin{array}{l}\text { Inhomogeneity leads to phase separation, partial phase separation, layering, poor mixing, and } \\
\text { inconsistency in handling, storage, and processing. }\end{array}$ & 25 \\
\hline
\end{tabular}

Notes: LHV-lower heating value; HHV-higher heating value. 
With the exception of the aforementioned chemical and physical bio-oil upgrading technologies, blending of additives, such as methanol, can significantly reduce the viscosity of bio-oil. Diebold and Czernik $^{139}$ reported that adding 10 wt\% methanol to bio-oil can reduce its viscosity to 20 times less than that of crude bio-oil. Moreover, the stability of bio-oil can be significantly increased using $\mathrm{ZnO}$ catalysts, with the increase in viscosity reduced to $55 \%$ after heating at $80^{\circ} \mathrm{C}$ for 24 hours, compared to a $129 \%$ increase in viscosity in the absence of $\mathrm{ZnO}$ catalysts. ${ }^{140}$

\subsubsection{F-T fuel}

F-T hydrocarbon fuels produced from syngas are clean, of high value, ${ }^{141}$ non-toxic, and do not produce $\mathrm{NO}_{\mathrm{x}}$ emissions. They have a high cetane number, low particulate emissions, and low sulfur and aromatic contents. $^{76}$ F-T fuel does not need specialized distribution infrastructure, due to the high fuel quality. ${ }^{141}$ Additionally, F-T fuel is characterized by wider feedstock flexibility, as it is produced from syngas. However, due to the lack of sulfur, F-T fuel is low in lubricity; ${ }^{76}$ one solution for this is to blend it with conventional fuel. ${ }^{76}$ Due to its low efficiency (of $25-50 \%$ ) and high price, F-T fuel is generally unpopular from a power and fuel economy viewpoint. ${ }^{141}$ One potential problem in its application is fuel leakage in the engine while blending, due to its lack of aromatic compounds, but the use of additives can minimize this problem. ${ }^{76}$ The F-T hydrocarbons produced can be further converted into a wide range of products, including gasoline, diesel, and chemicals. Linear oils and waxes are also tagged as high price products. ${ }^{142}$ The production of chain alkanes from the F-T process range from $\mathrm{C} 1$ to $\mathrm{C} 50$, while methane is also a major byproduct of F-T synthesis. Product selectivity of F-T fuels can be adjusted by controlling the catalytic properties.

\subsubsection{Char}

Char produced during pyrolysis can be directly utilized as a solid fuel for boilers. Global wood charcoal production was around 51 million tons in 2012, with annual production estimated to remain in the order of 50 million tons in the near future. ${ }^{7}$ Char also acts as an intermediate in the production of activated carbon and carbon nano-tubes, or for soil amendment. ${ }^{143}$ It can also be gasified or steam reformed into syngas, through similar mechanisms to those of torrefied biomass. Wood charcoal is normally made into briquettes, requiring additives as binders; these are normally anthracite coal, mineral charcoal, starch, sodium nitrate, limestone, borax, and sawdust. ${ }^{7}$

The main component of char is carbon, along with hydrogen and various inorganic species. Char yield is normally 35 wt\% from wood on a dry basis. However, as biomass has a higher volatile content than coal, its char yield is lower. Thus, an efficient way of utilizing biomass is by combining the production char and gases. The combustion of biomass normally gives a temperature of $850^{\circ} \mathrm{C}$, while charcoal combustion can produce temperatures as high as $2000^{\circ} \mathrm{C}^{30}$

It has been noted that the char yield from hemicellulose is higher than that from cellulose, mainly due to the former's higher mineral content catalytically promoting char formation. Conversely, the higher crystallinity of cellulose obstructs char formation. ${ }^{12}$ The high char yield from lignin is mainly due to the benzene rings present in lignin. Thus, biomass with a high lignin content is recommended for coal substitution in industrial applications, while biomass with a low lignin content is recommended for bio-oil production via fast pyrolysis. During the latter process, lignin is the main reason for the production of high molecular weight compounds that contribute to bio-oil viscosity, mainly due to the high stability of the benzene rings. ${ }^{144}$ Depolymerization of lignin mainly produces phenolic compounds. ${ }^{12}$

\subsubsection{Renewable gasoline/diesel-range hydrocarbons}

Renewable gasoline/diesel-range hydrocarbons produced from biomass are one type of drop-in biofuel, in that their properties meet the requirements of existing fuel utilization systems. These hydrocarbons can be widely upgraded from F-T fuel, syngas, methanol, and bio-oil.

The conversion rate of gasoline/diesel-range hydrocarbons from F-T fuel is $40 \%$, using a high capacity FFB reactor at around $340^{\circ} \mathrm{C}$ with Fe catalysts. Production of gasoline requires specific properties, such as high linearity and low aromatic content, and the F-T products (propane and butane) are highly branched, with high octane values. Compared with diesel, gasoline is not a favored F-T fuel product due to its production complexity. ${ }^{142}$ The process of converting F-T fuel into diesel requires high-capacity slurry bed reactors with cobalt catalysts, operated to maximize wax production. ${ }^{142}$ The selectivity of "straight run" diesel can be $20 \%$, with a cetane number of 75 after hydrotreatment; the final cetane number of diesel is around 70 after hydrocracking, higher than the market requirement. It can therefore be used for blending with diesel and to increase the fuel quality. ${ }^{142}$ Coupling the Co or Fe catalyst with ZSM-5 zeolite catalysts can crack the long chains in gasoline-range fuels, and directly produce high-octane gasoline from the F-T process. ${ }^{145}$ The heavy waxes produced can be hydrocracked to increase the yield of gasoline and diesel.

Gasoline-range hydrocarbons can also be produced from syngas, using bi-functional catalysts, which are a combination of transition metal species and zeolites. During the process, syngas initially converts into mixed alcohols by $\mathrm{CO}$ chemisorption on the catalyst as a first step. The alcohols are further converted into low olefins. Hydrocarbons are formed from these olefins by oligomerization, followed by hydrogenation. ${ }^{74} \mathrm{Bi}-$ functional catalysts have a higher energy efficiency than metal catalysts. The main reason for this is that, when using the same metal catalyst, correctly chosen zeolite supports (mainly from the point of view of size and acidity level) determine the selection of desired hydrocarbons. For example, $\mathrm{H}-\mathrm{Y}$ zeolite leads to highoctane fuels, while the HZSM-5 catalyst leads to aromatics for more expensive jet fuels. One probable reason for this difference is the different pore sizes of different zeolite catalysts. ${ }^{146}$ The metal/support ratio 
also affects the hydrocarbon type, mainly by affecting protonic acid sites. It is considered that a balance exists in the ratio of metal/support for optimal catalyst design. ${ }^{74}$ Olefins can be formed from methanol over a Ca-modified HZSM-5 zeolite catalyst. Further, it has been shown that optimal Ca loading for a given HZSM5 catalyst provides the best performance of the methanol-to-olefin process. ${ }^{147}$ During the alcohol-tohydrocarbon process, carbenium ions are important intermediates in the formation of long molecules on zeolite catalysts. Carbenium ions can be formed from the dehydrogenation of an olefin on the acid site of the catalyst, $^{74}$ with these increasing in size through the transfer of hydrogen ions. Finally, products can be formed from the larger carbenium ions by hydrogenation. $^{74}$

The methanol to gasoline (MTG) process involves the production of gasoline-range hydrocarbons from methanol over a composite catalyst containing H-ZSM5 and a mixed oxide ( $\mathrm{Cu}-\mathrm{Co}-\mathrm{Cr}$ ) alcohol synthesis catalyst. ${ }^{148}$ Methanol converts into ethanol, with the formation of the first $\mathrm{C}-\mathrm{C}$ bond; this is considered the rate limiting step during the MTG process. ${ }^{149}$ Following this, progressively higher value alcohols produce higher gasoline yields than methanol. This remains a challenge for catalyst development for higher alcohol synthesis. ${ }^{148}$ Gujar et al. ${ }^{151}$ investigated the effects of temperature, total pressure, and $\mathrm{H}_{2}$ partial pressure on MTG in a batch reactor, finding that high pressures and $\mathrm{H}_{2}$ promoted gasoline yield and decreased polyaromatic compounds. Aromatics comprise $40 \%$ of gasoline produced from MTG. The MTG process can be described as DME formation, with water being produced from the dehydration of methanol at a temperature of $300^{\circ} \mathrm{C}$ and a pressure of $27 \mathrm{~atm}$, followed by the production of hydrocarbons and water from DME at $350^{\circ} \mathrm{C}$ and 20 atm over ZSM- 5 catalysts. ${ }^{20}$

Gasoline-range hydrocarbons can also be produced from the upgrading of bio-oil. HDO oil is separated into two parts: the light volatile fractions and the heavy non-volatile fractions (37 wt\%). The light parts are correspondingly blended with petroleum, while the heavy parts are blended with vacuum gas oil (VGO) for further upgrading. Blending the heavy portion of HDO oil with VGO increases gasoline and diesel production, but simultaneously increases the coke yield. Coke blocks the active catalyst site and the structure of the catalyst must be adjusted accordingly. ${ }^{150}$ Blending of HDO oil with VGO in an FCC unit or in hydro-treating, up to $20 \mathrm{wt} \%$, has shown that it is possible to operate without the reactor plugging, with coke formation at $5 \%$. This is the same level as for the VGO upgrading, and the gasoline fraction yield is the same as with the VGO-only unit. ${ }^{150,151}$ A mixture of 15 wt\% HDO bio-oil with light cycle oil can be used in the FCC unit, producing a bio-gasoline with similar quality to the products upgraded from VGO, but with a lower yield of around $20 \mathrm{wt} \%{ }^{152}$

\subsubsection{Fuel additives}

Oxygenated compounds produced from methanol can be blended with conventional fuel diesel or gasoline to reduce pollutants such as $\mathrm{NO}_{x}$ and particulates. Such compounds include DME, and oxymethylene ethers (OME). DME can be used as a diesel additive and is produced from the dehydration of methanol. It can also be directly produced from syngas over bi-functional catalysts. ${ }^{20}$ The operating temperature for DME formation is lower than that of the bi-functional catalytic syngas-to-olefin process. A hybrid catalyst, referred to as HMCM-22 zeolite, with different $\mathrm{SiO}_{2} / \mathrm{Al}_{2} \mathrm{O}_{3}$ ratios, has been studied for a syngas-to-DME one step process. Results showed that a higher $\mathrm{SiO}_{2} / \mathrm{Al}_{2} \mathrm{O}_{3}$ ratio leads to a higher DME yield and lower yield of side-products. Further results have shown that a high-silica HMCM-22 zeolite catalyst is preferred for the syngas-to-DME process. ${ }^{153}$ An admixed catalyst of methanol synthesis catalyst (CuOZnO-Al ${ }_{2} \mathrm{O}_{3}$ ) combined with $\mathrm{HZSM}-5$ zeolite was also tested for the syngas-to-DME process. It was shown that a DME selectivity of $69 \%$ can be attained under the optimal operating conditions, at a temperature of $260^{\circ} \mathrm{C}$ and a pressure of $4 \mathrm{MPa} .{ }^{154} \mathrm{OME}$ is another promising diesel additive that has advantages over DME due to its more similar physical properties to conventional diesel, requiring less engine modification. ${ }^{155,156,157}$

Butanol $(29 \mathrm{MJ} / \mathrm{I})$, which has higher energy than ethanol $(21 \mathrm{MJ} / \mathrm{l})$, is preferred as a gasoline additive (34 MJ/I) over ethanol. Furthermore, another high octane number gasoline additive, methyl tertiary-butyl ether (MTBE), is produced from methanol reacting with isobutene over a solid acid catalyst H-ZSM-5. ${ }^{20,74}$ The use of MTBE raises environmental concerns related to groundwater contamination from leaking tanks in gas stations, which limits its use as a gasoline additive in the US. ${ }^{20}$

\subsubsection{Renewable jet fuels}

Bio-oil HDO generates aviation fuels, or so-called hydro-processed renewable jet fuels (HRJs), mainly comprising paraffinic hydrocarbons with the formula $\mathrm{C}_{n} \mathrm{H}_{2 n+2 .}{ }^{76}$ The process involves HDO followed by isomerization and cracking to remove the oxygen in bio-oil through the addition of hydrogen. HRJs can be solely and directly used in conventional aircraft engines due to their high energy content and high quality. The paraffinic hydrocarbons contained in HRJs have a high cetane number and are thermally stable fuels free of aromatics, oxygen, and sulfur. The high purity of these fuels results in ash free combustion with low emissions of $\mathrm{CO}, \mathrm{HC}, \mathrm{NO}_{x}$, and particulate matter. ${ }^{76}$ Some conventional jet fuel or fuel additives should be blended with HRJs to improve its low lubricity, due to its absolute lack of oxygen and sulfur. ${ }^{158}$

Bio-alcohols (methanol, ethanol, and butanol) cannot be used as aviation fuels due to their low flash points, low energy densities, and pure low temperature properties. However, they can be used as the feedstock to produce jet fuels. There are other options for jet fuel include liquid hydrogen and liquid methane; however, their applications are limited by high production costs and lower suitability for conventional aircraft engines. ${ }^{76}$ For example, liquid hydrogen produces more energy per weight compared 
with conventional aviation fuel but high storage volumes and other modifications are required for its use in aircraft engines. There are also associated security and storage challenges. Furthermore, during hydrogen combustion, large amounts of water are produced, posing a problem for potential hydrogen aircraft. ${ }^{76}$

\subsubsection{Hydrogen}

Hydrogen can be produced from biomass steam gasification. Where $\mathrm{H}_{2}$ needs to be separated from $\mathrm{CO}$ and $\mathrm{CO}_{2}$, this can be done using either the membrane method or through chemical methods. The hydrogen yield can be further improved through the water-gasshift (WGS) reaction, by adjusting the $\mathrm{CO} / \mathrm{H}_{2}$ ratio. $^{20}$ Industrial WGS decreases $\mathrm{CO}$ concentration to $0.2 \%$ through a two-step reaction, first decreasing $\mathrm{CO}$ concentration to $2-3 \%$ at high temperatures of $350-$ $500^{\circ} \mathrm{C}$ with Fe-oxide-based catalysts, followed by $\mathrm{H}_{2}$ purification methods including pressure swing adsorption at low temperatures $\left(200^{\circ} \mathrm{C}\right)$ with $\mathrm{Cu}$-based catalysts, $^{20}$ preferential air oxidation (PROX), and Pd membranes. ${ }^{20}$

Hydrogen can also be produced from gasification or catalytic steam reforming of bio-oil. The carbohydratederived fraction of bio-oil is converted to hydrogen and $\mathrm{CO}_{2}$ with nickel-based catalysts. The overall yield of hydrogen from biomass via bio-oil is lower than direct gasification of biomass feedstock (6 wt\% compared with 11-12 wt\%), however, the economics of the biomass $\rightarrow$ bio-oil $\rightarrow$ hydrogen route can be improved by selling lignin-derived products as a replacement for phenol in phenol-formaldehyde resins. ${ }^{134}$ Carbohydrate-derived bio-oil theoretically generates around $80 \%$ hydrogen, equivalent to an approximately 6 wt\% hydrogen yield from wood. ${ }^{57}$

Three major pathways for the production of hydrogen from methanol are auto-thermal reforming (Eq. 1), partial oxidation (Eq. 2), and aqueous-phase reforming (APR). These are used to supply hydrogen to proton-exchange membrane (PEM) fuel cells. Autothermal reforming is an endothermic process, while partial oxidation is an exothermic process; however both occur within a temperature range of $150-350^{\circ} \mathrm{C}$ and require a catalyst, such as $\mathrm{Pd} / \mathrm{ZnO}, \mathrm{Pt} / \mathrm{ZnO}$, and $\mathrm{Cu} / \mathrm{ZnO} .^{20}$

$\begin{array}{ll}\mathrm{CH}_{3} \mathrm{OH}+\mathrm{H}_{2} \mathrm{O}=\mathrm{CO}_{2}+3 \mathrm{H}_{2} & \text { Eq. } 1 \\ \mathrm{CH}_{3} \mathrm{OH}+\frac{1}{2} \mathrm{O}_{2}=\mathrm{CO}_{2}+2 \mathrm{H}_{2} & \text { Eq. } 2\end{array}$

Considering lignocellulosic biomass feedstocks, different fractions of hemicellulose, cellulose, and lignin lead to differences in hydrogen production. In general, $\mathrm{H}_{2}$ from hemicellulose starts to be formed at a temperature of $480^{\circ} \mathrm{C}$, while $\mathrm{H}_{2}$ from cellulose and lignin is formed from $500^{\circ} \mathrm{C}$. The lower starting temperature of hemicellulose can be explained by its mineral composition, which acts as a catalyst for hemicellulose decomposition. ${ }^{12}$

\subsubsection{Bio-chemicals}

Another important application of lignocellulosic biomass is the production of bio-chemicals (see Fig. 9). For example, carboxylic acids (formic acid, acetic acid, and propionic acid) can be used to produce calcium salts as road de-icers. It is technically possible to scale up the production of biomass-derived de-icers, however, this is not presently economically feasible. Other applications include the use of carbonyl groups for the production of nitrogen fertilizers, the use of terpenoid and phenolic compounds as wood preservatives, and the use of aldehydes (especially glycolaldehyde) as meat browning agents. Phenolic compounds can be used to give smoky flavors. Levoglucosan/levoglucosenone has various applications, including in the manufacture of pharmaceuticals, surfactants, biodegradable polymers, antibiotics, and flavor compounds. ${ }^{134}$ Furfural from the pyrolysis of cellulose or hemicellulose can be used as a chemical solvent or as a platform molecule for other chemicals or fuels. ${ }^{159}$

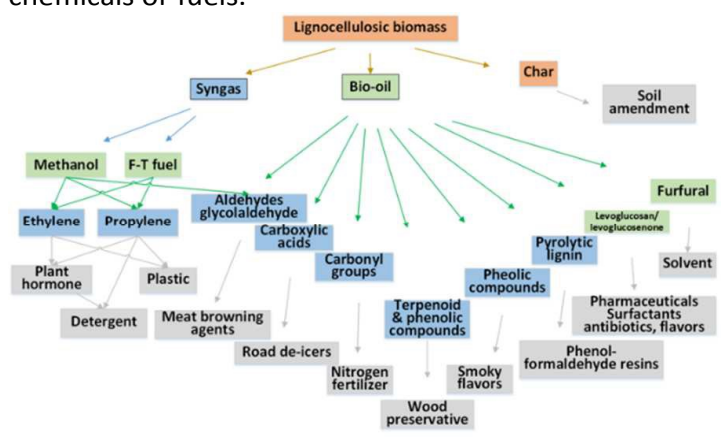

Figure 9. Main bio-chemical production routes.

The water-insoluble fraction of bio-oil, referred to as pyrolytic lignin, can be converted into resin. ${ }^{134}$ Chemical extraction provides a possible means of separating these compounds, with the main limitation being the ability to develop low-cost separation and refining techniques. ${ }^{59}$

Some chemicals can also be produced from the conversion of syngas. For example, ethylene, propylene, i-C4, and aldehydes can be produced via the platform molecules of methanol and F-T fuels. The methanol to olefin (MTO) process was discovered in the $1970 \mathrm{~s},{ }^{20}$ and olefin selectivity from methanol is as high as $80-90 \% .{ }^{160,161,162,163,164}$ These chemicals can be further used to produce plant hormones, detergents, and bio-plastics. For example, ethylene and propylene can be used for the production of polyethylene, polyvinylchloride, polypropylene, and acrylonitrile. Long chain olefins can be used to produce linear alcohols by hydroformylation, to further produce biodegradable detergents, with prices six times higher than that of fuel. ${ }^{142}$

\section{Energy perspective}

\subsection{Energy quality}

Fuel quality can be expressed in terms of its $\mathrm{C}, \mathrm{H}$, and $O$ contents, ${ }^{6}$ using the atomic ratios $\mathrm{O} / \mathrm{C}$ and $\mathrm{H} / \mathrm{C}^{135}{ }^{165}$ often summarized in the well-known Van Krevelen diagram ${ }^{165}$ to compare different solid feedstocks. Another two hydrogen-to-carbon atomic effective ratios have been further defined to better indicate fuel quality, as shown in Eqs. $3^{166}$ and $4 .{ }^{167}$ $\mathrm{H} / \mathrm{C}_{\text {eff }}$ considers the effect of $\mathrm{H}$ and $\mathrm{O}$, while $\mathrm{H} / \mathrm{C}_{\text {eff-ad }}$ 
considers the influences of a wider spectrum of elements $(\mathrm{H}, \mathrm{O}, \mathrm{N}$, and $\mathrm{S})$.

$$
\begin{array}{ll}
\boldsymbol{H} / \boldsymbol{C}_{\text {eff }}=\frac{\boldsymbol{H}-2 \boldsymbol{O}}{\boldsymbol{C}} & \text { Eq. } 3 \\
\boldsymbol{H} / \boldsymbol{C}_{\text {eff-ad }}=\frac{\boldsymbol{H}-2 \boldsymbol{O}-3 \boldsymbol{N}-2 \boldsymbol{S}}{\boldsymbol{C}} & \text { Eq. } 4
\end{array}
$$

Fig. 10 illustrates and compares the $\mathrm{HHV}$ and $\mathrm{H} / \mathrm{C}_{\text {eff }}$ values of 22 types of fuel obtained through biomass thermochemical conversion, including most biomass feedstock and bio-products. Three categories of fuel are indicated: solids, liquids, and gases. The figure shows that the heating value of solid char is lower than that of fuel gas, fuel oil, or bio-chemicals. Converting biomass into gaseous and liquid fuels is therefore of greater value than converting it into solid products. Biomass-derived liquid fuels, in the form of "drop-in" fuels, like butanol and diesel/gasoline-range hydrocarbons, may be directly used in existing engines without significant modifications. While some fuels with high oxygen content are not suitable for direct use in engines, they could instead be used as fuel additives. For instance, gasoline has a near-zero oxygen content, and therefore improving its oxygen content with additives will facilitate auto-ignition.

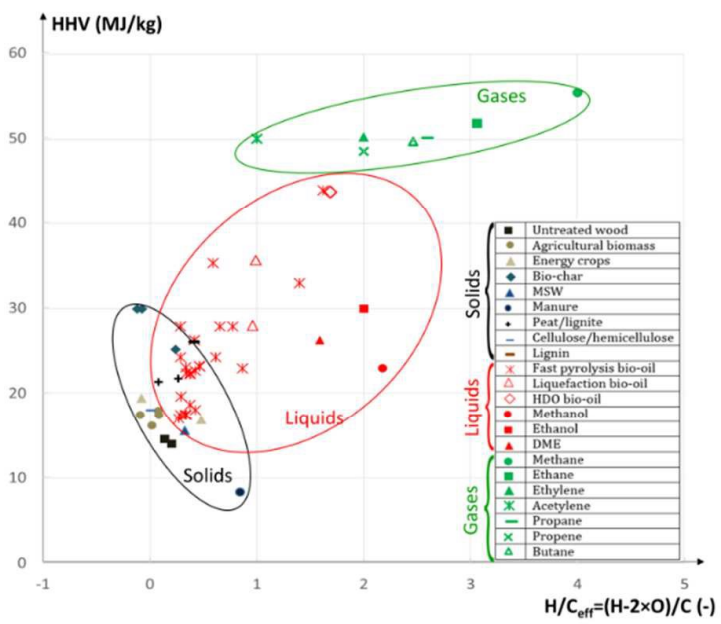

Figure 10. $\mathrm{HHV}-\mathrm{H} / \mathrm{C}_{\text {eff }}$ map for solid, liquid, and gaseous fuels; hydrogen is not included because its $\mathrm{H} / \mathrm{C}_{\text {eff }}$ value is infinite. $\mathrm{HHV}$ for hydrogen is $142 \mathrm{MJ} / \mathrm{kg}$. HHV: high heating value; DME: dimethyl ether; HDO: hydro-deoxygenation; MSW: municipal solid waste. ${ }^{8,11,15,17,22,23,24,25,26,27,28,80,}, 90,91,92,93,94$

Compared with fossil fuels, biomass has a low energy density, and its HHV normally lies within the range of $15-25 \mathrm{MJ} / \mathrm{kg}^{, 90,}{ }^{91}$ as shown in Fig. 10. Low density $\left(80-100 \mathrm{~kg} / \mathrm{m}^{3}\right.$ for grasses, $150-200 \mathrm{~kg} / \mathrm{m}^{3}$ for woody biomass ${ }^{6}$ ) is another problem that can result in biomass having a lower quality than oleaginous feedstock. This low density could be addressed by biomass densification, such as through torrefaction, pelletization, briquetting, steam explosion, and carbonization. ${ }^{6}$ Torrefaction provides the potential of improving biomass quality through a significant decrease in the $\mathrm{O} / \mathrm{C}$ ratio, ${ }^{168}$ and an increase in HHV to $20-25 \mathrm{MJ} / \mathrm{kg}^{168}$ Air-dried wood normally has an energy content of $15 \mathrm{MJ} / \mathrm{kg}$, which can be increased to 28-33 $\mathrm{MJ} / \mathrm{kg}$ for char after carbonization. Additionally, higher carbon content in a feedstock gives higher energy content. Lignin normally contains greater amounts of carbon and its energy content is around $26 \mathrm{MJ} / \mathrm{kg}$, close to that of coal. ${ }^{20,80}$

The energy content of syngas ranges from 5 to 20 $\mathrm{MJ} / \mathrm{Nm}^{3},{ }^{5}$ roughly $10-45 \%$ of that of natural gas. Typically, for gasification of wood to syngas, the carbon conversion rate is $92 \%$, the hydrogen conversion rate is $71 \%$, and the energy conversion rate is $62 \%$, with a syngas yield of around $1.2 \mathrm{Nm}^{3} / \mathrm{kg}$ wood. ${ }^{7}$ The production of fuels from biomass via syngas normally has a low overall process thermal efficiency of $16-50 \%$ because some proportion of biomass energy is lost during the biomass-to-syngas step. Biomass air gasification has been widely employed, as air is a low-cost agent and is easy to obtain, however, using air as a gasifying agent is disadvantageous as it produces low-ranked syngas with heating values of around 3-6 MJ/ $\mathrm{Nm}^{3}$. ${ }^{65}, 169,170$ The heating value of syngas can be increased by using pure $\mathrm{O}_{2}$ as a gasifying agent, although this requires an additional $\mathrm{O}_{2}$ separation unit, which significantly increases operating costs. Alternatively, steam gasification can improve $\mathrm{H}_{2}$ yield and thus produce syngas with a high heating value $\left(10-15 \mathrm{MJ} / \mathrm{Nm}^{3}\right) .{ }^{171,172}$ $\mathrm{CO}_{2}$ is also considered to be a preferred gasifying agent because both carbon and oxygen components are included in the product gases. In particular, the use of $\mathrm{Ni} / \mathrm{Al}$ catalysts in the $\mathrm{CO}_{2}$ gasification process provides a feasible means of increasing syngas yield, and the production of $\mathrm{CO}$ and $\mathrm{H}_{2}$ increases with increases the amount of catalyst. However, the gas yields do not increase beyond a threshold. ${ }^{173}$

The heating value of crude bio-oil is lower than that of other liquid fuels (see Fig. 10): around $36-47 \%$ of that of fuel oil (16-19 MJ/kg for bio-oil and 40-44 $\mathrm{MJ} / \mathrm{kg}$ for conventional fuel oil). ${ }^{15,33,134}$, It has been shown that a higher lignin content in feedstock will lead to a bio-oil product with a higher heating value. The upgrading processes for the two types of bio-oil (fast pyrolysis and liquefaction) are similar, although the upgrading of hydrothermal liquefaction bio-oil is more straightforward. ${ }^{19}$ The production of either pyrolysis bio-oil or liquefaction bio-oil requires only a single reactor, significantly minimizing energy loss due to complicated multi-step reactors, and thereby offering relatively large energy recovery during solid biomass feedstock conversion into liquid products (around $50-90 \%$ ). ${ }^{20}$ Nevertheless, further upgrading of bio-oil reduces energy efficiency and increases costs. For example, $70 \%$ of energy and $83 \%$ of the mass of wood feedstock are retained in pyrolysis oil, $63 \%$ of energy is retained after hydro-treating, and $53 \%$ is retained after zeolite upgrading. The corresponding values at the final stage of refining hydrocarbons are 25-27 wt\% and 55\% energy. The thermal efficiency of pyrolysis and further upgrading is higher than that of gasification followed by F-T synthesis. ${ }^{20}$

\subsection{Reaction heat}

Reaction heat is an important parameter required to understand the energy balance and efficiency of specific thermochemical technologies. Fig. 11 summarizes the standard enthalpy changes for the detailed reactions involved in individual processes. 
Torrefaction normally has a thermal efficiency, represented by the ratio between energy in the product and energy in the feedstock, of up to $96 \%$ (on a dry, ash free basis) ${ }^{24,168}$ with a proportion of the process energy being derived from the combustion of torrefaction gas. The net process efficiency, represented by the ratio between energy in the product and the sum of energy in the feedstock and process energy input, such as internal electricity consumption, is $92 \% .{ }^{24}$ The net process efficiency can be reduced to $80 \%$ or even less on a wet basis. ${ }^{174}$

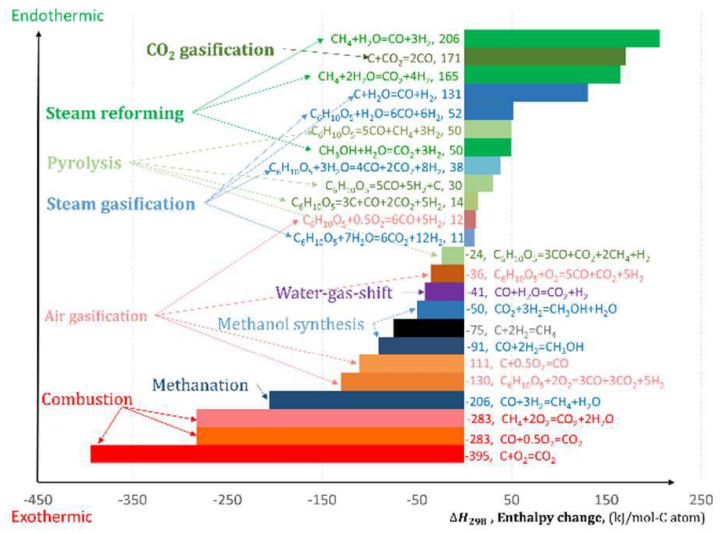

Figure 11. Enthalpy changes during main thermochemical conversion and further upgrading technologies. $7,20,74,78,149,160$, $161,162,163,175,176,177,178,179$

Pyrolysis is an endothermic process, with external heat sources provided for the reaction. Elevated temperatures can prompt the release of volatiles and char, but when the released volatiles approach solid fuel particles, they can be condensed onto the fuel surface and form tar. ${ }^{22}$

For biomass gasification, the reaction heat varies with different gasifying agents. As shown in Fig. 11, air or $\mathrm{O}_{2}$ gasification is exothermic, as a portion of the energy required is provided by partial combustion. This is not the case with steam or $\mathrm{CO}_{2}$ gasification, which are endothermic reactions, and thus external energy must be supplied for continuous operation. From an energy-saving perspective, the use of external energy sources should be avoided, especially high-quality energy sources. Alternatively, a combination of air and steam or air and $\mathrm{CO}_{2}$ gasifying agents can be used, providing benefits both in terms of high heating value syngas, and by providing essential system energy. ${ }^{180,181 \text {, }}$

\section{Economic assessment and feasibility of commercialization}

\subsection{Economic assessment}

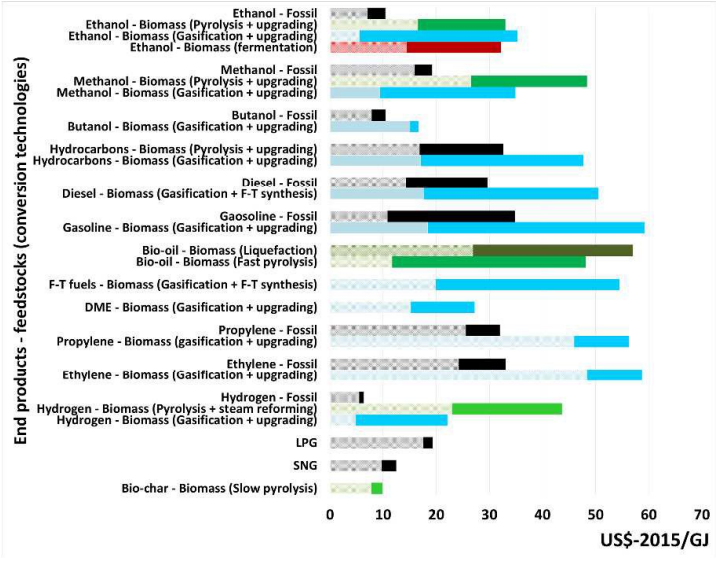

Figure 12. The range of production costs for the main secondgeneration bio-fuels and bio-chemicals, compared with the price of fuel from fossil sources. $5,84,182,183,184,185,186,187,188,189,190$, 191, 192, 193, 194, 195, 196, 197, 198, 199, 200, 201, 202, 203, 204, 205, 206, 207, 208 All costs are in US\$, with an average exchange rate of $€ 1=\$ 1.09$ and $£ 1=\$ 1.5$, based on current currency in 2015. All production prices were converted into 2015 costs using an inflation rate of $2 \%$. Within the two parts of each bar, the length of the dash filled part represents mineral production cost, and the total length of each bar presents the maximal production.

Fig. 12 presents the production costs of the main fuels and allied products produced from both lignocellulosic biomass and fossil fuels. The production costs of bio-fuel are around 2-3 times higher than those of conventional fuels. For each specific bio-fuel, there is a large range of production costs, which are dependent on feedstock cost, conversion efficiency, plant capacity, product value, and the producing region. ${ }^{209}$

Feedstock cost is the most significant factor influencing the economy of bio-fuel production. High biomass feedstock cost can be explained by intrinsic features, such as diversity and low quality. Biomass is a complicated feedstock and a number of pre-treatment factors need to be considered, such as cultivation, harvesting, transportation, processing, and storage. Moreover, the cost of deliverable biomass depends greatly on the plant type and production regions. ${ }^{20}$ The predicted order of delivery costs for different feedstocks is as follows: waste > straw > woody biomass > corn stover > high-yield grasses (Miscanthus) > normal-yield grasses (switchgrass, prairie grasses) $=$ hay $>$ corn grain. ${ }^{193}$ One potential solution to address the diversity and low quality of biomass feedstocks is the development and integration of feasible technologies to simultaneously process various biomass feedstocks, improving energy efficiency, reducing cost, and minimizing the waste stream. $^{6}$ Bio-refineries ${ }^{210}, 211,212,213$ provide another promising way of mitigating the low value of biomass feedstocks; by coupling with the facilities of petroleum refineries, they focus on converting low-value highvolume (LVHV) biomass feedstock into multiple highvalue low-volume (HVLV) bio-fuels or bio-chemicals at low costs.

For the liquid bio-products, fast pyrolysis with biooil processing (such as catalytic cracking or hydroprocessing) provides a relatively low-investment cost 
option, ${ }^{\mathbf{2 8}}$ compared with either fermentation or gasification followed by F-T synthesis. The low capital cost of fast pyrolysis is due to the small scale of the process. In contrast, fermentation needs a longer reaction time, leading to higher capital costs. ${ }^{195}$ The process of gasification combined with the F-T process for liquid production, has high investment costs. ${ }^{9}$ Moreover, the thermal efficiency of bio-oil production from pyrolysis or liquefaction is higher than that for liquid fuel derived from biomass gasification followed by F-T synthesis (16-43\%). ${ }^{20}$

The cost of bio-oil production is 10-100\% higher than that of fossil fuel. ${ }^{134}$ When comparing fast pyrolysis and liquefaction pathways for bio-oil production, the production cost of the latter (either crude bio-oil or refined bio-oil) is higher, mainly due to high capital costs and variable operating costs driven by long reaction times. ${ }^{19,20,}$ Chemical production from bio-oils faces technical and economic obstacles due to the complexity of the bio-oils and various product separation issues. ${ }^{134}$

The upgrading of bio-oil to specific usable liquid fuels is still in development, due to technical challenges and a lack of economic feasibility. Visbreaking has low cost as no hydrogen is required, it is carried out at laboratory scales. ${ }^{9}$ Catalytic vapor cracking can produce aromatics from bio-oil; ${ }^{48}$ however, its technical feasibility has not yet been fully demonstrated. ${ }^{134}$ The main issues are catalyst deactivation and high processing costs, which render the product uncompetitive with fossil fuels. A combined mode, with the production of bio-oil in several small pyrolysis plants, followed by transportation to a central bio-refinery for further conversion, could provide an economically preferable option, because the transport cost of dense bio-oil will be lower than that of solid biomass feedstock. Biooil/diesel emulsification can generate fuel that is easily ignited, however, the cost of emulsification is high because of the high cost of surfactant, and the fact that emulsification also requires more energy with further complications caused by corrosion of engines and subassemblies. ${ }^{59,134}$

The largest fraction of production costs for syngasderived bio-fuel is the syngas production cost, which accounts for $50-75 \%$ of total; ${ }^{78}$ this is mainly due to the costly and energy-consumptive step of syngas purification. ${ }^{7}$ The order of costs for syngas-derived fuel is $\mathrm{H}_{2}<$ methanol $\approx$ ethanol $<\mathrm{F}-\mathrm{T}$ liquids. F-T diesel is 40-50\% more expensive than methanol or hydrogen, ${ }^{20}$ and biomass-derived methanol is more expensive than its market price. Gasification followed by F-T synthesis can produce high-quality fuels that are compatible with conventional fossil fuels, however their high investment costs make them economically unfeasible.

The production cost of jet fuels (HRJs) is \$0.80$2.00 / \mathrm{L}$, three times higher than the cost of petroleum. ${ }^{76}$ This needs to be reduced to compete with petroleum jet fuel. The development of renewable aviation fuels would reduce dependence on fossil fuel sources, thus reducing environmental impacts. To achieve this, the production costs must be reduced, for example, by reducing feedstock cost. ${ }^{76}$
Finally, the production cost of hydrogen is within the cost range of the hydrogen market price. ${ }^{20,} 78$ Its commercial price depends on the cost of fossil fuels, with higher fossil fuel costs leading to higher hydrogen costs.

\subsection{Feasibility of full commercialization}

Currently, biomass utilization is dominated by combustion and co-firing with coal/natural gas for heat and power production. Most bio-fuels, especially biodiesel and bioethanol, still rely on first-generation biomass in phase I bio-refineries, with no flexibility for resource input, ${ }^{\mathbf{2 1 4}}$ using conventional esterification technologies. It has been reported that biomass cofiring and first-generation biodiesel and bioethanol make up two-thirds of renewable energy consumption in Europe. 9 To meet future renewable energy requirements, phase II bio-refineries, with fixed input and processing capabilities, that utilize lignocellulosic materials, and phase III bio-refineries, which can flexibly accommodate both feedstocks, are needed. However, the related costs are high due to the required facilities for such innovative technologies. Alternatively, biomass-derived intermediates can be integrated within existing oil refineries, offering a viable option for bio-fuel and bio-chemical production at a reasonable cost. ${ }^{9}$ Table 6 lists the secondgeneration bio-fuel plants at various stages of development (operational, under construction, planned, or shut down).

\subsubsection{Liquid fuel commercialization}

Technologies for the commercial production of transportation liquid fuels from first-generation biomass feedstocks are available in some countries. For example, bioethanol produced from corn grain in the US meets $10 \%$ of the gasoline demand in the country. $^{215}$ Similar cases are found in the use of bioethanol from sugarcane in Brazil, and the use of biodiesel from rapeseed and bioethanol from wheat and barley in Europe. ${ }^{9}$ Unfortunately, technologies for second-generation bio-fuels for transportation are still under commercialization. The most promising technology chains include: i) fast pyrolysis followed by bio-oil upgrading, ii) gasification with F-T synthesis, and iii) gasification, methanol synthesis, and additional alcohol upgrading.

CFP, as a technology for producing transportation fuel from biomass via a one-step reactor, has been investigated extensively by Professor George Huber's laboratory at the University of MassachusettsAmherst, and has been further developed by Anellotech, during which the process of producing cost-competitive aromatics from lignocellulosic biomass was patented. However, no commercial plant has yet been established. 
Table 6. Economic evaluation of different products produced through different pathways.

\begin{tabular}{|c|c|c|c|c|c|c|}
\hline Product & Scale & Company & Description & \begin{tabular}{|l} 
Capacity \\
\end{tabular} & Location & Status \\
\hline \multirow{21}{*}{ Bio-oil } & Commercial & $\begin{array}{l}\text { Dynamotive Energy Systems } \\
\text { Corporation }\end{array}$ & $\begin{array}{l}\text { Fast pyrolysis; a bubbling fluid bed reactor } \\
\text { to generate electricity }\end{array}$ & $130 \mathrm{t} / \mathrm{d}$ feedstock & West Lorne , Ontario & Shut down \\
\hline & Commercial & $\begin{array}{l}\text { Dynamotive Energy Systems } \\
\text { Corporation }\end{array}$ & Fast pyrolysis to generate electricity & $200 \mathrm{t} / \mathrm{d}$ feedstock & Guelph, Ontario & Shut down \\
\hline & Pilot & Union Fenosa & $\begin{array}{l}\text { Fast pyrolysis in a bubbling fluid bed } \\
\text { reactor }\end{array}$ & $4.8 \mathrm{t} / \mathrm{d}$ feedstock & Spain & Dismantled \\
\hline & Pilot & Agri-Therm & Flash pyrolysis in a fluidized bed reactor & $4.8 \mathrm{t} / \mathrm{d}$ feedstock & Canada & Developing \\
\hline & Pilot & Agri-Therm & $\begin{array}{l}\text { Mobile pyrolysis in a fluidized bed reactor } \\
\text { with heat recovery }\end{array}$ & $5 \mathrm{t} / \mathrm{d}$ feedstock & Canada & Developing \\
\hline & Pilot & Biomass Technology Group & $\begin{array}{l}\text { Fast pyrolysis in a rotating cone reactor to } \\
\text { generate electricity }\end{array}$ & $4.8 \mathrm{t} / \mathrm{d}$ feedstock & UK & Operational \\
\hline & Pilot & $\begin{array}{l}\text { Wellman Process Engineering } \\
\text { Ltd. (WPEL) } \\
\end{array}$ & $\begin{array}{l}\text { Fast pyrolysis in a bubbling fluid bed } \\
\text { reactor to generate electricity }\end{array}$ & $6 \mathrm{t} / \mathrm{d}$ feedstock & Oldbury, UK & Finished \\
\hline & Demo & Licella & $\begin{array}{l}\text { Fast pyrolysis to convert radiate pine, } \\
\text { banana grass, algae into 'drop-in' fuels, } \\
\text { including aviation fuel }\end{array}$ & $\begin{array}{l}1000 \text { odt feedstock } \\
350 \mathrm{t} / \mathrm{y} \text { bio-oil }\end{array}$ & $\begin{array}{l}\text { Somersby } \\
\text { Australia }\end{array}$ & Operational \\
\hline & Demonstration & Licella & Fast pyrolysis & 200,000 odt feedstock & 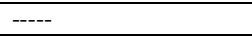 & Planning \\
\hline & Pilot & Biomass Engineering Ltd & $\begin{array}{l}\text { Fast pyrolysis in fluidized bed reactor to } \\
\text { process sawdust }\end{array}$ & $6 \mathrm{t} / \mathrm{d}$ feedstock & $\begin{array}{l}\text { Newton-le-Willows, } \\
\text { UK }\end{array}$ & Operational \\
\hline & Commercial & \begin{tabular}{|l} 
BTG-BTL \\
\end{tabular} & Rotating cone reactor & $120 \mathrm{t} / \mathrm{d}$ feedstock & Hengelo, Netherlands & Operational \\
\hline & Commercial & \begin{tabular}{|l} 
BTG-BTL \\
\end{tabular} & Rotating cone BTG unit & $48 \mathrm{t} / \mathrm{d}$ feedstock & Malaysia & Shut down \\
\hline & Commercial & Ensyn & $\begin{array}{l}\text { Transported bed \& CFB; A dedicated RFO } \\
\text { bio-fuels facility }\end{array}$ & 3 million gallons/year bio-oil & Renfrew, Ontario & Operational \\
\hline & Commercial & $\begin{array}{l}\text { Ensyn } \\
\text { Red Arrow RTP Facilities }\end{array}$ & $\begin{array}{l}\text { Transported bed \& CFB for production of } \\
\text { food flavorings }\end{array}$ & $40.8 \mathrm{t} / \mathrm{d}$ feedstock & $\begin{array}{l}\text { Rhinelander, } \\
\text { Wisconsin }\end{array}$ & Operational \\
\hline & Industrial & Pyrovac & Vacuum pyrolysis & $93 \mathrm{t} / \mathrm{d}$ feedstock & Québec, Canada & Operational \\
\hline & Industrial & ENEL & The Ensyn unit transported bed \& CFB & $650 \mathrm{t} / \mathrm{d}$ feedstock & Italy & Not operated \\
\hline & Industrial & PyTec & Ablative pyrolysis & $2 * 250 \mathrm{t} / \mathrm{d}$ feedstock & Germany & Operational \\
\hline & Pilot & $\begin{array}{l}\text { UPM, Metso and Fortum, } \\
\text { Technical Research Centre of } \\
\text { Finland (VTT) }\end{array}$ & $\begin{array}{l}\text { A pyrolysis transported bed \& CFB reactor } \\
\text { is integrated into a power boiler to } \\
\text { convert wood }\end{array}$ & $9.6 \mathrm{t} / \mathrm{d}$ feedstock & Finland & Finished \\
\hline & Industrial & Lurgi LR & Augur or Screw reactor & \begin{tabular}{|l}
$* 500 \mathrm{t} / \mathrm{d}$ feedstock \\
\end{tabular} & Germany & Operational \\
\hline & Industrial & Renewable Oil Intl & Augur or Screw reactor & $4 * 200 \mathrm{t} / \mathrm{d}$ feedstock & USA & Operational \\
\hline & Industrial & Anhui Yineng Bioenergy Ltd. & Moving bed and fixed bed reactor & $3^{*} 600 \mathrm{t} / \mathrm{d}$ feedstock & China & Operational \\
\hline \multirow{3}{*}{ F-T liquids } & Pilot & GTI Gas Technology Institute & Forest residues & $21 \mathrm{t} / \mathrm{d}$ feedstock & $\begin{array}{l}\text { Des Plaines } \\
\text { United States }\end{array}$ & Operational \\
\hline & Pilot & TUBITAK & $\begin{array}{l}\text { Combination of hazelnut shell, olive cake, } \\
\text { wood chips, and lignite blends }\end{array}$ & $6 \mathrm{t} / \mathrm{d}$ feedstock & $\begin{array}{l}\text { Gebze } \\
\text { Turkey }\end{array}$ & $\begin{array}{l}\text { Under } \\
\text { construction }\end{array}$ \\
\hline & Pilot & $\begin{array}{l}\text { Vienna University of } \\
\text { Technology; } \\
\text { BIOENERGY 2020+; Repotec; } \\
\text { Biomassekraftwerk Güssing }\end{array}$ & Gasification followed by FT & $\begin{array}{l}7 \mathrm{Nm}^{3} / \mathrm{h} \text { syngas } \\
0.2 \mathrm{t} / \mathrm{y} \text { F-T liquids }\end{array}$ & Güssing, Austria & Operational \\
\hline $\begin{array}{l}\text { F-T liquids; gasoline- } \\
\text { type fuel }\end{array}$ & Pilot & GTI Gas Technology Institute & Wood, corn stover, bagasse, algae & $0.05 \mathrm{t} / \mathrm{d}$ feedstock & $\begin{array}{l}\text { Des Plaines } \\
\text { United States }\end{array}$ & Operational \\
\hline F-T liquids; mixed & Pilot & \begin{tabular}{|l|} 
Research Triangle Institute \\
\end{tabular} & Gasification with further upgrading & $0.5 \mathrm{t} / \mathrm{d}$ feedstock & Research Triangle & Under \\
\hline
\end{tabular}




\begin{tabular}{|c|c|c|c|c|c|c|}
\hline \multirow[t]{2}{*}{ alcohols } & & & & & Park, United States & construction \\
\hline & Pilot & Southern Research Institute & Feedstock is cellulosics, municipal wastes & $2-4 \mathrm{t} / \mathrm{d}$ feedstock & $\begin{array}{l}\text { Durham, United } \\
\text { States }\end{array}$ & Operational \\
\hline $\begin{array}{l}\text { Renewable F-T diesel } \\
\text { and F-T jet fuel }\end{array}$ & Pilot & Clearfuels-Rentech & $\begin{array}{l}\text { FT process converting green waste, } \\
\text { municipal and solid wastes, wood waste, } \\
\text { and bagasse to synthetic jet fuels }\end{array}$ & $20 \mathrm{t} / \mathrm{d}$ feedstock & $\begin{array}{l}\text { Commerce City, CO, } \\
\text { USA }\end{array}$ & $\begin{array}{l}\text { Under } \\
\text { construction }\end{array}$ \\
\hline \multirow{5}{*}{ Ethanol } & Pilot & Chemrec \& Weyerhaeuser & $\begin{array}{l}\text { Processing wood using thermochemical } \\
\text { technologies }\end{array}$ & 330 t BLS /day & New Bern, NC & Finished \\
\hline & Demonstration & Coskata & $\begin{array}{l}\text { Gasification and fermentation; Natural } \\
\text { gas, wood chips, and simulated waste } \\
\text { materials }\end{array}$ & NA & Madison, PA & Operational \\
\hline & Commercial & $\begin{array}{l}\text { Indian River BioEnergy Center, } \\
\text { Vero Beach, FL. Owned by the } \\
\text { Swiss firm Ineos Bio INEOS }\end{array}$ & $\begin{array}{l}\text { Gasification and anaerobic fermentation; } \\
\text { Lignocellulosic biomass }\end{array}$ & $\begin{array}{l}60 \text { million tonnes of } \\
\text { petrochemicals }\end{array}$ & USA & Operational \\
\hline & Pilot & Gulf Coast Energy & $\begin{array}{l}\text { Thermochemical conversion; Urban waste } \\
\text { including sorted MSW and C\&D debris }\end{array}$ & & Livingston, AL & Operational \\
\hline & Pilot & Pearson Technologies Inc. & $\begin{array}{l}\text { Thermochemical conversion; Agricultural } \\
\text { residues, wood }\end{array}$ & $30 \mathrm{t} / \mathrm{d}$ feedstock & Aberdeen, MS & Operational \\
\hline \multirow{6}{*}{$\begin{array}{l}\text { Diesel-type } \\
\text { hydrocarbons }\end{array}$} & Demonstration & Cello Energy & $\begin{array}{l}\text { Catalytic depolymerization; Agricultural } \\
\text { residues, wood }\end{array}$ & $20 \mathrm{MGY}$ & Bay Minette, AL & Not operated \\
\hline & Demonstration & $\begin{array}{l}\text { ThermoChem Recovery } \\
\text { International (TRI) }\end{array}$ & $\begin{array}{l}\text { Thermochemical conversion; Agricultural } \\
\text { residues, wood, energy crops, and urban } \\
\text { waste, including sorted MSW and C\&D } \\
\text { debris }\end{array}$ & $0.02 \mathrm{MGY}$ & Durham, NC & Operational \\
\hline & Demonstration & Virent & $\begin{array}{l}\text { Steam reforming gasification; Pine } \\
\text { residues, sugarcane bagasse, and corn } \\
\text { stover }\end{array}$ & $30 \mathrm{t} / \mathrm{y}$ diesel & $\begin{array}{l}\text { Madison, Wisconsin } \\
\text { United States }\end{array}$ & Operational \\
\hline & Pilot & $\begin{array}{l}\text { CHOREN Tech. GmbH } \\
\text { Sold to Linde Engineering } \\
\text { Dresden }\end{array}$ & Gasification following by FT & $100 \mathrm{l} /$ day diesel & Freiberg (Germany) & Developing \\
\hline & Demonstration & CHOREN Tech.GmbH & Gasification, BTL & $2739 \mathrm{t} / \mathrm{d}$ feedstock & Schwedt (Germany) & Developing \\
\hline & Pilot & Neste and Stora Enso & Gasification and the FT process; Wood & -- & Varkaus, Finland & Cancelled \\
\hline Jet fuel & Commercial & $\begin{array}{l}\text { Solena Fuels } \\
\text { British Airways }\end{array}$ & $\begin{array}{l}\text { Unique combination of high temperature } \\
\text { plasma gasification, and FT tech }\end{array}$ & $1575 \mathrm{t} / \mathrm{d}$ feedstock & Thurrock, Essex & $\begin{array}{l}\text { Under } \\
\text { construction }\end{array}$ \\
\hline Syngas & Commercial & Premier Green Energy & Lignocellulosic biomass & $72 \mathrm{t} / \mathrm{d}$ feedstock & Thurles, Ireland & Planning \\
\hline Syngas & Commercial & Rentech-SilvaGas & Gasification & -- & Burlington, $\mathrm{VT}$ & Finished \\
\hline Syngas/SNG & Pilot & ECN & & $5 \mathrm{t} / \mathrm{d}$ feedstock & $\begin{array}{l}\text { Petten } \\
\text { Netherlands }\end{array}$ & Operational \\
\hline \multirow{3}{*}{ SNG } & Demonstration & $\begin{array}{l}\text { ECN - Consortium Groen Gas } \\
2.0\end{array}$ & $\begin{array}{l}\text { Convert waste wood, prunings, or mown } \\
\text { grass into electricity and heat }\end{array}$ & $\begin{array}{l}6500 \mathrm{t} / \mathrm{y} \mathrm{SNG} \\
11.6 \mathrm{MW}_{\text {thermal }} \text { output gasifier }\end{array}$ & $\begin{array}{l}\text { Alkmaar } \\
\text { Netherlands }\end{array}$ & Planning \\
\hline & Demonstration & Goteborg Energi $A B$ & $\begin{array}{l}\text { Forest residues, wood pellets, branches, } \\
\text { and tree tops } \\
\text { District heating }\end{array}$ & 11200 t/y SNG & $\begin{array}{l}\text { Göteborg } \\
\text { Sweden }\end{array}$ & Operational \\
\hline & Demonstration & $\begin{array}{l}\text { Biomassekraftwerk Güssing } \\
\text { Vienna University of }\end{array}$ & $\begin{array}{l}\text { Two inter-connected fluidized bed systems } \\
\text { of the fluidized bed steam gasifier }\end{array}$ & $576 \mathrm{t} / \mathrm{y}, 100 \mathrm{Nm}^{3} / \mathrm{y} \mathrm{SNG}$ & Güssing, Austria & Operational \\
\hline
\end{tabular}


Please do not adjust margins

\begin{tabular}{|c|c|c|c|c|c|c|}
\hline & & $\begin{array}{l}\text { Technology, } \\
\text { Paul Scherrer Institute, } \\
\text { Repotec, }\end{array}$ & (reactor). & & & \\
\hline $\begin{array}{l}\text { Syngas, methanol, } \\
\text { acetates, and second- } \\
\text { generation ethanol }\end{array}$ & Pilot & Enerkem & $\begin{array}{l}\text { Thermochemical from wood urban waste } \\
\text { including sorted MSW and C\&D debris }\end{array}$ & $4.8 \mathrm{t} / \mathrm{d}$ feedstock & Sherbrooke (CAN) & Operational \\
\hline \multirow{4}{*}{$\begin{array}{l}\text { Ethanol; methanol; } \\
\text { various chemicals }\end{array}$} & $\begin{array}{l}\text { Commercial } \\
\text { Demonstration }\end{array}$ & Enerkem & $\begin{array}{l}\text { Treated wood (i.e. decommissioned } \\
\text { electricity poles and railway ties), wood } \\
\text { waste, and MSW }\end{array}$ & $48 \mathrm{t} / \mathrm{d}$ feedstock & $\begin{array}{l}\text { Westbury } \\
\text { Canada }\end{array}$ & Operational \\
\hline & Commercial & $\begin{array}{l}\text { Enerkem - Varennes Cellulosic } \\
\text { Ethanol L.P. }\end{array}$ & $\begin{array}{l}\text { Sorted industrial, commercial, and } \\
\text { institutional waste }\end{array}$ & $350 \mathrm{t} / \mathrm{d}$ feedstock & $\begin{array}{l}\text { Varennes } \\
\text { Canada }\end{array}$ & Planning \\
\hline & Commercial & Enerkem Alberta Bio-fuels LP & Sorted municipal solid waste (SMSW) & $350 \mathrm{t} / \mathrm{d}$ feedstock & $\begin{array}{l}\text { Edmonton } \\
\text { Canada }\end{array}$ & Operational \\
\hline & Commercial & $\begin{array}{l}\text { Enerkem Mississippi Bio-fuels } \\
\text { LLC }\end{array}$ & $\begin{array}{l}\text { Sorted municipal solid waste (SMSW) and } \\
\text { wood residues }\end{array}$ & $350 \mathrm{t} / \mathrm{d}$ feedstock & $\begin{array}{l}\text { Pontotoc } \\
\text { United States }\end{array}$ & Developing \\
\hline $\begin{array}{l}\text { Chemical products - } \\
\text { resins, } \\
\text { lignosulfonates, and } \\
\text { ethanol }\end{array}$ & Demonstration & Tembec Chemical Group & Spent sulfite liquor & $13000 \mathrm{t} / \mathrm{y}$ chemicals & $\begin{array}{l}\text { Temis-caming } \\
\text { Canada }\end{array}$ & Operational \\
\hline DME & Pilot & Chemrec $A B$ & Gasification; Black liquor & $20 \mathrm{t} / \mathrm{d}$ feedstock & Pitea, Sweden & Operational \\
\hline $\begin{array}{l}\text { DME; gasoline-type } \\
\text { fuel }\end{array}$ & Pilot & $\begin{array}{l}\text { Karlsruhe Institute of } \\
\text { Technology (KIT) Bioliq }\end{array}$ & Lignocellulosic biomass & $12 \mathrm{t} / \mathrm{d}$ feedstock & $\begin{array}{l}\text { Karlsruhe } \\
\text { Germany }\end{array}$ & Operational \\
\hline Various chemicals & Pilot & $\begin{array}{l}\text { NREL (National Renewable } \\
\text { Energy Laboratory) }\end{array}$ & Dry biomass & $0.5-1 \mathrm{t} / \mathrm{d}$ feedstock & $\begin{array}{l}\text { Golden, Colorado } \\
\text { United States }\end{array}$ & $\begin{array}{l}\text { Operational in } \\
1985 ; \\
\text { expansion } \\
\text { ongoing }\end{array}$ \\
\hline $\begin{array}{l}\text { Bio-oil, steam, } \\
\text { electricity and organic } \\
\text { acids }\end{array}$ & Demonstration & $\begin{array}{l}\text { EMPYRO } \\
\text { BTG Biomass Technology } \\
\text { Group B.V. }\end{array}$ & $\begin{array}{l}\text { Using fast pyrolysis technology to convert } \\
\text { woody biomass }\end{array}$ & $25 \mathrm{MW}_{\text {thermal }}$ polygeneration & $\begin{array}{l}\text { Hengelo, The } \\
\text { Netherlands }\end{array}$ & Operational \\
\hline $\begin{array}{l}\text { Bio-oil, electricity, } \\
\text { heat, resins }\end{array}$ & Commercial & $\begin{array}{l}\text { Ensyn Technologies Inc. } \\
\text { Tolko Industries Ltd. }\end{array}$ & $\begin{array}{l}\text { Converting sawmill into energy by fast } \\
\text { pyrolysis }\end{array}$ & $400 \mathrm{t} / \mathrm{d}$ feedstock & Alberta, Canada & $\begin{array}{l}\text { Under } \\
\text { construction }\end{array}$ \\
\hline $\begin{array}{l}\text { Low-carbon } \\
\text { renewable fuel }\end{array}$ & Commercial & Sierra Bio-fuels Plant & $\begin{array}{l}\text { Gasification; Urban waste, including sorted } \\
\text { MSW and C\&D debris, to produce } \\
\text { electricity }\end{array}$ & $246 \mathrm{t} / \mathrm{d}$ feedstock & McCarran, Nevada & $\begin{array}{l}\text { Expected to } \\
\text { start } \\
\text { operation in } \\
2017 \\
\end{array}$ \\
\hline
\end{tabular}




\section{Green Chemistry}

\section{REVIEW}

The production of ethanol from lignocellulosic biomass has still not been completely commercialized, because of its high production cost and complicated feedstock supply system. Reported cellulosic ethanol production from global pilot plants was 20,000 gal in 2012, with production increasing to 218,000 gal in 2013. ${ }^{216}$ The MTG process is used commercially with gasoline selectivity over $85 \%$, and the remainder comprising light petroleum gas. ${ }^{112} \mathrm{~A}$ commercial plant producing gasoline from methanol (MTG) was operated in New Zealand by Mobil from 1981 to 1984 , producing 14,500 bbl/day. ${ }^{20}$ Commercial processes for the production of mixed higher alcohols have been developed by Snamprogetti-Topsoe, Lurgi, Dow, and IFPIdemitsu. ${ }^{20}$ Considering the isosynthesis process, research has recently more focused on catalytic performance, which is the key process element. Oxosynthesis is one commercial technology for the application of syngas, ${ }^{78}$ and the aldehydes (butanol, propanol, isobutanol, and ethylhexanol ${ }^{20}$ ) generated in this process can be further used to produce detergents or polyvinyl chloride. $^{74}$

The conversion of biomass to jet fuel is a promising process, which is of interest to several companies. Airlines are providing support by signing contracts for the use of jet fuel produced from biomass, including British Airways, Airbus, Hainan Airlines, General Electric Aviation, and the Air Force Certification Office, a fuel certifying agency that has legalized the use of F-T fuel blends in aviation fuel. ${ }^{76}$ The ASTM international standard, D7566, has approved specifications for aviation fuels, with F-T fuels approved in 2009 and HRJs in $2011^{76}$

\subsubsection{Gaseous fuel commercialization}

Gasification feedstocks can be any carbon-rich materials, including coal, petroleum, natural gas, or biomass. Gasification is a mature technology based on the resources of coal, petroleum, and natural gas, with these comprising around $51 \%, 25 \%$, and $22 \%$, respectively, of the total capacity of 144 commercial gasification plants in 2010. However, biomassbased gasification accounted for only $0.5 \%$ of capacity in 2010 . ${ }^{7}$ Of the total produced syngas, $45 \%$ was used to produce chemicals, $38 \%$ was used for transportation fuels, $11 \%$ for electricity, and $6 \%$ for use as gaseous fuel. ${ }^{7}$ From Table 6 , it can be noted that second-generation liquid bio-fuels, produced from biomass gasification followed by F-T synthesis, are still at various stages of development.

\subsubsection{Solid fuel commercialization}

Carbonization for the production of char is currently practiced in traditional stoves in developing countries, in barbecues in Western countries, and in the Brazilian steel industry. ${ }^{5}$ Torrefaction has not yet been commercially applied, with research and development focusing on addressing challenges related to handling, logistics, safety, and optimization of process design for high energetic and economic efficiency. Furthermore, combinations of biomass densification processes, such as pelletization with torrefaction, also provide a possible direction for technological development, with the added benefits of reduced dust formation. ${ }^{24}$

\subsubsection{Chemicals commercialization}

The conversion of bio-oil into chemicals is a promising commercial possibility for products such as fertilizers, liquid smoke, and resins, ${ }^{134}$ which have higher values than bio-fuels. Some biochemical production processes have already been commercialized (such as for liquid smoke), or are highly likely to be commercialized through fast pyrolysis technology. ${ }^{134}$ Commercial production of chemicals from bio-oil must consider low-cost chemical separation processes and market requirements. ${ }^{134}$

Honeywell UOP currently runs a commercial process producing olefins from methanol (originally from natural gas/coal/petroleum residues) using silicoaluminophosphate (SAPO) catalysts. New opportunities for producing olefins from methanol may be provided by using other catalysts, such as eight-membered ring zeolites, chabazite, ITQ-3,151 ITQ29,152 , and ITQ-32. ${ }^{20}$

\section{Environmental analysis}

The renewability and sustainability of biofuel has been deemed questionable, as a result of its ecological impacts, such as cleanliness measured by $\mathrm{CO}_{2}$ and other pollutant emissions, impacts on water resources, land use, and biodiversity, and its socioeconomic impacts on food security, income, and employment. 217,218 Rather than simply considering biofuel as a renewable and carbon-neutral resource owing to the inherent photosynthesis that will absorb $\mathrm{CO}_{2}$, the renewability of biofuel is also dependent on the non-renewable energy used during the production of the biofuel itself. ${ }^{219}$ Based on Fossil Energy Ratio (FER) or Net Energy Ratio (NER), which define the amount of energy that can be produced from the consumption of one unit of energy, individual fuels can be classified as entirely renewable, partially renewable, or nonrenewable. The extra fossil energy needed to generate the biofuel will release $\mathrm{CO}_{2}$, although the regrowth of the plant will absorb $\mathrm{CO}_{2}$. However, in some cases, this absorption cannot be taken into consideration, depending on the origin of the raw material, for example, the absorbed $\mathrm{CO}_{2}$ can be take into consideration if the feedstock is grown on wastelands or deserts, but it cannot been considered when it is grown on deforested land. ${ }^{220}$

"Corn to ethanol" is one commonly debated pathway for firstgeneration biofuels, where the claimed renewability is offset against the fossil fuel requirement and the GHG emissions of the process. ${ }^{221}$ Second-generation biofuel will potentially generate fewer GHG emissions and have a better environmental performance. ${ }^{222}$ These biofuels tend to compete less with food and fibre production, and have higher energy yields per unit of land area. In addition, second-generation biofuels have greater land 
adaptability, although adequate water and nutrient supplies are needed. ${ }^{223}$

Land conservation under biofuel production falls into two categories: direct land use change (dLUC), due to the direct transformation of previously untouched areas into biofuel crops; and indirect land use change (iLUC), which refers to the additional change in land use in other places to maintain the same production of food and feed crops as demanded in the market. Traditional Life Cycle Assessment (LCA) cannot normally consider the GHG emissions of iLUC, due to their variability and complexity, in addition to the fact that it usually occurs across country borders. ${ }^{218}$ Thus, in order to consider the influence of iLUC, the European Commission (EC) has proposed the addition of a specific iLUC factor for different biofuel sources. However, subsequent investigations have indicated that it is oversimplified to consider the effect of iLUC using a single factor, due to the difficulty in calculating the impacts from theoretical models based on hypotheses, assumption, and market predictions, which is necessary due to the significant uncertainty in iLUC ${ }^{218}$.

The iLUC issue is that using agricultural areas and dedicating land for biofuel production is closely related to rates of deforestation, irrigation water use, and crop price. As a result, second-generation biofuels typically perform much better, except when the crops are directly competing for agricultural land, in which case the performance is worse than for first-generation biofuels. 224

The effects of biofuel production on water use, soil quality, and biodiversity are not typically considered in the traditional LCA approach. The impacts on water use mainly focus on water consumption and the effects of water pollution on ecosystems and human health. ${ }^{225}$ Impacts on soil quality are related to land use and land transformation, ${ }^{225}$ and depend on different biofuel systems. An obvious example is that biofuel production may significantly alter forest ecosystems, but will have limited impact on microalgal cultural systems, except for the salinization of the soil and groundwater. ${ }^{225}$ For biodiversity, biofuel production is becoming a key environmental concern, as biodiversity is strongly linked to the impacts of land use and land use change, as well as water use. ${ }^{225}$

The conventional measurement of greenhouse gas emissions is the amount of carbon dioxide equivalent emitted per unit of energy provided by a particular pathway (i.e. $\mathrm{gCO}_{2} \mathrm{e} / \mathrm{MJ}$ ). ${ }^{226}$ The GHG emissions of some typical biofuels from different pathways are shown in Fig. 13.

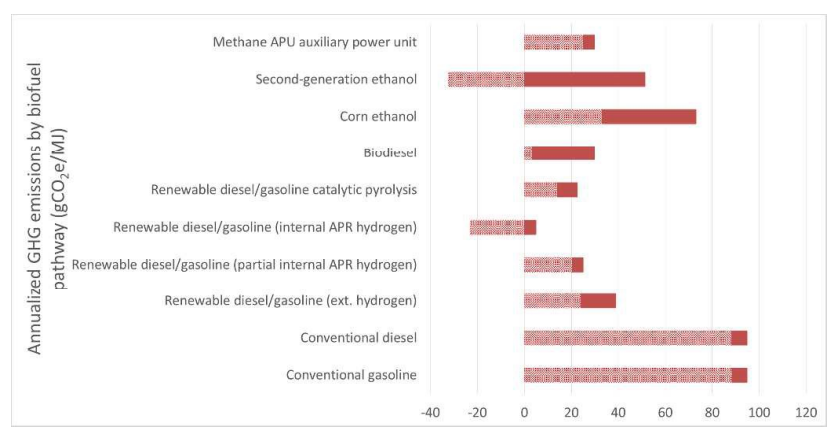

Figure 13. GHG emissions of several typical bio-fuels in from different pathways in $\mathrm{gCO} 2 \mathrm{e} / \mathrm{MJ}$. The dash filled part represents mineral annualized GHG emissions, and the maximum value of the solid filled part presents the maximal annualized GHG emissions.

Considering the GHG emissions of biofuels, there is not yet any fixed conclusions as to the cleanness of biofuel, although one study calculated that the first-generation biofuel will reduce approximately $78 \%$ of the GHG emissions, while second-generation biofuel will reduce $94 \%$ of GHG emissions, compared with fossil fuels. ${ }^{218}$ Comparing forest-based renewable diesel and microalgaebased diesel, it has been shown that the GHG emissions of microalgae are higher than those of forest residue-based diesel, due to the relative immaturity and uncertainty of microalgaeprocessing technology, although in contrast, microalgae systems result in a lower impact on land use and biodiversity. ${ }^{225}$

The renewability of biofuel depends on the feedstock. For example, the biofuel produced from corn grain, corn stover, and switchgrass can be defined as advanced biofuel, however that produced from corn starch cannot be considered an advanced biofuel. ${ }^{226}$ In the generation of second-generation liquid biofuels from sugarcane bagasse, it was concluded that the thermal conversion process with gasification followed by Fischer-Tropsch synthesis has higher environmental benefit than by the two biochemical conversion pathways. The main reason for this is the relatively high energy efficiency $(51.7 \pm 0.8 \%$ vs. $43 \pm 1.1 \%)$ due to the heat integration during the thermochemical process, in addition to the fact that the large amount of processing chemicals utilized in the biochemical process also have a negative impact on the environment. ${ }^{227}$ It has also been reported that FT-diesel from forest residues can reach the $60 \%$ emission reduction target set by the EU. ${ }^{225}$

Another measurement of GHG emissions was proposed by Kauffman et al. ${ }^{226}$, based on the unit of land rather than the energy provided by the pathway. One benefit of utilizing a land-based measurement is that it can consider various different feedstocks, which is practical as multiple types of feedstock are normally utilized together during biofuel production, due to land scarcity. For example, the ethanol produced from corn is not considered as an advanced fuel in an energy-based LCA evaluation, however, under a land-based LCA evaluation, by combining the bio-fuel produced from corn with the associated conversion of corn stover to drop in fuel via fast pyrolysis, and the by-product bio-char used as soil fertilizer, the GHG emissions can realize a $52.1 \%$ reduction when compared with 2005 gasoline-based emissions, and can therefore be considered an advanced fuel. ${ }^{226}$

\section{Challenges and future trends}

Complete commercialization of the production of directly usable second-generation bio-fuels and allied products can be envisaged in the near future. Fig. 14 summarizes the relationships between key challenges and future directions, which are further discussed in this section. 


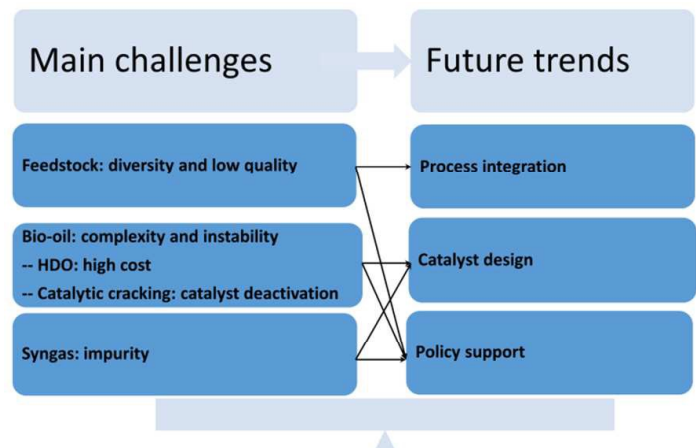

Figure 14. Main challenges and future trends.

\subsection{Main challenges}

\subsubsection{Diversity and low-quality of feedstock}

The imminent utilization of lignocellulosic feedstocks faces numerous challenges, including diverse distribution and complex multi-scale structures. Some primary conversion steps are needed to purify the feedstock and give high product yields, by mitigating the intrinsic difficulties of the lignocellulosic biomass, such as those related to harvesting, handling, and transportation.

Harvesting and collecting pose problems for biomass utilization, because the feedstock is concentrated, as with fossil fuels. The low harvesting density also creates transportation problems, and the storage of biomass is likewise problematic. A large biomass harvesting area, especially of agricultural land, must be available to guarantee local supply, except in the case of extensive imports. Moreover, unlike fossil fuels, biomass also suffers from discontinuous production influenced by harvesting season, climate, and region. ${ }^{6}$ The diversity of biomass feedstocks also makes continuous supply difficult. ${ }^{6}$

Low energy density is another barrier, mainly as a result of high moisture and oxygen contents. Even if pre-treatment improves biomass properties through energy densification, a number of existing technical and economic challenges remain unresolved. For example, depolymerization of lignin into aromatic alcohols and further end products remains problematic. $^{6}$ In addition, bio-fuel cannot be compatible with conventional fuels, mainly due to its sulfur and aromatic content, auto ignition temperature, thermal stability, and storage stability in the case of bio-jet fuel.

The complex structure and diversity in size of biomass, with a length scale from 0.1 to $10 \mathrm{~m}$, also limits the production of bio-fuels and bio-chemicals from biomass. ${ }^{9}$ The precise characteristics of the biomass structure helps to determine its conversion process, ${ }^{228}$ however, the detailed conversion mechanisms are still unclear due to complex feedstock structures. A description of the fundamental mechanisms of biomass-to-biofuel/biochemical processes would be a powerful tool in optimizing the process and providing theoretical understanding. ${ }^{229,230,231,232,233}$ Despite approximate descriptions of several key steps of the main thermochemical processes (such as pyrolysis and gasification), there are still insufficient satisfactorily-detailed explanations of conversion pathways and kinetics. ${ }^{6}$ Accurate structural descriptions of biomass feedstocks and of interactions between constituents, either based on molecular/atomic modeling or on experiments, are needed, and would eventually contribute to developing high-efficiency and low-cost conversions of biomass into useful bioenergy. Other problems include the tenacious and fibrous structure of biomass and its heterogeneous composition, further complicating the conversion process.

\subsubsection{Complexity and instability of bio-oil}

Bio-oil has considerable potential to replace current petroleum fuels, due to its low cost of production. However, it is typically low quality and complex, and there is still no standard for bio-oil usage and distribution. The main challenges lie in finding effective ways to scale up, reducing production costs, and improving quality. In general, the challenge for fast pyrolysis of biomass into bio-oil is still the commercial upgrading of crude bio-oil into marketable products, especially through the development of hydrogenlean or hydrogen-free technologies. ${ }^{234}$ At the same time, since bio-oil compositions vary with feedstock type, inorganic content, and operating conditions, optimal process design could make it possible to obtain a high-quality bio-oil. Theoretically accurate characterization of the process, using fundamental models, would be needed for this approach. ${ }^{234}$

Bio-oil produced using hydrothermal liquefaction is still under development. High pressures pose challenges for scaling up, and feedstock impurities are of critical concern, especially when utilizing low quality feedstock, which often leads to fouling and plugging problems, coke formation, and catalyst deactivation. Another operating barrier is the feeding of feedstock into a high pressure reactor: in addition to the technical difficulties of scaling up, hydrothermal high pressures involve high capital costs, because of the specific reactor and separator requirements. Additionally, more that 15-20 wt\% solid loading is required to render commercial production profitable. Otherwise, with low concentrations of solid loading, high capital costs will create economic barriers. ${ }^{19}$

None of the bio-oil upgrading technologies are yet sufficiently mature to be commercialized. HDO, catalytic cracking, and steam reforming are complex processes that require high-performance reactors, and each possesses its own difficulties. Bio-oil HDO is limited by the high cost of highpressure hydrogen, as hydrogen for treating biomass is even more expensive than for hydro-treating of conventional petroleum, because of the higher oxygen content in biomass feedstock. ${ }^{6}$ The availability of active surface hydrogen is crucial for the HDO process, especially for the deoxygenation and decarboxylation steps. HDO can be promoted if hydrogen is largely produced from renewable sources, such as solar, wind, or biomass. ${ }^{235}$ For example, there are promising attempts to combine APR and HDO. APR produces hydrogen for the HDO process from biomass-derived oxygenated compounds (e.g. glycerol) in aqueous solution, at low temperatures, and in the presence of platinum as a catalyst ${ }^{6}$. In addition to the costs of pressured hydrogen, the complex HDO equipment also incurs extra costs, and catalyst deactivation and reactor clogging remain significant challenges. ${ }^{59}$ The use of high pressures (around $170 \mathrm{~atm}$ ) and longer contact times can help to avoid such problems, however, this further increases costs. ${ }^{137}$ The HDO process also suffers other limitations, including the large amount of water produced during the HDO process, which is an undesirable component of bio-oil. ${ }^{59}$ 
Upgrading via catalytic cracking avoids the high cost of pressurized $\mathrm{H}_{2}$ used in $\mathrm{HDO}$, providing both economic and safety advantages. The challenge of catalytic cracking of bio-oil is catalyst deactivation, mainly due to the large amount of coke formed (8-25\%) during the process, ${ }^{13,59}$ although catalyst deactivation could also be partially due to volatile components blocking the active catalyst sites. ${ }^{236}$ Coke formation poisons the catalyst because of the latter's small pore size. When large oxygenate compounds are produced, these cannot enter the catalyst pores, and coke will therefore be formed on the catalyst surface, leading to catalyst deactivation and a decrease in hydrocarbon yield. It has been reported that acetic acid is the main compound leading to coking. Sugars are not the main cause, because they are thermally decomposed before reaching the catalyst surface. ${ }^{237}$ The problem of catalyst deactivation due to coking is even more severe during bio-oil steam reforming than for petroleum oil, due to the high reactivity of bio-oil.

\subsubsection{Syngas impurity}

The main challenge for biomass gasification into bio-fuels and bio-chemicals is the cleaning and processing of raw syngas, for both technical and economic reasons. Process design, including sorbent, filters, and heat exchangers, plays a crucial role in future commercialization of bio-fuels and biochemicals via gasification. ${ }^{10}$ For example, a lab-scale experiment in Karlsruhe in Germany ${ }^{\mathbf{2 3 8}}$ combined a sorption stage at the head of the filter and a tar reforming stage at the end of the filter. However, these concepts have not yet been commercially applied.

Biomass gasification followed by the F-T process is still limited by high capital costs ${ }^{9}$ and by the high contaminants of crude syngas. Catalyst poisoning is also a major challenge limiting commercialization. These difficulties could potentially be overcome economically through the development of reliable technologies or discoveries of new catalysts. ${ }^{84}$

The utilization of side products from biomass gasification, which would improve process efficiency, remains another challenge, ${ }^{74}$ as it currently requires low-cost separation technologies.

For an integrated biomass gasification cycle, biomass production and processing (crushing, drying) comprise a large share of total energy consumption (around $50 \%$ and $43 \%$, respectively). ${ }^{9}$ Biomass transportation consumes $4-16 \%$ of the total energy. To reduce this cost, an option is to transport the produced bio-oil instead of the low bulk density biomass feedstock. To do this, bio-oil should be produced near the crops and subsequently transported to a central plant. The drawback of this option is that it is only cost effective for a large generation plant (more than $20 \mathrm{PJ} /$ year), with a maximum $30 \%$ reduction. ${ }^{9}$

\subsubsection{Challenges facing environmental evaluation}

Challenges facing the environmental evaluation of biofuel systems involve tackling the issue of iLUC, mainly through data collection and indicator definition. Currently, although consideration of iLUC is made in some analysis systems, a lack of a uniform and widely-used model, and insufficient transparency between different analysis approaches limits its utility. ${ }^{225}$ Moreover, the lack of a commonly accepted methodology capable of comprehensively estimating the chosen environmental impacts becomes another problem when considering the environmental impact of the biofuel production process. ${ }^{225}$
Furthermore, when evaluating the environmental impact, most cases are site-dependent, which will create more difficulties for data collection and uniform modelling of data sets for holistic evaluation. ${ }^{225}$

From perspective of policy, the impacts of iLUC should be considered in the national reporting on GHG emissions, such as in Renewable Energy Directive (RED) of the European Commission. ${ }^{225}$

The uncertainties in the GHG emission calculation using the existing methodology is a further challenge. This creates problems, in that the evaluation results cannot be used directly for political and economic decision-making. Uncertainty assessment can help to address this issue to some extent, but sometimes it may compound the problem by widening the range of uncertainties. ${ }^{225}$

\subsection{Future trends}

\subsubsection{Process integration}

The integration and optimization of multi-state processes is a feasible way of improving economic viability and overall process efficiency. Examples include further conversion of waxy materials into useful fuels via the F-T process, ${ }^{9}$ tar separation from produced fuel, combined hydrogen production and biomass gasification, steam reforming, the water-gas-shift reaction, and $\mathrm{H}_{2}$ separation and $\mathrm{CO}_{2}$ capture. The use of various sources of waste materials is helpful for sustainable production and distribution of feedstock. Moreover, energy efficiency and economic benefits can be improved by combining targeted products with marketable byproducts. The latter can be heat, electricity, fuels, and chemicals, depending on the process optimization, but with the aim of maximizing value. ${ }^{84}$

Bio-refineries remain within the early stages of development, due to high capital costs. Co-processing of renewable lignocellulosic biomass using the infrastructure of existing petroleum refineries provides a potential solution for capital investment savings, ${ }^{235}$ with the additional benefits of wider product choices, such as LPG, kerosene, or fuel oil, rather than just gasoline and diesel. ${ }^{6}$ Upgrading of bio-oil for direct utilization in conventional equipment will also help to improve the process. However, the high water ${ }^{6}$ and oxygen contents of crude bio-oil limits its application. Pre-processing of bio-oil using HDO or hydrogenation is therefore normally required to maintain a longer catalyst lifetime and to ensure high quality of the final products. ${ }^{6}$

The concept of using small-scale bio-refineries to overcome the high transportation cost of biomass feedstocks has been proposed. However, this does not feasibly address the problem of smaller capacities, as an increasing number of biorefineries will be needed for equable production. Satellite storage locations have also been proposed, representing temporary storage facilities for renewable biomass feedstock before transportation to bio-refineries. A combination of both small refineries and satellite storage locations has also been proposed to minimize the transportation costs of lignocellulosic biomass. $^{6}$

However, process integration is not easy and requires further research and development. Macroscopic integrated simulations of the bio-fuel production process may provide a way of describing biomass utilization, which could serve as a bridge between theoretical modeling and the industrial world.

\subsubsection{Catalyst regeneration}


Proper catalyst design can significantly assist in improving desired products. This mainly depends on the catalyst properties, such as their chemisorption rates and levels of acidity. The use of catalyst promoters is a good option: for example, $\mathrm{K}_{2} \mathrm{CO}_{3}$ (potassium carbonate) can be used as a catalyst promoter to significantly improve the alcohol yield from syngas when using molybdenum disulfide as catalyst. ${ }^{239}$ Similarly, the performance of Mo/HZSM-5 can be improved by using catalyst promoters such as $\mathrm{Ag}, \mathrm{Al}, \mathrm{Cu}, \mathrm{Co}, \mathrm{Fe}, \mathrm{Ga}, \mathrm{Pt}, \mathrm{Ru}$, $\mathrm{W}, \mathrm{Zn}$, and $\mathrm{Zr}{ }^{74}$

Novel heterogeneous catalysts for the production of second-generation bio-fuels, which differ from the conventional catalysts used in the petroleum industry, still need to be developed. ${ }^{6}$ Novel catalyst design should also consider the interaction between different biomass constituents and the influence of the mineral contents of biomass. ${ }^{12}$ Some studies have proposed novel catalysts, including a mixture of mesoporous, macroporous (Gamma$\mathrm{Al}_{2} \mathrm{O}_{3}, \mathrm{CaO}$, and $\mathrm{MCM}-41$ ), and microporous (LOSA-1) catalysts ${ }^{9}$ to avoid catalyst deactivation. Using these catalysts, large oxygenate compounds can be cracked into small compounds, such as olefins and aromatics. Acetic acid can be steam reformed using a noble metal catalyst, such as $\mathrm{Pt}, \mathrm{Rh}$, and $\mathrm{Pd}$ supported on $\mathrm{Al}_{2} \mathrm{O}_{3}$ and $\mathrm{CeO}_{2}-\mathrm{ZrO}_{2}$.

Several potential solutions can be explored to address the issue of catalyst deactivation resulting from coke formation. One option is to use a specific thermal pre-step to crack coke. $^{240}$ Similarly, a two-reactor system was specially developed by Bakhshi et al. ${ }^{241}$ to minimize coke formation and extend catalyst lifetime. In this, a thermal reactor was used first, followed by a catalytic reactor. During the thermal reaction, there is a separation of bio-oil into light and heavy organics. The heavy bio-oil feed is thermally cracked to avoid catalyst deactivation in the second catalytic upgrading reactor. Co-feeding of methanol (around 70 wt\%) allows catalyst activity to be maintained. ${ }^{242}$ Co-feeding of other model bio-oil compounds, (acetic acid, hydroxyacetone, and phenol) can also reduce coke formation and increase bio-oil conversion, giving higher production yields. However, feeding of these biooil compounds influences the reactivity of the catalyst. ${ }^{6}$. Therefore, coke formation can also be avoided using aqueousphase reactants. However, these require high operating temperatures. Instead of using water-containing reactants, ionic liquids have also been proposed as reaction media. The use of ionic liquid is a better option than water, as it leads to a higher conversion of feedstock, especially of lignin-derived phenols. In the case of lignin-derived bio-oil production, $\mathrm{Mo}_{2} \mathrm{C} / \mathrm{CNF}$ is a better catalyst choice than $\mathrm{CoMo} / \mathrm{Al}_{2} \mathrm{O}_{3}$ for the production of oxygen-free products like benzene and toluene.

To solve the problem of catalyst deactivation during the steam reforming process, it has been demonstrated that fluidized bed reactors are preferable to fixed bed reactors, due to catalyst stability associated with better steam-catalyst contact. ${ }^{20}$ Fixed bed reactors are not suitable for generating hydrogen through bio-oil steam reforming, especially for lignin-derived compounds, due to coke formation leading to catalyst deactivation. ${ }^{59}$ Catalyst regeneration during the steam reforming process in a fixed bed requires 3-4 hours. ${ }^{20}$ However, in a fluidized bed reactor, catalyst attrition is a further problem that must be considered. A high ratio of steam to carbon may be a good way of avoiding catalyst

28 | Green Chemistry 2016, 00, 1-3 deactivation from coking; this should normally be greater than 7.

One possible means of decreasing catalyst deactivation is to recycle a portion of the hydrogen generated from the steam reforming process to hydrogenate the bio-oil and improve its stability. ${ }^{20}$ The catalyst can then be regenerated by steam or $\mathrm{CO}_{2}$ gasification. Commercial nickel catalysts can be readily regenerated within $20 \mathrm{~min}$ to 2 hours by steam or $\mathrm{CO}_{2}$ gasification after deactivation during reforming. ${ }^{59}$ Coke can also be oxidized through continuous catalyst regeneration after the catalytic cracking process. Despite this, some technical issues still persist, such as poor control of the system and high processing costs. ${ }^{25}$

Moreover, it has been shown that a combination of HDO and catalytic cracking to treat crude bio-oil, generating a stream, would not poison the catalyst downstream. Additionally, further upgrading can also be carried out in the FCC, leading to better performance and a higher quality of final hydrocarbon fuels.

\subsubsection{Policy support}

Bio-fuels can also be encouraged through governmental policy support in the short-term (2020-2030). To meet the $10 \%$ mandatory bio-fuel target by 2020 without interfering with other goals, it was determined that $3 \%$ should be obtained from second-generation bio-fuels. To achieve this target, the $\mathrm{CO}_{2}$ cost needs to be set at $€ 60 / \mathrm{t} \mathrm{CO}_{2} .{ }^{9}$ However, the carbon price remained stable at $€ 10 / \mathrm{t} \mathrm{CO}_{2}$ in 2012 .

In addition, modern carriers for transporting lignocellulosic biomass from high production areas (Scandinavian countries) to high fuel demand areas (Holland, Belgium, and North Germany) will be very helpful for the use of second-generation bio-fuels. ${ }^{9}$ Market orientation of bio-fuel may also be another direction in which to promote the development of secondgeneration bio-fuels.

\subsubsection{Future trends of environmental evaluation}

The identification of common sustainability criteria is one way in which the lack of common models can be addressed, allowing the assessment of different scenarios, and a reduction of uncertainties. 242

Process design and plant capacity design will be helpful for the overall optimization of both economic cost and environmental benefits. For example, various negative environmental impacts of biofuel production can be eased by adjusting the design of system components, such as through the use of recycled materials 219222

\section{Concluding remarks}

Producing second-generation bio-fuels using lignocellulosic biomass can represent a solution for biomass utilization in the short-term.

Technical efforts toward this end should be invested in each conversion pathway to enable their universal application. Promising pathways for industrialization include fast pyrolysis for bio-oil and gasification for syngas, with downstream upgrading of the raw products. Technical barriers to the conversion of lignocellulosic biomass into fuels via pyrolysis include bio-oil upgrading, while barriers to gasification include syngas purification.

In the case of bio-fuels and bio-chemicals produced from bio-oil, a short-term goal may be to minimize the consumption 
of hydrogen, which is reliant on the development of active and efficient catalysts that enable deoxygenation with minor or no hydrogen requirements. With the same aim, hydrogen generation processes can be combined with bio-oil generation to upgrade bio-oil, providing a single promising pathway with both environmental and economic benefits.

The essentials of thermochemical conversion of lignocellulosic biomass involve trade-offs among technical, economical, and environmental aspects. One trade-off exists between high biofuel quality and low economic cost; another one exists between low production costs and increased environmental benefits, although the environmental benefits of bio-fuels are still under debate.

The main focus of the short-term development of the technologies of second-generation bio-fuels is still the lowering of the production cost. To decrease the cost gap between the biomass-derived and fossil-fuel derived products, future development should be focused in two main directions, namely, improving feedstock processing technologies to assure sustainable and continuous provision of biomass feedstock, and co-processing biomass-derived fuels within conventional petroleum facilities. Furthermore, process integration, proper catalyst design, and policy support would significantly facilitate full commercialization of second-generation bio-fuels and allied products in the near future.

\section{Notes and references}

1. IEA, Key world energy statistics, 2014.

2. IEA, Resources to reserves 2013, oil, gas and coal technologies for the energy markets of the future, 2013.

3. EIA, International Energy Outlook 2013, 2013.

4. IEA, World Energy Outlook, 2014.

5. IPCC, Renewable Energy Sources and Climate Change Mitigation, 2012.

6. J. A. Melero, J. Iglesias and A. Garcia, Energy Environ. Sci., 2012, 5, 7393-7420.

7. M. Guo, W. Song and J. Buhain, Renewable and Sustainable Energy Reviews, 2015, 42, 712-725.

8. E. Agbor, X. Zhang and A. Kumar, Renewable and Sustainable Energy Reviews, 2014, 40, 930-943.

9. A. Sanna, BioEnergy Research, 2014, 7, 36-47.

10. M. Crocker, Thermochemical Conversion of Biomass to Liquid Fuels and Chemicals; The Royal Society of Chemistry: 2010; P001532.

11. M. J. C. Van Der Stelt, H. Gerhauser, J. H. A. Kiel and K. J. Ptasinski, Biomass Bioenergy, 2011, 35, 3748-3762.

12. F. Collard, J. Blin, Renewable and Sustainable Energy Reviews, 2014, 38, 594-608.

13. N. Taufiqurrahmi, S. Bhatia, Energy Environ. Sci., 2011, 4, 10871112.

14. O. Onay, O. Mete Koçkar, Biomass Bioenergy, 2004, 26, 289299.

15. A. V. Bridgwater, G. V. C. Peacocke, Renewable and Sustainable Energy Reviews, 2000, 4, 1-73.

16. A. V. Bridgwater, J. Anal. Appl. Pyrolysis, 1999, 51, 3-22. 17. P. A. Horne, P. T. Williams, Fuel, 1996, 75, 1051-1059.

18. H. B. Goyal, D. Seal and R. C. Saxena, Renewable and Sustainable Energy Reviews, 2008, 12, 504-517.
19. A. A. Peterson, F. Vogel, R. P. Lachance, M. Froling, J. Antal Michael J. and J. W. Tester, Energy Environ. Sci., 2008, 1, 32-65. 20. G. W. Huber, S. Iborra and A. Corma, Chem. Rev., 2006, 106, 4044-4098.

21. T. Damartzis, A. Zabaniotou, Renewable and Sustainable Energy Reviews, 2011, 15, 366-378.

22. D. Mohan, Pittman Charles U. and P. H. Steele, Energy Fuels, 2006, 20, 848-889.

23. D. Vamvuka, Int. J. Energy Res., 2011, 35, 835-862.

24. P. Bergman, A. Boersma, R. Zwart and J. Kiel, Torrefaction for biomass co-firing in existing coal-fired power stations "biocoal", July, 2005.

25. A. V. Bridgwater, Biomass Bioenergy, 2012, 38, 68-94.

26. A. E. Pütün, A. Özcan, H. F. Gerçel and E. Pütün, Fuel, 2001, 80, 1371-1378.

27. D. A. Laird, R. C. Brown, J. E. Amonette and J. Lehmann, Biofuels, Bioproducts and Biorefining, 2009, 3, 547-562.

28. A. A. Lappas, S. Bezergianni and I. A. Vasalos, Catalysis Today, 2009, 145, 55-62.

29. M. J. Prins, K. J. Ptasinski and F. J. J. G. Janssen, J. Anal. Appl. Pyrolysis, 2006, 77, 35-40.

30. M. J. Antal, M. Grønli, Ind Eng Chem Res, 2003, 42, 1619-1640. 31. D. S. Scott, J. Piskorz and D. Radlein, Industrial \& Engineering Chemistry Process Design and Development, 1985, 24, 581-588. 32. O. Onay, O. M. Kockar, Renewable Energy, 2003, 28, 2417-2433. 33. E. Taarning, C. M. Osmundsen, X. Yang, B. Voss, S. I. Andersen and C. H. Christensen, Energy Environ. Sci., 2011, 4, 793-804. 34. P. McKendry, Bioresour. Technol., 2002, 83, 55-63.

35. L. Zhang, R. Liu, R. Yin and Y. Mei, Renewable and Sustainable Energy Reviews, 2013, 24, 66-72.

36. D. A. Ruddy, J. A. Schaidle, J. R. Ferrell lii, J. Wang, L. Moens and J. E. Hensley, Green Chem., 2014, 16, 454-490.

37. A. V. Bridgwater, Applied Catalysis A: General, 1994, 116, 5-47. 38. P. M. Mortensen, J. -. Grunwaldt, P. A. Jensen, K. G. Knudsen and A. D. Jensen, Applied Catalysis A: General, 2011, 407, 1-19. 39. P. B. Weisz, W. O. Haag and P. G. Rodewald, Science, 1979, 206, 57-58.

40. T. R. Carlson, Y. Cheng, J. Jae and G. W. Huber, Energy Environ. Sci., 2011, 4, 145-161.

41. J. D. Adjaye, N. N. Bakhshi, Fuel Process Technol, 1995, 45, 161183.

42. J. D. Adjaye, N. N. Bakhshi, Fuel Process Technol, 1995, 45, 185202.

43. P. A. Horne, N. Nugranad and P. T. Williams, J. Anal. Appl. Pyrolysis, 1995, 34, 87-108.

44. P. A. Horne, P. T. Williams, Fuel, 1996, 75, 1043-1050.

45. J. Adam, M. Blazsó, E. Mészáros, M. Stöcker, M. H. Nilsen, A. Bouzga, J. E. Hustad, M. Grønli and G. Øye, Fuel, 2005, 84, 14941502.

46. A. Aho, N. Kumar, K. Eränen, T. Salmi, M. Hupa and D. Y. Murzin, Fuel, 2008, 87, 2493-2501.

47. M. I. Haniff, L. H. Dao, Applied Catalysis, 1988, 39, 33-47.

48. H. J. Park, J. -. Dong, J. -. Jeon, K. -. Yoo, J. -. Yim, J. M. Sohn and Y. -. Park, Journal of Industrial and Engineering Chemistry, 2007, 13, 182-189.

49. M. C. Samolada, A. Papafotica and I. A. Vasalos, Energy Fuels, 2000, 14, 1161-1167.

50. A. A. Lappas, M. C. Samolada, D. K. latridis, S. S. Voutetakis and I. A. Vasalos, Fuel, 2002, 81, 2087-2095.

51. J. Singh, M. M. Kumar, A. K. Saxena and S. Kumar, Chem. Eng. J., 2005, 108, 239-248. 
52. G. Bozzano, M. Dente and F. Carlucci, Comput. Chem. Eng., 2005, 29, 1439-1446.

53. A. Del Bianco, G. Garuti, C. Pirovano and R. Russo, Fuel, 1995, 74, 756-760.

54. K. U. Ogbuneke, C. E. Snape, J. M. Andrésen, S. Crozier, C. Russell and R. Sharpe, Energy Fuels, 2009, 23, 2157-2163.

55. J. G. Speight, Catalysis Today, 2004, 98, 55-60.

56. J. L. Sánchez, A. Gonzalo, G. Gea, R. Bilbao and J. Arauzo, Energy Fuels, 2005, 19, 2140-2147.

57. S. Czernik, R. French, C. Feik and E. Chornet, Ind Eng Chem Res, 2002, 41, 4209-4215.

58. L. Garcia, R. French, S. Czernik and E. Chornet, Applied Catalysis A: General, 2000, 201, 225-239.

59. Q. Zhang, J. Chang, T. Wang and Y. Xu, Energy Conversion and Management, 2007, 48, 87-92.

60. M. Ikura, M. Stanciulescu and E. Hogan, Biomass Bioenergy, 2003, 24, 221-232.

61. T. Dabros, A. Yeung, J. Masliyah and J. Czarnecki, J. Colloid Interface Sci., 1999, 210, 222-224.

62. D. Chiaramonti, M. Bonini, E. Fratini, G. Tondi, K. Gartner, A. V. Bridgwater, H. P. Grimm, I. Soldaini, A. Webster and P. Baglioni, Biomass Bioenergy, 2003, 25, 85-99.

63. T. A. Milne, N. Abatzoglou and R. J. Evans, Biomass Gasifier "tars": Their Nature, Formation, and Conversion, 1998. 64. S. D. Sharma, M. Dolan, D. Park, L. Morpeth, A. llyushechkin, K. McLennan, D. J. Harris and K. V. Thambimuthu, Powder Technol, 2008, 180, 115-121.

65. L. Wang, C. L. Weller, D. D. Jones and M. A. Hanna, Biomass Bioenergy, 2008, 32, 573-581.

66. J. N. Kuhn, Z. Zhao, L. G. Felix, R. B. Slimane, C. W. Choi and U. S. Ozkan, Applied Catalysis B: Environmental, 2008, 81, 14-26. 67. R. Coll, J. Salvadó, X. Farriol and D. Montané, Fuel Process Technol, 2001, 74, 19-31.

68. R. Zhang, R. C. Brown, A. Suby and K. Cummer, Energy Conversion and Management, 2004, 45, 995-1014.

69. S. J. Yoon, Y. Choi and J. Lee, Energy Conversion and Management, 2010, 51, 42-47.

70. S. Cheah, K. R. Gaston, Y. O. Parent, M. W. Jarvis, T. B. Vinzant, K. M. Smith, N. E. Thornburg, M. R. Nimlos and K. A. Magrini-Bair, Applied Catalysis B: Environmental, 2013, 134-135, 34-45.

71. M. A. Nahil, X. Wang, C. Wu, H. Yang, H. Chen and P. T. Williams, RSC Adv., 2013, 3, 5583-5590.

72. A. Lamacz, A. Krzton, A. Musi and P. D. Costa, Catalysis Letters, 2009, 128, 40-48.

73. S. D. Sharma, M. Dolan, A. Y. Ilyushechkin, K. G. McLennan, T. Nguyen and D. Chase, Fuel, 2010, 89, 817-826.

74. J. Street, F. Yu, Biofuels, 2011, 2, 677-691.

75. Ciobica, I. M. The Molecular Basis of the Fischer Tropsch Reaction, 2002.

76. T. Kandaramath Hari, Z. Yaakob and N. N. Binitha, Renewable and Sustainable Energy Reviews, 2015, 42, 1234-1244.

77. Y. Li, D. He, S. Ge, R. Zhang and Q. Zhu, Applied Catalysis B: Environmental, 2008, 80, 72-80.

78. P. L. Spath, D. C. Dayton, Preliminary Screening - Technical and Economic Assessment of Synthesis Gas to Fuels and Chemicals with Emphasis on the Potential for Biomass-Derived Syngas, 2003. 79. Y. Li, D. He, Q. Zhu, X. Zhang and B. Xu, Journal of Catalysis, 2004, 221, 584-593.

80. P. Tanger, J. L. Field, C. E. Jahn, M. W. DeFoort and J. E. Leach, Frontiers in Plant Science, 2013, 4, 218.

81. R. A. A. Suurs, M. P. Hekkert, Energy, 2009, 34, 669-679.
82. J. Sheehan, T. Dunahay, J. Benemann and P. Roessler, A Look Back at the U.S. Department of Energy's Aquatic Species Program: Biodiesel from Algae, 1998.

83. L. A. Ribeiro, P. P. d. Silva, Renewable and Sustainable Energy Reviews, 2013, 25, 89-96.

84. R. E. H. Sims, W. Mabee, J. N. Saddler and M. Taylor, Bioresour. Technol., 2010, 101, 1570-1580.

85. D. I. Bransby, S. B. McLaughlin and D. J. Parrish, Biomass Bioenergy, 1998, 14, 379-384.

86. W. G. Hohenstein, L. L. Wright, Biomass Bioenergy, 1994, 6, 161173.

87. Z. Ma, C. W. Wood and D. I. Bransby, Biomass Bioenergy, 2000, 18, 93-104.

88. D. R. Keshwani, J. J. Cheng, Bioresour. Technol., 2009, 100, 15151523.

89. M. Sterner, U. Fritsche, Biomass Bioenergy, 2011, 35, 4797-

4814.

90. D. Neves, H. Thunman, A. Matos, L. Tarelho and A. GómezBarea, Progress in Energy and Combustion Science, 2011, 37, 611630.

91. S. A. Channiwala, P. P. Parikh, Fuel, 2002, 81, 1051-1063.

92. ECN https://www.ecn.nl/phyllis2/Browse/Standard/ECN-Phyllis. 2015).

93. N. Tröger, D. Richter and R. Stahl, J. Anal. Appl. Pyrolysis, 2013, 100, 158-165.

94. S. V. Vassilev, D. Baxter, L. K. Andersen and C. G. Vassileva, Fuel, 2010, 89, 913-933.

95. A. V. Bridgwater, A. J. Toft and J. G. Brammer, Renewable and Sustainable Energy Reviews, 2002, 6, 181-246.

96. K. R. Cummer, R. C. Brown, Biomass Bioenergy, 2002, 23, 113128.

97. J. Brar, K. Singh, J. Wang and S. Kumar, International Journal of Forestry Research, 2012, 2012, 10.

98. A. V. Bridgwater, Upgrading Fast Pyrolysis Liquids. In Thermochemical Processing of Biomass; John Wiley \& Sons, Ltd: 2011; 157-199.

99. D. M. Wilson, D. L. Dalluge, M. Rover, E. A. Heaton and R. C. Brown, Bioenergy Research, 2013, 6, 103-113.

100. C. Couhert, J. Commandre and S. Salvador, Fuel, 2009, 88, 408417.

101. D. Lv, M. Xu, X. Liu, Z. Zhan, Z. Li and H. Yao, Fuel Process

Technol, 2010, 91, 903-909.

102. R. Fahmi, A. V. Bridgwater, L. I. Darvell, J. M. Jones, N. Yates, S. Thain and I. S. Donnison, Fuel, 2007, 86, 1560-1569.

103. K. David, A. J. Ragauskas, Energy Environ. Sci., 2010, 3, 11821190.

104. J. Li, A. Brzdekiewicz, W. Yang and W. Blasiak, Appl. Energy, 2012, 99, 344-354.

105. B. Arias, C. Pevida, J. Fermoso, M. G. Plaza, F. Rubiera and J. J. Pis, Fuel Process Technol, 2008, 89, 169-175.

106. M. Phanphanich, S. Mani, Bioresour. Technol., 2011, 102, 12461253.

107. X. Xu, Y. Matsumura, J. Stenberg and M. J. Antal, Ind Eng Chem Res, 1996, 35, 2522-2530.

108. Y. Liu, K. Murata, M. Inaba, I. Takahara and K. Okabe, Fuel, 2013, 104, 62-69.

109. R. P. Datar, R. M. Shenkman, B. G. Cateni, R. L. Huhnke and R. S. Lewis, Biotechnol. Bioeng., 2004, 86, 587-594.

110. K. T. Klasson, M. D. Ackerson, E. C. Clausen and J. L. Gaddy, Fuel, 1993, 72, 1673-1678.

111. H. Younesi, G. Najafpour and A. R. Mohamed, Biochem. Eng. J., 2005, 27, 110-119. 
112. I. Wender, Fuel Process Technol, 1996, 48, 189-297.

113. Johansson, E. Process integration study of biomass-tomethanol (via gasification) and methanol-toolefins (MTO) processes in an existing steam cracker plant, Chalmers University of Technology, 2013.

114. H. Arakawa, J. -. Dubois and K. Sayama, Energy Conversion and Management, 1992, 33, 521-528.

115. T. B. Reed, R. M. Lerner, Science, 1973, 182, 1299-1304. 116. R. Dillon, S. Srinivasan, A. S. Aricò and V. Antonucci, J. Power Sources, 2004, 127, 112-126.

117. D. W. Shin, S. Y. Lee, N. R. Kang, K. H. Lee, M. D. Guiver and Y. M. Lee, Macromolecules, 2013, 46, 3452-3460.

118. X. Li, A. Faghri, J. Power Sources, 2013, 226, 223-240.

119. C. E. Barrios, M. V. Bosco, M. A. Baltanás and A. L. Bonivardi, Applied Catalysis B: Environmental, 2015, 179, 262-275.

120. Y. Ma, G. Guan, C. Shi, A. Zhu, X. Hao, Z. Wang, K. Kusakabe and A. Abudula, Int J Hydrogen Energy, 2014, 39, 258-266.

121. R. Shokrani, M. Haghighi, N. Jodeiri, H. Ajamein and M. Abdollahifar, Int J Hydrogen Energy, 2014, 39, 13141-13155.

122. A. Monney, E. Barsch, P. Sponholz, H. Junge, R. Ludwig and M. Beller, Chemical Communications, 2014, 50, 707-709.

123. N. Vinothkumar, M. De, Int J Hydrogen Energy, 2014, 39, 11494-11500.

124. M. E. Boucher, A. Chaala and C. Roy, Biomass Bioenergy, 2000, 19, 337-350.

125. S. Yaman, Energy Conversion and Management, 2004, 45, 651671.

126. M. Saidi, F. Samimi, D. Karimipourfard, T. Nimmanwudipong, B. C. Gates and M. R. Rahimpour, Energy Environ. Sci., 2014, 7, 103129.

127. S. Panigrahi, A. K. Dalai, S. T. Chaudhari and N. N. Bakhshi, Energy Fuels, 2003, 17, 637-642.

128. J. D. Adjaye, R. K. Sharma and N. N. Bakhshi, Fuel Process Technol, 1992, 31, 241-256.

129. F. De Miguel Mercader, M. J. Groeneveld, S. R. A. Kersten, N. W. J. Way, C. J. Schaverien and J. A. Hogendoorn, Applied Catalysis B: Environmental, 2010, 96, 57-66.

130. E. Furimsky, Applied Catalysis A: General, 2000, 199, 147-190.

131. D. C. Elliott, T. R. Hart, Energy Fuels, 2009, 23, 631-637.

132. D. C. Elliott, T. R. Hart, G. G. Neuenschwander, L. J. Rotness, M. V. Olarte, A. H. Zacher and Y. Solantausta, Energy Fuels, 2012, 26, 3891-3896.

133. S. Zhang, Y. Yan, T. Li and Z. Ren, Bioresour. Technol., 2005, 96, 545-550.

134. S. Czernik, A. V. Bridgwater, Energy Fuels, 2004, 18, 590-598. 135. R. Rinaldi, F. Schuth, Energy Environ. Sci., 2009, 2, 610-626. 136. I. Graça, F. R. Ribeiro, H. S. Cerqueira, Y. L. Lam and M. B. B. de Almeida, Applied Catalysis B: Environmental, 2009, 90, 556-563. 137. T. Marker, J. Petri, T. Kalnes, M. McCall, D. Mackowiak, B. Jerosky, B. Reagan, L. Nemeth and M. Krawczyk, Opportunities for biorenewables in oil refineries, 2005.

138. A. I. Pavlova, D. S. Dobrev and P. G. Ivanova, Fuel, 2009, 88, $27-$ 30.

139. J. P. Diebold, S. Czernik, Energy Fuels, 1997, 11, 1081-1091. 140. M. I. Nokkosmäki, E. T. Kuoppala, E. A. Leppämäki and A. O. I. Krause, J. Anal. Appl. Pyrolysis, 2000, 55, 119-131.

141. EPA, Clean alternative fuels: Fischer-Tropsch, 2002.

142. M. E. Dry, Catalysis Today, 2002, 71, 227-241.

143. J. L. Field, C. M. H. Keske, G. L. Birch, M. W. Defoort and M. Francesca Cotrufo, GCB Bioenergy, 2013, 5, 177-191.
144. Q. Bu, H. Lei, A. H. Zacher, L. Wang, S. Ren, J. Liang, Y. Wei, Y. Liu, J. Tang, Q. Zhang and R. Ruan, Bioresour. Technol., 2012, 124, 470-477.

145. A. Martínez, C. López, Applied Catalysis A: General, 2005, 294, 251-259.

146. S. Liu, A. C. Gujar, P. Thomas, H. Toghiani and M. G. White, Applied Catalysis A: General, 2009, 357, 18-25.

147. S. Zhang, B. Zhang, Z. Gao and Y. Han, Ind Eng Chem Res, 2010, 49, 2103-2106.

148. A. C. Gujar, V. K. Guda, M. Nolan, Q. Yan, H. Toghiani and M. G. White, Applied Catalysis A: General, 2009, 363, 115-121.

149. C. Lo, C. A. Giurumescu, R. Radhakrishnan and B. L. Trout, Mol. Phys., 2004, 102, 281-288.

150. G. Fogassy, N. Thegarid, G. Toussaint, A. C. van Veen, Y. Schuurman and C. Mirodatos, Applied Catalysis B: Environmental, 2010, 96, 476-485.

151. M. M. de, M. J. Groeneveld, S. R. A. Kersten, C. Geantet, G. Toussaint, N. W. J. Way, C. J. Schaverien and K. J. A. Hogendoorn, Energy Environ. Sci., 2011, 4, 985-997.

152. M. C. Samolada, W. Baldauf and I. A. Vasalos, Fuel, 1998, 77, 1667-1675.

153. D. Mao, J. Xia, Q. Chen and G. Lu, Catalysis Communications, 2009, 10, 620-624.

154. D. Mao, J. Xia, B. Zhang and G. Lu, Energy Conversion and Management, 2010, 51, 1134-1139.

155. X. Zhang, O. Oyedun, A. Kumar, D. Oestreich, U. Arnold and J. Sauer, Biomass and Bioenergy, 2016, 90, 7-14.

156. J. Burger, M. Siegert, E. Ströfer and H. Hasse, Fuel, 2010, 89, 3315-3319.

157. J. Burger, E. Ströfer and H. Hasse, Ind Eng Chem Res, 2012, 51, 12751-12761.

158. M. Lapuerta, M. Villajos, J. R. Agudelo and A. L. Boehman, Fuel Process Technol, 2011, 92, 2406-2411.

159. X. Zhu and Q. Lu, Production of Chemicals from Selective Fast Pyrolysis of Biomass. In Biomass; Maggy Ndombo Benteke Momba (Ed.): 2010; .

160. C. Mei, P. Wen, Z. Liu, H. Liu, Y. Wang, W. Yang, Z. Xie, W. Hua and Z. Gao, Journal of Catalysis, 2008, 258, 243-249.

161. F. Zhou, P. Tian, Z. Liu, G. Liu, F. Chang and J. Li, Chinese Journal of Catalysis, 2007, 28, 817-822.

162. T. Inui, M. Kang, Applied Catalysis A: General, 1997, 164, $211-$ 223.

163. P. Dutta, S. C. Roy, L. N. Nandi, P. Samuel, S. M. Pillai, B. D. Bhat and M. Ravindranathan, Journal of Molecular Catalysis A: Chemical, 2004, 223, 231-235.

164. T. Masuda, T. Asanuma, M. Shouji, S. R. Mukai, M. Kawase and K. Hashimoto, Chemical Engineering Science, 2003, 58, 649-656. 165. Krevelen, D. W. van, Krevelen,D.W.van, Coal--typology, physics, chemistry, constitution; Elsevier: Amsterdam; New York, 1993; .

166. T. P. Vispute, H. Zhang, A. Sanna, R. Xiao and G. W. Huber, Science, 2010, 330, 1222-1227.

167. N. Y. Chen, T. F. Degnan Jr. and L. R. Koenig, Chemtech, 1986, 16, 506-511.

168. T. G. Bridgeman, J. M. Jones, I. Shield and P. T. Williams, Fuel, 2008, 87, 844-856.

169. M. Gabra, E. Pettersson, R. Backman and B. Kjellström, Biomass Bioenergy, 2001, 21, 351-369.

170. Z. A. Zainal, A. Rifau, G. A. Quadir and K. N. Seetharamu, Biomass Bioenergy, 2002, 23, 283-289.

171. S. Rapagnà, N. Jand, A. Kiennemann and P. U. Foscolo, Biomass Bioenergy, 2000, 19, 187-197. 
172. J. Gil, J. Corella, M. P. Aznar and M. A. Caballero, Biomass Bioenergy, 1999, 17, 389-403.

173. L. Garcia, M. L. Salvador, J. Arauzo and R. Bilbao, Fuel Process Technol, 2001, 69, 157-174.

174. D. Ciolkosz, R. Wallace, Biofuels, Bioproducts and Biorefining, 2011, 5, 317-329.

175. S. Zhang, C. Guo, Q. Qian and G. Yuan, Catalysis Communications, 2008, 9, 853-858.

176. J. R. Rostrup-Nielsen, Catalysis Today, 2000, 63, 159-164. 177. W. Gumz, Gas Producers and Blast Furnaces: Theory Ad Metods of Calculation; John Wiley \& Sons: 1950; .

178. T. Seitarides, C. Athanasiou and A. Zabaniotou, Renewable and Sustainable Energy Reviews, 2008, 12, 1251-1276.

179. A. V. Bridgwater, Thermochemical processing of biomass; Butterworths: 1984;

180. P. M. Lv, Z. H. Xiong, J. Chang, C. Z. Wu, Y. Chen and J. X. Zhu, Bioresour. Technol., 2004, 95, 95-101.

181. C. Lucas, D. Szewczyk, W. Blasiak and S. Mochida, Biomass Bioenergy, 2004, 27, 563-575.

182. S. Sarkar, A. Kumar, Bioresour. Technol., 2010, 101, 7350-7361. 183. S. Sarkar, A. Kumar, Energy, 2010, 35, 582-591.

184. M. Mozaffarian, R. W. R. Zwart, H. Boerrigter and E. P. Deurwaarder, Biomass and waste related SNG production technologies, Technical, economic and ecological feasibility, 2004. 185. O. P. R. Van Vliet, A. P. C. Faaij and W. C. Turkenburg, Energy Conversion and Management, 2009, 50, 855-876.

186. M. M. Wright, D. E. Daugaard, J. A. Satrio and R. C. Brown, Fuel, 2010, 89, Supplement 1, S2-S10.

187. R. M. Swanson, A. Platon, J. A. Satrio and R. C. Brown, Fuel, 2010, 89, Supplement 1, S11-S19.

188. T. R. Brown, R. Thilakaratne, R. C. Brown and G. Hu, Fuel, 2013, 106, 463-469.

189. R. Thilakaratne, T. Brown, Y. Li, G. Hu and R. Brown, Green Chem., 2014, 16, 627-636.

190. S. D. Phillips, J. K. Tarud, M. J. Biddy and A. Dutta, Ind Eng Chem Res, 2011, 50, 11734-11745.

191. P. Haro, F. Trippe, R. Stahl and E. Henrich, Appl. Energy, 2013, 108, 54-65.

192. F. Trippe, M. Fröhling, F. Schultmann, R. Stahl, E. Henrich and A. Dalai, Fuel Process Technol, 2013, 106, 577-586.

193. NRC, Liquid Transportation Fuels from Coal and Biomass: Technological Status, Costs, and Environmental Impacts, 2009. 194. E. D. Larson, G. Fiorese, G. Liu, R. H. Williams, T. G. Kreutz and S. Consonni, Energy and Environmental Science, 2010, 3, 28-42. 195. R. P. Anex, A. Aden, F. K. Kazi, J. Fortman, R. M. Swanson, M. M. Wright, J. A. Satrio, R. C. Brown, D. E. Daugaard, A. Platon, G. Kothandaraman, D. D. Hsu and A. Dutta, Fuel, 2010, 89,

Supplement 1, S29-S35.

196. S. Shabangu, D. Woolf, E. M. Fisher, L. T. Angenent and J. Lehmann, Fuel, 2014, 117, Part A, 742-748.

197. B. Amigun, J. Gorgens and H. Knoetze, Energy Policy, 2010, 38, 312-322.

198. S. Sarkar, A. Kumar and A. Sultana, Energy, 2011, 36, 62516262.

199. C. N. Hamelinck, A. P. C. Faaij, J. Power Sources, 2002, 111, 122.

200. CARE, $250 \mathrm{~kg} / \mathrm{h}$ biomass fast pyrolysis plant for power generation, 2002.

201. J. G. Rogers, J. G. Brammer, Biomass Bioenergy, 2012, 36, 208217.
202. A. V. Bridgwater, Determination of norms and standards for biomass fast pyrolysis liquids as an alternative renewable fuel for electricity and heat production. In 2005; .

203. A. Bauen, G. Berndes, M. Junginger, M. Londo and F. Vuill, Bioenergy-a sustainable and reliable energy source: a review of status and prospects, 2009.

204. F. Trippe, M. Fröhling, F. Schultmann, R. Stahl and E. Henrich, Waste and Biomass Valorization, 2010, 1, 415-430.

205. C. Reyes Valle, A. L. Villanueva Perales, F. Vidal-Barrero and A. Gómez-Barea, Appl. Energy, 2013, 109, 254-266.

206. J. Holmgren, R. Marinangeli, P. Nair, D. Elliott and R. Bain, Hydrocarbon Process., 2008, 87, 95-103.

207. R. L. Bain, World biofuels assessment, worldwide biomass potential: technology characterizations, 2007.

208. C. N. Hamelinck, A. P. C. Faaij, Energy Policy, 2006, 34, 32683283.

209. M. Patel, X. Zhang and A. Kumar, Renewable and Sustainable Energy Reviews, 2016, 53, 1486-1499.

210. F. Cherubini, Energy Conversion and Management, 2010, 51, 1412-1421.

211. M. Fatih Demirbas, Appl. Energy, 2009, 86, Supplement 1, S151-S161.

212. A. Demirbas, Energy Conversion and Management, 2009, 50, 2782-2801.

213. S. Octave, D. Thomas, Biochimie, 2009, 91, 659-664.

214. S. Fernando, S. Adhikari, C. Chandrapal and N. Murali, Energy Fuels, 2006, 20, 1727-1737.

215. USDA, US bioenergy statistics, 2013.

216. IER EPA Ignores Reality with 2014 Ethanol Mandate. 2015).

217. T. Searchinger, R. Heimlich, Avoiding Bioenergy Competition for Food Crops and Land, 2015.

218. D. Garraín, C. de la Rúa and Y. Lechón, Biomass Bioenergy,

2016, 85, 187-197.

219. X. Ji, X. Long, Renewable and Sustainable Energy Reviews, 2016, 61, 41-52.

220. F. H. Sobrino, C. R. Monroy and J. L. H. Pérez, Renewable and Sustainable Energy Reviews, 2011, 15, 2621-2628.

221. R. Melamu, H. von Blottnitz, J. Clean. Prod., 2011, 19, 138-144. 222. S. C. de Vries, G. W. J. van de Ven and M. K. van Ittersum, Eur. J. Agron., 2014, 52, Part B, 166-179.

223. R. E. H. Sims, W. Mabee, J. N. Saddler and M. Taylor, Bioresour. Technol., 2010, 101, 1570-1580.

224. P. Havlík, U. A. Schneider, E. Schmid, H. Böttcher, S. Fritz, R. Skalský, K. Aoki, S. D. Cara, G. Kindermann, F. Kraxner, S. Leduc, I. McCallum, A. Mosnier, T. Sauer and M. Obersteiner, Energy Policy, 2011, 39, 5690-5702.

225. A. Holma, K. Koponen, R. Antikainen, L. Lardon, P. Leskinen and P. Roux, J. Clean. Prod., 2013, 54, 215-228.

226. A. M. Petersen, R. Melamu, J. H. Knoetze and J. F. Görgens, Energy Conversion and Management, 2015, 91, 292-301.

227. N. Kauffman, D. Hayes and R. Brown, Fuel, 2011, 90, 33063314.

228. X. Zhang, W. Yang and W. Blasiak, Energy Fuels, 2011, 25, 4786-4795.

229. X. Zhang, W. Yang and C. Dong, J. Anal. Appl. Pyrolysis, 2013, 104, 19-27.

230. X. Zhang, W. Yang and W. Blasiak, Fuel, 2013, 109, 476-483. 231. X. Zhang, J. Li, W. Yang and W. Blasiak, Energy Fuels, 2011, 25, 3739-3746.

232. X. Zhang, W. Yang and W. Blasiak, J. Anal. Appl. Pyrolysis, 2012, 96, 110-119.

233. X. Zhang, W. Yang and W. Blasiak, Fuel, 2012, 96, 383-391. 
234. M. S. Mettler, D. G. Vlachos and P. J. Dauenhauer, Energy Environ. Sci., 2012, 5, 7797-7809.

235. G. W. Huber, A. Corma, Angewandte Chemie International Edition, 2007, 46, 7184-7201.

236. R. V. Pindoria, A. Megaritis, A. A. Herod and R. Kandiyoti, Fuel, 1998, 77, 1715-1726.

237. M. Marquevich, S. Czernik, E. Chornet and D. Montané, Energy Fuels, 1999, 13, 1160-1166.

238. H. Leibold, A. Hornung and H. Seifert, Powder Technol, 2008, 180, 265-270.

239. X. Youchang, B. N. Naasz and G. A. Somorjai, Applied Catalysis, 1986, 27, 233-241.

240. A. G. Gayubo, B. Valle, A. T. Aguayo, M. Olazar and J. Bilbao, Ind Eng Chem Res, 2010, 49, 123-131.

241. S. T. Srinivas, A. K. Dalai and N. N. Bakhshi, The Canadian Journal of Chemical Engineering, 2000, 78, 343-354.

242. A. G. Gayubo, B. Valle, A. T. Aguayo, M. Olazar and J. Bilbao, Energy Fuels, 2009, 23, 4129-4136.

243. S. Heyne, S. Harvey, Appl. Energy, 2013, 101, 203-212. 


\title{
Essential scientific mapping of the value chain of thermochemical converted second-generation bio- fuels
}

\author{
Xiaolei Zhang*
}

School of Mechanical and Aerospace Engineering, Queen's University Belfast, UK *xiaolei.zhang@qub.ac.uk Tel: +44(0)2890974490

One sentence of text, maximum 20 words, highlighting the novelty of the work: A profound and comprehensive comparison of thermochemical techniques of second-generation biofuel from technical, economic, commercial, and environmental perspectives.

\section{Graphic abstract:}

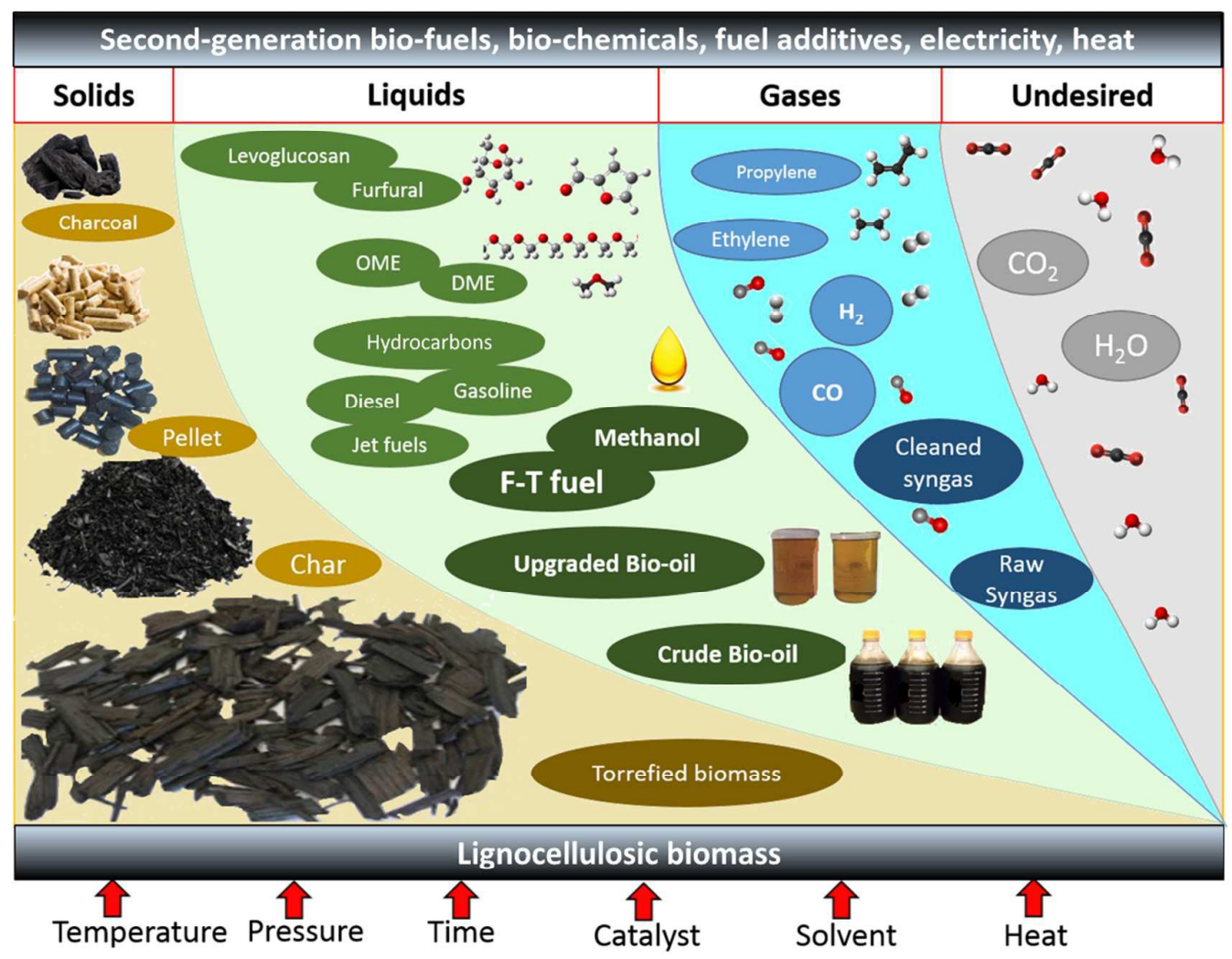

